\title{
Epidemiological cancer mortality studies in occupational health : examples, methods and risk assessment
}

Citation for published version (APA):

Swaen, G. M. H. (1989). Epidemiological cancer mortality studies in occupational health : examples, methods and risk assessment. [Doctoral Thesis, Maastricht University]. Rijksuniversiteit Limburg. https://doi.org/10.26481/dis.19890915gs

Document status and date:

Published: 01/01/1989

DOI:

10.26481/dis.19890915gs

Document Version:

Publisher's PDF, also known as Version of record

\section{Please check the document version of this publication:}

- A submitted manuscript is the version of the article upon submission and before peer-review. There can be important differences between the submitted version and the official published version of record. People interested in the research are advised to contact the author for the final version of the publication, or visit the DOI to the publisher's website.

- The final author version and the galley proof are versions of the publication after peer review.

- The final published version features the final layout of the paper including the volume, issue and page numbers.

Link to publication

\footnotetext{
General rights rights.

- You may freely distribute the URL identifying the publication in the public portal. please follow below link for the End User Agreement:

www.umlib.nl/taverne-license

Take down policy

If you believe that this document breaches copyright please contact us at:

repository@maastrichtuniversity.nl

providing details and we will investigate your claim.
}

Copyright and moral rights for the publications made accessible in the public portal are retained by the authors and/or other copyright owners and it is a condition of accessing publications that users recognise and abide by the legal requirements associated with these

- Users may download and print one copy of any publication from the public portal for the purpose of private study or research.

- You may not further distribute the material or use it for any profit-making activity or commercial gain

If the publication is distributed under the terms of Article $25 \mathrm{fa}$ of the Dutch Copyright Act, indicated by the "Taverne" license above, 


\section{EPIDEMIOLOGICAL CANCER MORTALITY STUDTES \\ IN OCCUPATIONAL HEALTH}

Examples, methods and isk assessment

\section{PROEFSCHRIFT}

ter verkrijging van de graad van doctor aan de Rijksuniversiteit Limburg te Mastricht, op gezag van de Rector Magnificus, Prof. Dr. F.I.M. Bonke, volgens het besluit van het college van Dekanen in het openbaar te verdedigen op vrijdag, 15 september 1989 om 16.00 wur

aoor

Gerard Marius Henricus Swaen

geboren op 5 Juni 1954 te 's-Gravenhage 
promotores: Frof. Dr. F. Stumans

prof. Dr. "ij. de Boorder

Beoordelingscomissie: Prof. Dr. J.A. Knottnerus (voorzitter)

Dr. R.J.M.M. Does

Prot, Dr. R. Kroes

Prof. DF. H.A.J. Struyker Boudier

Prof. Dr. R.L. Zielhuis

Coloton:

Omslag : Marco swaen: Orenatekker op cokesfabriek

Lay-out: Marliese van Wissen

Druk : Drukkerij Alberts/Druko, Gulpen

ISBM $\quad: 90-9003018-2$ 
Mors Nemini Cedit

Het epidemiologisch onderzoek dat de grondslag vormt wan at proefschrift is tot stand gekomen met financiële ondersteuning vall de Nederlandse Kankerbestrijding (voorheen: Koningin Wilhelminafonds). 
AAN MIJN OUDERS 


\section{TABLE OF CONTENTS}

General Introduction

Part I : Occupational epidemiology

I.1: The conduct of retrospective cohort studies in the Netherlands

I.2 : Long term mortality of coke oven workers in The Netherlands

I.3 " Long term mortality of former workers of coke plant byproduct facilities in the Netherlands

I.4 : Gastric cancer in coalminers: Final report

Part II : Epidemiologic methods

II.1 : Investigating dose-response relations in occupational mortality studies: Something to keep in mind

II.2 : Influence of design characteristics on the outcome of retrospective cohort studies

II. 3 : The influence of design characteristics on the healthy worker effect

Part III : Environmental Risk Assessment

III.1: The use of epidemiological data in risk assessment

III.2: A scientific bas is for the risk assessment of vinyl chloride

III.3: Carcinogenic risk assessment of benzene in outdoor air

III.4: Risk assessment of occupational exposure to benzene and leukemia 
$-2-$

मtक 


\section{GENERAL INTRODUCTION}

occupational epidemiology is that section of epidemiology focussing on the relationship between work conditions as a causal factor and the occurrence of disease. of many occupational exposures only limited knowledge is available regarding possible long term health risks. Although the expasure concentrations today are much lower than in the past, it is of great importance to develop research methods by which these health risks can be evaluated.

particularly the Anglo-Saxon and Scandinavian countries have built up a tradition in the field of occupational epidemiology. Epidemiologic research in these countries has helped to identify and quantify a number of occupational risks. Several of these perhaps would not have been identified ithout epidemiologic research. The risk of mesothelioma related to the amphibole type of asbestos was obserwed without the aid of epidemiologic research. However, the additional risk of lung cancer in quantity exceeding the mesothelioma risk, was only recognized after epudemiologic research had been carried out. Increases in risk for diseases that also occur in large numbers among accupationally nom-exposed individuals are difficult to detect by means of clinical observation. In these instances epidemiologic research is a more appropriate approach.

In general there are two types of analytical epidemiological study designs that can be applied in the study of disease etiology. One of these two forms is the cohort study. In this type of study the epidemiologist will identify an exposed population and a non-exposed population. Then both groups are followed through time to abserve the occurrence of disease. The identification of the study populations is almost always done retrospectively, to avoid that the investigator will have to wait long periods for the occurrence of diseases and before conclusions can be drawn. An advantage of cohort studies over case-control studies is that at the same time more than one health effect can be studied. A disadvantage is that generally only one type of exposure can be investigated. If the objective of a study is to evaluate the potential health fects of a particular exposure, a cohort design should be preferred over a casecontrol design. The study of mortality among workers of coke plants, described in the first section of this the sis, is an example of a retrospective cohort study. In this first section also an article is presented in which the feasibility and conduct of retrospective cohort studies in The Metherlands is discussed.

The second design in analytical epidemiology is the case-contral study. In a case-controi study a group of cases suffering from a particular disease is compared to a group of controls free of that disease in respect of past exposure to 
particular wublances. The underlying supposition of a case-control study is, that if an exposure leads to the developnent of a particular disease, this exposure will be more frequent among cases than among controls. The advantage of this approach is that nore causal factors of one disease can be investigated simultaneously. The disadvantage of course is, that only the causes of one particular disedse can be investigated. A case-control design should be preferred if the purpose of the study is to investigate the causes of one particular disease. "The study of gastric cancer and coal mining, also presented in the first section of this thesis, is an example of a case-control study in the field of occupational epidemiology.

IE the purpose of a study is to investigate a specific relationship. e.g. is exposure $X$ related to disease $\Psi$, the choice between the two types of designs can be made on practical considerations.

In part II of this thesis several methodologic aspects of retrospective cohort studies are discussed. The first aspect is concerned with the investigation of dose-respone relations in a person-time analysis. In most cases epicemiologists do not have actual exposure measurements at their disposal and must the duration of exposure or employment serve as a surrogate of the dose. If the cohort members are categorized in a dose category, based on the duration of employment, it must. be realized that a worker moves through the lower dose categories prior to reaching the higher dose categories. The person-years should be classified according to the warious dose categories instead of the exposed workers. The approach of classifying workers will inevitably lead to an overestimation of the risk in the low exposure groups and to an underestimation of the risk in the high exposure group.

The second aspect of retrospective cohort methodology to be discussed in part II is the influence of design characteristics on the outcome of these studies. A survey was made of 179 published reports of cohort studies. All reports were classified positive studies, meaning that an occupational health risk was. reported, and negative studies with no occupational health risk being reported. Several relations between design characteristics and study outcome were found. for instance in studies with a minimal latency period and use of an occupational reference group had a higher chance of a positive outcome.

The third aspect of retrospective cohort methodology that is discussed, is the influence of design characteristics on the "Healthy worker effect". It can be arqued that the way in which a study is set up may affect the finding. For instance, if a cohort will be followed up over a short period a larger Healthy Worker Effect may occur. In order to investigate these possible effects 270 
published articles were reviewed. No clear relation between the length of followup and the frealthy worker fifect could be detected. Fixed cohorts did not show atronger Heal thy worker Effect than dynamic cohorts and studies in the chemical industry tended to have a stronger Healthy Worker Efect than other studies.

It can be expected that epidemiological research will become more and nore important in the process of standard seting in the workplace. Although these studies are limited to the workplace, the results can also be applied as a basis for the standard setting for environmental exposures in outdoor air. To a certain extent. epldemiological studies of the workplace can be extrapolated to the lower concentrations of exposure to the same agents in outdoor airs. This application of occupational epidemiology into the field of both occupational and enviromental risk assessment is discussed in part III of this thesis. 


\section{PART I}

OCCUPATIONAL EPIDEMIOLOOY

THE COMDUCT OF RETROSPECTIVE COHORT STUDIES IN THE NETHERLANDS

LONG TERM MORTALITY OF COKE OVEM WORKERS IN THE NETHERLANDS

LONG TERM MORTALITY OF FORMER WORKERS OF COKE PLANT BY-PRODUCT FACILITIES IN THE NETHERLAADS

GASTRIC CANCER IN COAL MINERS: FINAL REPORT 
- - 


\section{THE CONDUCT OF OCCUPATIONAL RETROSPECTIWE COHORT STUDTES}

\section{IM THE NETMERLANDS}
G.M.H. Swaen ${ }^{1}$
C. $\operatorname{van}$ viet ${ }^{1}$
J.M.M. Mejjers ${ }^{1}$
F. Sturmans ${ }^{2}$

1 Dpt, of Occupational Medicine, University of Limburg, The Netherlands

2 ppt. of Epidemiology, University of Limburg, The Netherlands 
1. 1

$-10=$ 


\section{INTRODUCTION}

Epidemiologic research is an important tool for the identifjcation of hedu hazards related to exposure to specific chemicals. In the field of occupational health occupational pinysicians, workers and management are concerned about health risks that may be related to exposure to some chemical. The impetus for conducting a study varies. Sometimes a cluster of a specific disease is observed, triggering the need for epidemiologic research. In other instances it may be the epidemiologist who takes the initiative to undertake a specific occupational epidemiologic study" because the study may contribute to be body of knowledge and understanding regarding the long term health effects of a particular exposure. Sometimes the maximal allowed exposure level of a chemical is debated and industry or the regulating agencies or both wish to acquire additional evidence about the magnitude of the potential long term human health effects.

Although the underlying motive to initiate an occupational epidemiologic study may vary, but the specific aim is always similar; namely the assessment of potential health risks related to a certain exposure in a human population.

An other approach to this issue is to conduct toxicological stuaies, for instance in the form of short term tests or animal experiments. Toxicological tests can provide knowledge regarding the potency of a chemical or regarding the mechanism by which a certain health effect may be caused. However, toxicological research can not provide direct evidence of the actual occurrence of health effects in humans who are or have been exposed to a particular exposure. This evidence can only be accumulated by epidemiologic research.

The relevance of epidemiologic research of occupational exposures reaches beyond the occupational environment. In the occupational environment exposures to many chemicals occur that are also encountered in the general environment in lower concentrations. The exposures in the general environment may be so low and if any) the effects so rare, that an epidemiologic study is not feasible. However, it is possible to extrapolate the health effects observed in the occupational environment to that in the general environment. Whus epidemiologic studies in am. cccupational setting may provide most relevant information for the evaluation of health risks related to exposures in the general environment.

In retrospective cohort studies an exposed group of persons is defined in the past and followed through time to observe the occurrence of disease or mortality. If the purpose of an epidemiological study is to investigate a range of potential. health effects, a retrospective cohort design is the most appropiate design. The retrospective aspect 1 ies in the fact that all relevant events, namely the 
expowure and health effect, have occurred in the past. A particular advantage of this approach is that the epidemiologist does not have to wait for disease to develop, which considerably shortens the time necessary to complete the study. A disadrantage of thig approach is that the epidemiologist must rely upon historical records that have been preserved to this day. His/her work is great 1 Y linited by the extent of record keeping that has been done in the past. A further Ititation is the fact that records have not been kept with the intention that they wil be useful for future epideniologic studies, let alone that they are collected in order to facilitate future epidemiologic studies in industry.

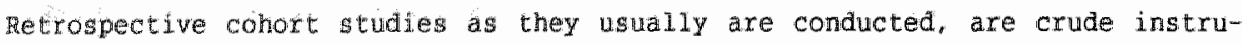
ments, only occasionally capable of controlling extraneous factors such as smokng, and co-exposures wth great emphasis on mortality as effect parameter, with serious censorship from death by other causes such as fatal accidents and loss to follow up. On the other hand these crude methods, still basically the same as the methods developed by case ${ }^{1}$ in the rubber industry forty years ago, have yie1dod valuble information in the field of accupational medicine by identifying a number of long term health effects associated with various occupational exposures.

whe objective of this article is to assess the feasibility of retrospective cohort studies in the Dutch industry and expand upon methods by which these studies can be improved in the future. So far experience has been gained with 15 chemlical companies in the Netherlands. The impressions gained from these experiences form the empirical basis of this article.

\section{DESTGN AND ANALYSES OF RETROSPECTIVE COHORT STUDIES}

din epidentology a retrospective cohort study can be defined as a study in which aroup of persons who have experienced a particular exposure in the past are followed up through time to observe the occurrence of disease and to compare the accurrence of diseage with that of a non-exposed population. The basic study design is described in figure 1 . Most retrospective cohort studies in the field of occupational epidemiology have focussed on mortality as the disease parameter under investigation. Only in countries with a cancer registry, morbidity has been treguently used as the disease parameter. 
Figure 1: The basic study design of a retrospective cohort study.

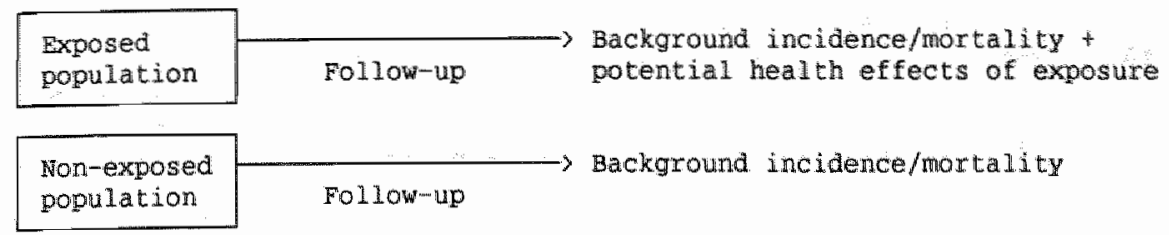

A common weakness of retrospective cohort studies in industry is the lack of an appropriate comparison or reference group. on a theoretical basis it car be argued that such a reference group should consist of a non-exposed working population. However, in practice this is hardy the case and a comparison is made with the occurrence of disease in the general population. In a survey of 233 pubilished occupational retrospective cohort studies 85 of the reported studies did not include a non-exposed working comparison group in the study design. Because working populations appear to be healthier than the general population. mainly due to the selection of healthy persons into incustry, such an inapprom priate comparison group that consists of the general population, leads to a "Healthy Worker Effect" which can mask small risks that may exist in the exposed graup.

In a retrospective cohort study three phases can be identified. The first phase consists of the compilation of a list of workers who have been exposed in the past and a list of workers who have not been exposed to that agent in the past. Without such a Iist jt is not possible to carry out a retrospective cohort study. A minimal set of data to be collected an each person to be entered into the study is: name, date of birth, last known address, first and last date of exposure. The guality of exposure data may vary greatly from one study to the other. Sometimes the only data available to the epidemiologist regarding exposure 1 that partcular person has ever been hired by the company. In the nost favorable instance exposure data in the form of measurements are available for individual workers, for the whole period of exposure. However this is hardy ever the case. Seweral eligibility criteria can be defined, for instance a certain minimal time of exposure, a period in which exposure must have accurred or specific ethnic background.

The second phase of a retrospective cohort study consists of the follow-up. the collection of data regarding the disease parameter. This disease parameter usuali ly is only observed in the form of cause-specific mortality. The follow-up generally is the most time consuming and most expensive phase of a retrospective 
cohort study. In most studies the workers that are investigated must be followed ower long pertods of tine, in which they wove from one place to another. Endpoints of the follow-up are: a worker who is still alive at the endate of the follow-up: a worker who has emigrated or died prior to that date. The cause of deatr usualy is obtaned through information on the death certificate. The follow-up hould be carried out without having knowledge about the exposure status of the person, in order to avoid observer bias. It has frequently been argued that the underlying cause of death given on the death certificate may suffer from a great anount of invalidity and thus is inferior to additional information that may be obtained regarding the cause of death. However, it must be kept in mind that this additiond information may invalidate any comparison with national catse-spetflc death rates and thus must be handled with great prudence.

whe third phase of a retrospective cohort study is the statistical analysis. The object of the atatistical analysis is to adjust the relationship between exposure and disease fot the effects of other parameters and to identify dose-response relationships. The observed mortality in a cohort is greatly influenced by the age distribution of the cohort, the length of follow-up, the period in which the follow-up took place and of course the exposure. In occupational retrospective cohort studies it has become custom to carry out this standardization by mears of a "person-time analysis", which is an indirect form of standardization. By means of this method the observed person-years of follow-up are divided into ageana calender time specific person-years. As an example the person-years of workers $A$ and $B$ are presented in Table 1. Worker A, born on 01-01-1934, was employed by the company on 01-01-1954, and emigrated to Australia on 31-12-1982. Worker $B$ with 01-01-1912 as date of birth, was employed since 01-01-1940 and died on 0107-1979. For each cohort such a table can be compiled.

These specific person-years are riultiplied by the corresponding mortality rates in the gervera population resulting in an expected number of deaths. This number can be interpreted as the number of deachs that would have occurred in the cohort, had the cohort experienced exactly the same mortality rates as the general population. the ratio of the observed number of deaths to the expected number, mutiplied by 100, is the Standardized Mortality tatio (SMR). A SMR of 100 means that the nortality in the conort is similar to that of the general population. A SWR of 110 means that the mortality in the cohort is 10 bigher than in the general population. In many studies the total SMR is lower than 100, even for non-exposed cohorts. A working cohort seems to be healthier than the general population. This phenomenon is called the "Healthy Worker Effect". 
Table 1: Example of the compilation of age- and calender time specific personyears in a retrospective cohort study.

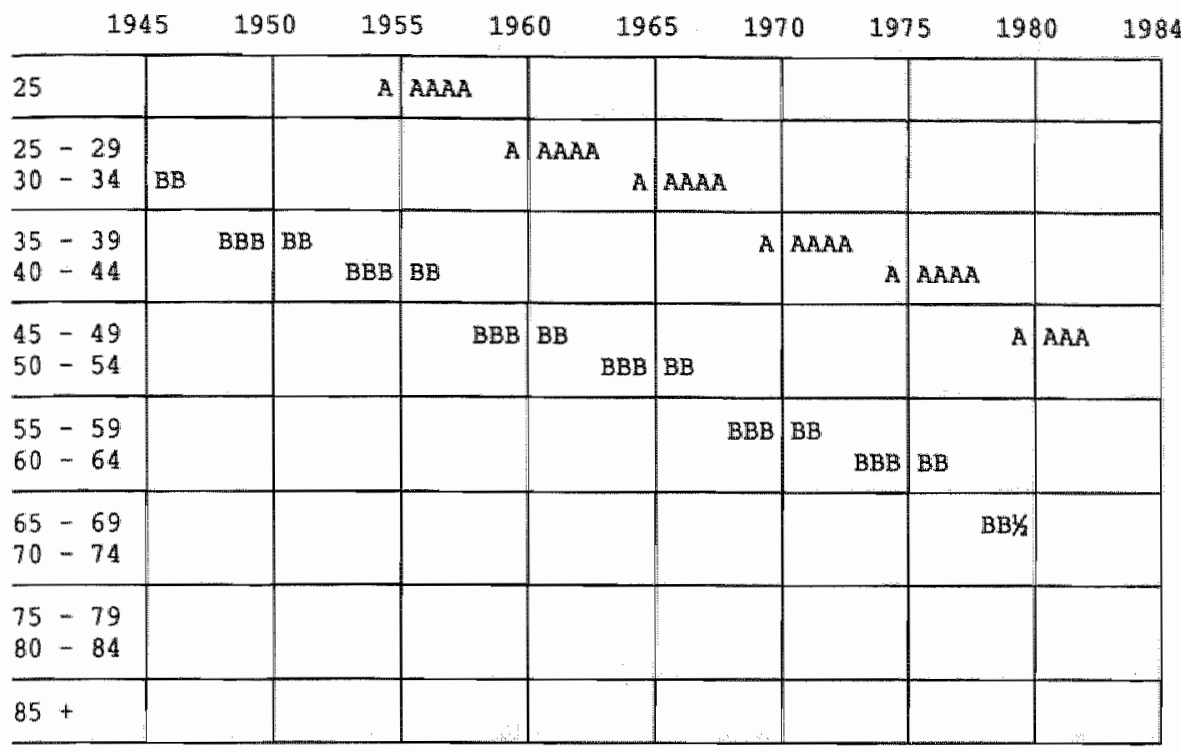

In the instance that an epidemiologist has followed an exposed cohort as well as a non-exposed cohort, the cause-specific mortality rates of the non-exposed cohort could be applied to the exposed cohort in order to generate expected number of deaths in the exposed cohort. However, this is not done, because the cause-specific mortality rates in the non-exposed group are too instable and thus unreliable. This instability of cause-specific mortality rates is related to relatively small numbers of observed deaths from a particular disease in each age- and period-specific cell. Because the observed numbers af death from a speciflc cause must be distributed over a large number of age- and calender time specific cells, many cells will have no or very few deaths, which will result in instable rates. It is custom to apply the cause-specific mortality rates of the general population to the exposed and non-exposed groups separately.

A simple way of investigating the existence of dose-response relationship is to divide the exposed group up into various dose groups and calculate SMR's for each dose group individually. Since reliable data on the magnitude of exposure are nearly always lacking in retrospective cohort studies, the duration of employment usually is taken as a surrogate of dose. A more sophisticated and more sensitive method to investigate dose-response relationships is the application of statistical modelling. In this method several assumptions are made, for instance limea- 
Ity of the blologic relationship and certain latency period, the parameters are seached for which the model provides a good $t$ it. the epldamologist needs to have access to the indidual exposure and health parameter data to be able to carry ow any atatistical modeling.

In the past ter to fifteen years attempts have been made to adjust for the influence of other factors (confounders) on the relationship between exposure and health parameter. This is particularly mortant in case of the existence of potent frequently occurring confounders, such as cigarette smoking and lung cancer for ingtance. The effect of smoking habits can be adjusted for if data on the smoking habits of the individual workers are available. This is hardly ever the case. The retrospective collection of these data, for the exposed cohort as well as the non-exposed cohort is almost an inaccomplishable task. An alternative is to carry out a nested case-control study. In such a study the cases consist of workers who died of for instance lung cancer and a control growp can be formed Erom a random ample drawn from the other workers. This procedure only requires to collect snoking data on a subset of the population under inrestigation. However the individual names of cases and controls must be known to the investigacor.

Several authors have already discussed the feasibility of occupational retrospective cohort studies in the Netherlands $2-5$

An assesment of the leasibility of retrospective cohort studies in the Netherlands can be made by reviewing the conditions that must be met for such a study to be completed with success. For a successful completion of a retrospective cohort study the following minimal conditions must be met:

1. Compilation of an uncensored list of workers potentially exposed in the past.

2. Facilities to carry out the fallow-up of these workers.

3. Availability of valid information regarding the occurrence of disease.

4. Avaldability of anudi age-" sex- and cause-specific disease rates, e.g. mortality rates.

In this article these four issus will be reviewed as far as the Dutch situation is concerned and aspects for which improvemeat can be achieved are discussed. 


\section{Compilation of an uncensored list of workers exposed in the past}

The compilation of such a list is a vital step in a retrospective cohort study. Several sources for such a list usualiy are available in industry. The first and most important source are records kept in the personel department. Since payment of salary and social security premiums are based on these rew cords, they usually are accurately maintained as long as the worker stid. is employed by the company. However after a person retires, chances incraase that records are displaced, lost or simply destroyed because of company policy. For the epidemiologist it is essential to know what has happened to records of workers who have left the company. Are they stored and if so, how long? Usually files are thrown out if a personnel department moves to a new bullding or if shortage of storing space becomes a problem. In general, personel records going back to the starting days of a company are available in larger companies, say larger than one thousand employees and become less self-evident in smaller companies. Considerable effort should be given to check the history of the files. These files may form the basis from which the exposed and nonexposed cohorts are formed. Any selection to which these files have been subject over time, may also be introduced into the cohorts. However, the introduction of selection will not automatically imply that bias occurs. As long as the selection is not related to exposure or the health outcomes, bias can not occur. If the files have been cleaned at a particular point in time, meaning that all records of workers who had left the company before that date have been destroyed, the files do not become useless for the compilation of an exposed cohort. However, the definition of the cohort must be adapted to that particular situation in the sense that the cohort must be restricted to those employed after the point in time on which the files were clemed. Person-years accumulated prior to that point in time should be lgnored in the person-years analysis, because they can not provide information concerning the person-years at risk.

In many instances the personel records contain information about jobs and workplaces. The first job title to be entered on the master card ugualiy has a general character, because of the fact that the recently hired employee will be deployed at several jobs in finding the proper work for the new employee. Thus if a newly hired employee only stays with the company for a short period, the epidemiologist is left with a poor description of job title. This again 
can be overcone by atricter cohort detinition e.g. that the worker must have been employed for at least a half year. If this approach is followed, this first half year of employment must also be left out of the person-years analysis, because in this period a worker included in the study could not have died in this Elrt halt year, because if he did, he would not have been included in the study.

Prior to data collection a list of job titles and workplaces should be compi1ed. so that job titles and workplaces can immediately be coded onto abstract forms. The job and workplace classification scheme should be designed in such a way that they can be linked to exposure indices or estimates. There is no epidemiological senat in collecting job titles and workplaces if it can be agsuned that exposures for the several jobs and workplaces hawe been similar. For instance if the extruder operator has experienced the same exposure as the compounding operator, they can be classified in the same job category. Problems occur when the situation is the other way round. For instance if the master card only states that a worker was employed as a process operator, but not every process operator has experienced the same exposure.

other relevant information obtainable from the master card are name and address. Experience with follow-up of ten thousands of persons in wich these data are checked at the population registry has learned, that this information is correct for over $99 \%$ of the instances. However accuracy is called for, a miss-spelled name will produce hours of extra work.

Althouglh every company uses its own master card, they are very comparable to each other, because they are designed to meet the same reguirements.

If a company has more than one location with separate personal departments and if only one location needs to be searched, it should be kept in mind that records can be transferred from one department to the other, if a worker is transterred. These will be missed if only one file is searched.

A second source that can be used to compilis a list of exposed workers are the medical files. personel files should be preferred over medical files because the relevant data from the medical files are derived from the personel files and becauge medcal flles are more sensitiwe in privacy issues. It must be clear however, that medical files usually also contain a master card, so that medical data do not have to be reviewed by abstractors. A problem with medical records is the accuracy of information about the dates of job changes and resignation. This is understandable because they do not form a piece of important information in the medical file. Medical files only are available in the larger companies.

A third source of data to compile a list of exposed workers, is the company 
pension fund. A perision fund must keep accurate records of what payments are made into the fund, so that the magnitude of pension benefits can be calculated. Records must be kept over a long period of time, even regarding workers who have already left the company, because as soom as the pensionable age is reached appeal to the built up rights can be made. However a weak point of these records is that they do not contain information regarding job title and workplace. This implies that even no distinction can be made between office personel and production workers. These data can be acquired by interviewing key persons in the company who remember the workers included in the cohort. This is a very time consuming one and is based on the recollection of the we key informants.

From the above it must be clear that cohorts of workers exposed in the past can be compiled in the Dutch chemical industry. But it is questionable if this also applies to exposures that occur in a more dispersed fashion, meaning that exposure is not concentrated in particular companies, but that a few workers are exposed in a large number of companies. The feasibility of compling an exposed cohort in two such instances has been investigated recenty. The first instance was exposure to chromates during stainless steel welding operations. Stainless steel welders have been reported to be at higher risk for developing lung cancer. An epidemiological study of welders is complicated by the fact that a company only employs a few stainless steel welders, so that participation of many companies would be required to obtain a cohort of sufficiemt size. Although this is mainly a problem of logistics, it is a very complicating factor. Theretore another approach was tested. Stainless steel welding is a fairly specialized type of welding. Therefore welders usually are required to take special training, even if they have been welding stainless steel already. There are several institutes in The Netherlands that of fer such training. After this training an examination will follow. Copies of the awarded aiplonas are kept. These copies can be used to compile a cohort of statinless steel welders, taking the diploma as an indicator of being employed as a stainless steel welder.

A second instance of such dispersed occupational exposure is the case of pess ticide sprayers. In several reports these speayers have been sald to be at higher risk for cancer of several sites. One occupational group regularly exposed to pesticides are "public park sprayers". Some of these are employed by the municipalities and some are employed by small botanical firms under contract from municipalities. Inquiries were made regarding the possibilities to compile a list of public park sprayers through the municipal personel department. This appeared to be very tedious job, perhaps even impossible, 
becatuse of ddentification problems of who had been a sprayer and who was not. In conversations with key persions it became apparant that pesticide sprayers must take a pecial course before they are permitted to apply pesticices. If this special course is successully taken, a certificate is given, stating that the person is certified to handle pesticides. Copies of the certificates are centrally sored for future reference. These certificates are open to the public. By means of these copies it was possible to complile a list of 1,200 workers who had been certifled to handie pesticides in the past and have very probably done so in the past.

A weak point of this approach is that there can be workers certified as sprayers, but who have not worked as sprayer at all. The same goes for the welders. This possible misclassification may lead to an underestimation of the true relative risk. A validity check on a sample of these workers could be made to gee to what extent misclassification has occurred. If this weak point Is accepted, the long term effects of occupational exposure to pesticides can be investigated.

A Eourth source of data, that can be used for the compilation of a cohort exposed in the past, are the files of trade unions. This source so far has not been used for the conduct of retrospective cohort studies in whe Netherlands, but it can be expected that the same problerns may be encountered as in other countries. A particular problem may be that trade urion files usually do not contain information regarding the particular occupation that the workers have and as such do not provide an opportunity to distinguish production workers irom oftice employees.

In summary it can be stated that in the chemical industry it is possible to compile a list of workers exposed in the past.

\section{Pacilites ro carry out the follow-up}

The follow-up is that part of a retrospective cohort study designed to observe the accurrence of disease. In most studies the obserwable occurrence of disease is restricted to mortality. Mortality of course reflects the most serious types of diseases. Another reason for this restriction is that retrospective cohort studies focussing on morbidity are difficult to conduct, because a special system for observing morbidity is required and age-specific morbidity rates for the general population must be available in order to calculate expected numbers.

In practice the only frequentily conducted retrospective cohort studies on di- 
sease norbidity are those focussing on cancer incidence in countries that maintain a cancer registry. In The Netherlands a system of cancer registries has come into existence only recently. Therefore it is not yet suitable for conducting retrospective cohort studies of cancer morbidity.

Especially in the Anglo-Saxon and Scandinavian countries much experitence has been acquired regarding follow-up procedures. In The United States, the country with by far the most published reports of retrospective cohort studies" the follow-up is regarded as the most time consuming and expensive phase of the study. In the United States the follow-up must be carried out in a nore improvised fashion. For workers who can not be followed up through the social Security System probes must be made at the Department of Motorvehicle Administration, former nextdoor neigbours, relatives, former colleagues evetera. In The Netherlands a system of population registries is in service " This administrative system has been designed to keep track of Dutch citizens. At birth or immigration a person card is made and entered into the system. This person card contains among other things information about the name, date and place of birth. current address of the person in question. Each municipality has its own population registry, covering the population of that particular municipality. If a person moves to another municipality, the person card will also be sent to the other municipality, but a copy will be kept for Euture reference. People who change residency but fail to report this to the Population Registry are punishable by law. The coverage of the system of population Registries is probably nearly 100\%, since many things are related to enlistment in it, such as elections, the taxsystem and military service. A certified copy of the population Registry is required in many formal instances such as: obtaining a driving licence.

If a person dies in The Netherlands a death certificate must be filed, signed by a physician. The person card and the death certificate are sent to the central Bureau of statistics for the compilation of the annul mortality statistics.

In the past several epidemiologists have employed this system of population registries to carry out the follow-up $2,3,8$. These attempts have always been very successful. This has also been the case in the recently completed retrospective cohort study of coke plant workers in which a completeness of more than 99 was achieved.

Aside of this procedure of active follow-up a procedure of passive follow up can also be employed in The Netherlands. This procedure is comparable to the National Death Index System in The united states. This system basically in a ist of deaths that have been registered in The United states. It greatly 
facilitate the follow-up. In the Nether Iands all person cards of deceased Dutch citizems are sent to the central Bureau ot statistics together with the death certuficate. These person cards are forwarded to the central Bureau of Genealogy where they are kept. This mode of follow-up has been tested in the coke plant study. The identification characteristics of the workers in study were sent to the central Bureau of Genealogy w the request to trace all the decedised workers. Of the 2,267 deaths in this group 1,733 were found, giving a completeness of 76 . It can be debated that if an internal comparison group Is avallable one could adjust for this incompleteness. The data from the central Bureau of Genealogy could be analyzed in a Proportional Mortality Ratiotype (PMR) of Eashion, for which no data of the total population at risk are necessiary. However, the investigator still has to compile a list of exposed workers and still has to oblain causes of death from the Central Bureau of Statistics, so that the advantage from a passive follow-up are only small compared to the total effort necessary for the study. However, the Central Bureau of Genealogy can be employed as an efficient way to complete the follow up on a large proportion of the deceased persons under investigation next to an active way of follow up. This is particularly true if a relatively large proportion of the cohort is deceased.

In summary, a priori conditions for a successful follow-up are more favorable in the wetherlands than for instance in the United states.

\section{Avaliability of valid information regarding the occurrence of disease}

As has been stated earlier, most retrospective cohort studies have facussed on cause-specific mortality as the digease outcome of interest. Information regarding the causes of death is also available in The Netherlands. The Dutch notification of a deceated individual requires two forms fron the physician, one without medical data for several registration purposes and the other for gtatistical purposes with the underlying cause of death. The death certificalies are gent by the municipalities to the Central Bureau of statistics, where they are coded by trained nosologists and computerized. If epidemiologists in The Nethexlands could obtain information regarding the causes of death following the same procedures and conditions required in the United states, Great Britain on the scandinavian countries, retrospective cohort studies could be carcied out very efictently in the vetherlands. This is not the case however. In order to abtain information regarding the causes of death in The Netherlands, the epidemiologist must obtain permission of two agencies, namely the 
Chief Inspectorate of Fublic Health and the Centrall Burean of Statistics. Both agencies have conditions, for instance:

The Chief Inspectorate of Public Health requires among other conditions a sound research protocol, that the causes of death can not be obtained through other channels and that the data are destroyed after termination of the study.

The Central Bureau of Statistics will require for instance, that the causes of death are not tracable to individual persons, that the costs are paid by the scientist and that the privacy of the individuals and medical confidentiality are safeguarded. Additional conditions may apply in particular cases. if the data can be traced to a particular private company.

In practice the epidemiologist willing to carry out a retrospective cohort study in the Netherlands must obtain permission from both agencies. whe permission from the Chief Inspectorate of Public Health will take a few weeks after having applied by a formal request. The permission from the central Bureau of statistics will take longer, because a contract must be drawn up by their legal department and clearances from several departments must be obtained. In this case the time period between first meetings and obtaimment of data was partly due to the fact that this was the first tirve that such a request was done at the central Bureau of statistics. The greatest difficulty is that guidelines of the central Bureau of Statistics prohibit the provision of data tracable to individual companies. Therefore a special contract had to be made in which the company involved allowed the Central Bureau of statistics to connect the causes of death with the exposure data of the company. Now that such a contract has been made and approved, next projects should be less time consuming. One particular problem remains unresolved, namely the possibilities of nested case-control study within a cohort. A nested case-conwol study can be of particular help in controling possible effects of extraneous exposures, such as smoking for instance. Smoking data can be collected on a limited number of persons, say two hundred cases and two hundred controls. However It is not feasible to collect retrospective smoking data on 10,000 workers of whom 25 have deceased and many have moved to other places. A nested case-control study could help unravel possible synergistic effects between occupational exposures and smoking habits. Because the Central Bureau of statistics can not provide the epideniologist with the individual causes of death, it seems not feasible to conduct nested case-control studies in The Netherlands. The primary task of the Central Bureau of statistics is to collect data and 
analyse these data in a statistical manner. However, the CBS also provides dat to outside scientists if these data are used for statistical analysis and if the data are not tracable to individuals or individual companies. In the coke plart study the data growided by the CBS were not tracable to individual wotkex, but they were tracable to particular company. Thus, the CBS anly wanted to provide the causes of death if the company in question wanted to sign an agreement in which the company specifically requegted to 1 ink the causes of death to their workers.

\section{Avaldability of annual age-, sex and cause-specific death rates}

This is the fourth and last condition that must be met to enable the conduct of retrospective cohort studies. For the Netherlands these death rates are available in the form of the "A"-series of causes of death published by the Central Bureau of statistics. These death rates sill are of wital importance, even if the study includes a non-exposed reference population, since the period age-, sex- and cause-specific death rates observed in this reference population are too instable to replace the national death rates. The published "A"-zeries are not directly usable. F"irst the data must be computerized, convergiontables to a recent ICD-revision, and reclassification into large disease groups must be made. These steps can easily be taken.

\section{DISCUSSTON}

In 1982 a book wa published about the relevance of epidemiologic research in the fletd of occupational health ${ }^{2}$. This book was a modified version of a report drawn up under the commission of the Sclentific Council for governmental policy. It was intended to contribute to changes in occupational health that would promote activitus focussed on the prevention of occupational health risks.

Several recominendations were made to stimulate this type of research such as collaboration between regional occupational health officies, uniformity in occupational health care and accessibility of external support. Although only few data exist on the developments of occupational. epidemiologists in the wetherlands it seens likely that efforts made in this field have greatly increased. In a recentw Iy conducted survey among Dutch epidemiologists 15 of the respondents stated 
that occupational epidemiology was their primary interest. Still however, the muber of projects evaluating long term health risks, such as cancer, related to occupational exposure has remained fairly limited. This can be illustrated by the fact that epidemiologic evidence for the existence or absence of these risks, necessary for regulatory standard setting nearly always originates from other countries. An industrial branch that could particular benefit from epidemiologic studies is the chemical industry. By this it is not meant that the working conditions in the chemical industry evoke more health hazards to the workers than in other industries. In the chemical industry a great number of chemicals are used. Many of these chemicals have been tested in toxicological studies and have been demonstrated to be capable of inducing tumors in animals, exposed to high concentrations. However, these results do not necessarily imply that humans exposed to low concentrations run the same risks. Epidemiologic studies of these workers may form a more realistic basis for the evaluation of these risks.

\section{QPTIONS FOR THE FUTURE}

There is a need for epidemiological evidence regarding potential long term human health risks of exposure to certain chemicals in the chemical industry and perhaps the putch chemical industry should create conditions for epidemiologic rem search itself, for instance in the form of an occupational health monitoring system. This database, especially designed for the conduct of epidemiologic studies should cantain information on exposure, confounders and the occurrence of disease for all production and maintenance workers in the Dutch chemical industry. Several individual companies in The Netherlands have already set up such a data base. but a disadvantage of these databases, is that the number of exposed workeris in one company may be too mall to draw firm conclusions on. If these databases are not combined in the design stage, non-uniform procedure for data callection may be the result. Such an industry wide database should be set up retrospectively, also including workers who were employed in the past. The retrospective component will allow the investigation of past exposures that were higher than they are now. and thus may provide more informative data. Knowledge of potential health effects of relatively high exposures that were present in the chemical industry twenty, thirty years can prove to be extremely waluable, because these are perhaps the last instances that these relatively high exposures hawe occurred. Such a data base should also contain information about the type and magnitude of expo- 
Sures experienced by the individual workers. The process of retrospective expogure assement and present exposure measurement requires a substantial input of industrial hygienists eriployed by the chemical companies.

Ever if such an extentive data base can succesfully be set up in the Dutch chemical industry, external support will remain indispensable, particularly regarding data collection of health effects. In this framework the presence of a national cance registry and accessability to individual causes of death play a crucial role.

\section{REFERENCES}

1. Case RAM, ME Hosker, DB McDonald, JT Pearson. Tumours of the urinary bladder in workmen engaged in the manufacture and wse of certain dyestuff intermediates in the Britigh chemical industry. Part 1. The role of aniline, benzidine, alpha-napthylamine and beta-napthylamine. Brit. J. Indust. Med. 1954; 11: $75-104$.

2. Sturmans F, MCJM van Dongen, GA Zielhuis. Naar een gezonde werkomgeving. Dekker en van de Vegt, Mijmegen, 1982.

3. Scheffers MM, LW Winter, WF ten Berge. Historisch cohort onderzoek in Nederland. Sterfte in een groep laboranten met een arbeidshistorie in een cokesfabriek. T. Soc. Gez. 1985; 63: 370-375.

4. Tordoir WF. Teleurstellend resultat van een industrieel epidemiologisch onderzoek, als Jes voor de toekomst. T. Soc. Geneesk. 1981; 59: 707.

5. Vandenbroucke JP. Teleurstellende epidemiologische kennis. T. Soc. Geneesk. $1982 ; 60: 21-22$.

6. Meijers JMM, GMH Swaen, $K$ wan Vliet. Occupational cohort gtudies. The inEluence of design characteristics on the healthy worker effect. In press, Int. T. Ep Edemiol.

7. Vulsma RF. Geboekt van wieg tot gra歨, Uitgave van het Centraal Bureau voor Genealogie, Jen Hagg, 1980.

B. Berkel J. Het reine leven. Aspekten van voedings- en gezondheidsstatus van zevende Dag Adventisten in Nederland. Hart Buldetin 1980; 11: 12-76. 


\section{LONG TERM MORTALITY OF COKE OVEN HORKERS}

IN THE NETHERLANDS
G.W.H. Swaen ${ }^{1}$
J.J.M. SIangen ${ }^{1}$
A. Nolovics ${ }^{3}$
F. . Sturmans ${ }^{2}$

This study was financially supported by grant no RUL-83-1 of the queen wilhelmina Fund.

1 Dpt. of Occupational Medicine, University of Limburg, The Netherlands

2 Dpt. of Epidemiology, University of Limburg, The Wetherlands

3 Dpt. of Biostatistics, University of Limburg, The Netherlands 
I. 2

$-28-$ 


\section{ABSTRACT}

A retrospective cohort study was conducted to evaluate possible cancer risks associated with occupational exposures that were present in three Dutch coke plants. A total group of 6.872 workers were selected for the study. These all held Dutch citizenship and were employed between 01-01-1945 and 01-01-1969 at least for a half year. The exposed cohort consisted of 1,132 workers who had worked on the top or at the side of the ovens. The reference group wet the same eligibility criteria and had been employed at a nearby nitrogen fikation plant. All workers were followed until 01-01-1984 to determine the accurrence of mortality.

In the coke oven workers mortality from lung cancer and respiratory diseases was higher than expected. An elevated risk for liwer cancer mortallty was also observed, which may be a chance finding.

In general the results support the findings reported from Great Britain.

\section{INTRODUCTION}

Coke is derived from bituminous coal by means of destructive heating in the absence of oxygen ${ }^{1}$. The main use of coke is as fuel for blast furnaces to retrieve iron from iron ore. In recent years the worldwide coke production has declined as a result of decreasing demands for products of the heavy iron and steel industry and also as a result of the application of other fuels. The worldw wide production of coke in 1977 has been estirnated to be approximately $360 \mathrm{mil}$ lion tons ${ }^{2}$. Coke is produced by heating bituminous coal in large ovens. After the oven is charged with coal particles from the topside, the over 4 s heated during a period of 20 hours to a temperature of 1100 degrees celcius. Then the doors of each side of the oven are removed and the coke is pushed out by a pusher machine. into a quenching car, which is shunted to the querch tower, where the hot coke is cooled with water. On the coke wharf the coke is allawed to cool down further. In illustration 1 a schematic representation is given of the coking process. During the coking process large quantities of gas escape from the coal and are collected in collecting mains. This coke oven gas can be processed in the chemical department, where a number of chemicals are extracted, mainly by means of destiliation processes. 
Wischematic representation of the coking process.

Ir top of the coke battery is filled with coal. alged into the coke oven.

wethe bituminous cal in the coke oven. e cocess takes place.

e pushed by means of a pusher machine.

it cooled dowm at the quenching station.

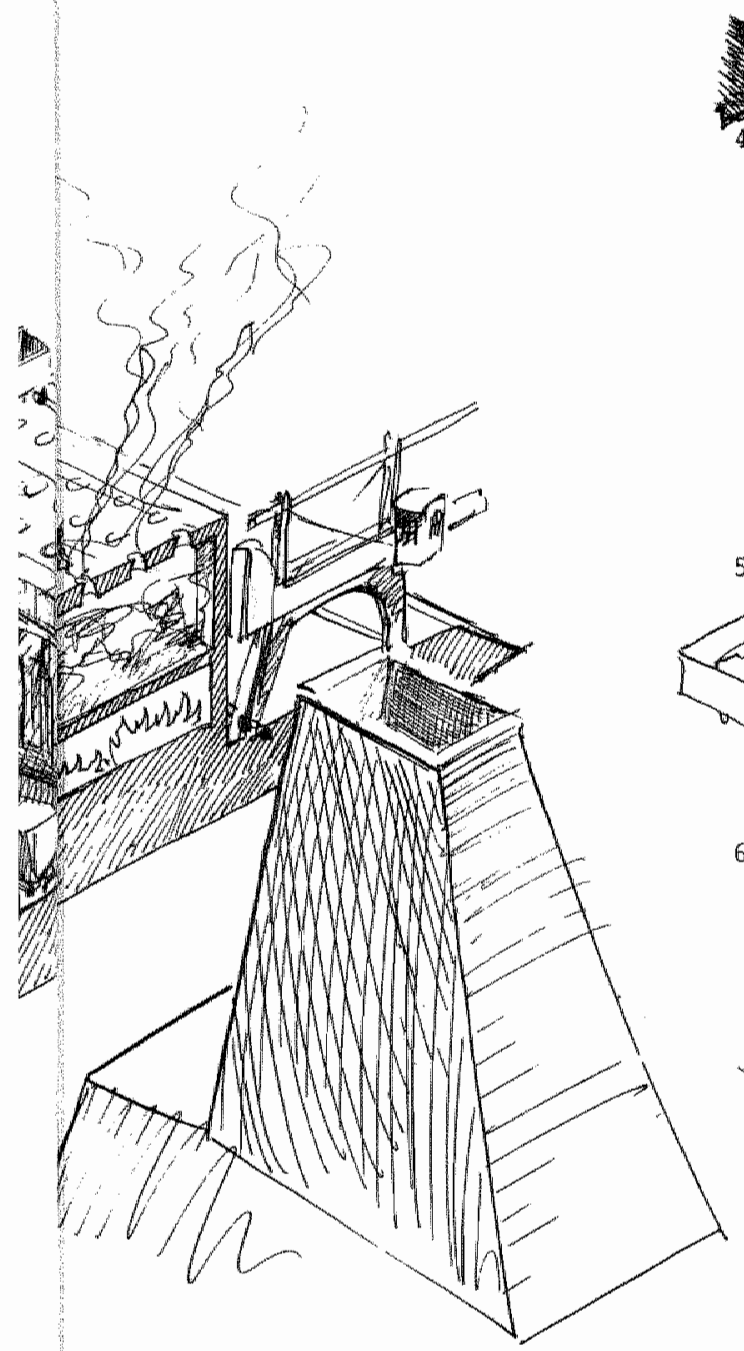

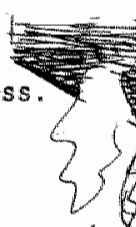

a. $y^{5}$ es
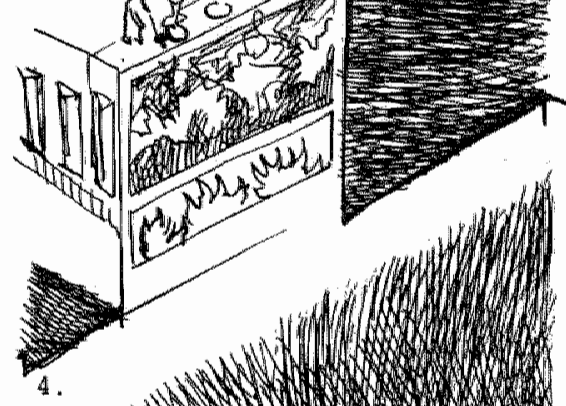

4.
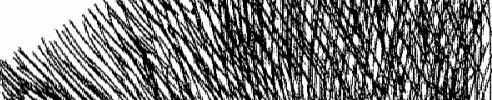

5.
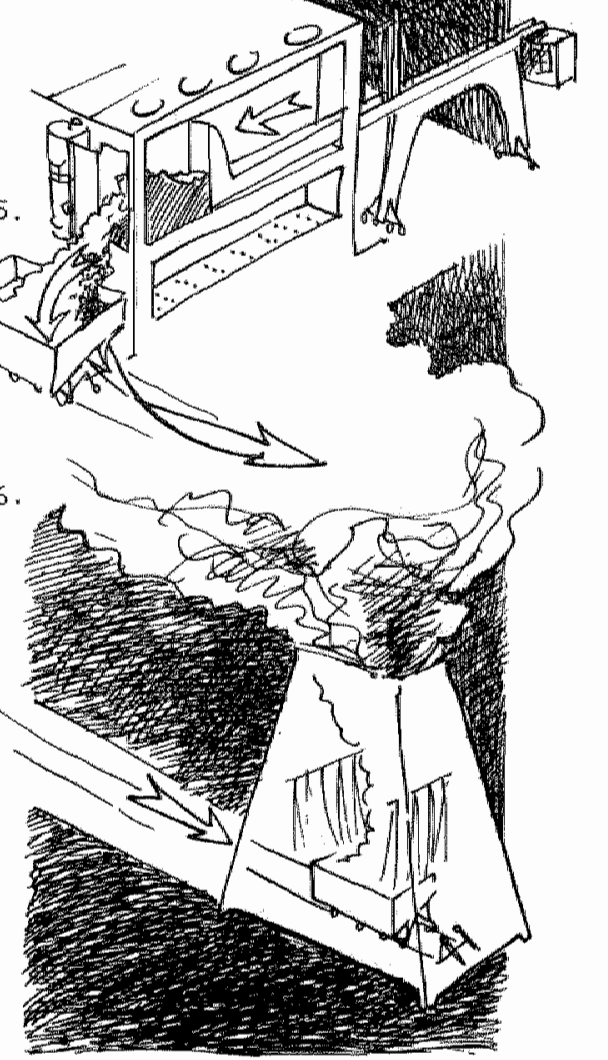
occupational exposures of coke plant workers wary greatly from department to department and from job to job. In several countries air samples have been taken at the top side of coke ovens. In these samples benz(a) prrene concentrations have been detemined. These concentrations are presented in Table 1 . In The Netherlands arramples close to coke ovens have been taken, but the fractions of benz(a) pyrene hawe not been detemined.

Table 2: Benztalpyrene concentrations in air samples taken from the top side of a number of coke ovens.

\begin{tabular}{|c|c|c|c|}
\hline $\begin{array}{l}\text { Country } \\
\text { (rear of publi- } \\
\text { cation) }\end{array}$ & Type of coke plant & $\begin{array}{l}\text { Lowest } \\
\text { concentgation } \\
\text { in } \mu / \mathrm{m}^{2}\end{array}$ & $\begin{array}{l}\text { Highest } \\
\text { concentration } \\
\text { in } \mu g / \mathrm{m}\end{array}$ \\
\hline $\begin{array}{l}\text { Sowjet Union } \\
(1962)\end{array}$ & Coke plant & 1.3 & 27.4 \\
\hline $\begin{array}{l}\text { Crechos lowakid } \\
\text { (1971) }\end{array}$ & $\begin{array}{l}\text { Metallurgical coke } \\
\text { plant } \\
\text { coke plant }\end{array}$ & $\begin{array}{l}3.0 \\
1.0\end{array}$ & $\begin{array}{l}33.0 \\
23.1\end{array}$ \\
\hline $\begin{array}{l}\text { United states } \\
(1974)\end{array}$ & Coke plant & 1.2 & 15.9 \\
\hline $\begin{array}{l}\text { Norway } \\
(1978)\end{array}$ & coke plant & 8.0 & 135.0 \\
\hline $\begin{array}{l}\text { poland } \\
\text { (1978) }\end{array}$ & $\begin{array}{l}\text { Old coke plant } \\
\text { At ter modernisation } \\
\text { Modern coke plant }\end{array}$ & $\begin{array}{r}20.0 \\
0 \\
0\end{array}$ & $\begin{array}{r}282.0 \\
6.8 \\
27.0\end{array}$ \\
\hline $\begin{array}{l}\text { West-Germany } \\
(1982)\end{array}$ & Coke plant & 5.0 & 15.5 \\
\hline $\begin{array}{l}\text { Sweden } \\
(1982)\end{array}$ & Coke plant & 9.4 & 13.5 \\
\hline $\begin{array}{l}\text { England } \\
(1972)\end{array}$ & Coke plant & 2.1 & 27.3 \\
\hline
\end{tabular}

In this paper we w11 focuss upon those workers directly involved in the coking process. The man occupational exposure in this section of the coke plant is exposure to coke oven gas. Chemical analysis of coke oven gas has demonstrated that it contains a mumber of carcinogenic substances such as benzla)pyrene, chrysene, 2-naphtylamine, arsenic and benzene" The carcinogenicity of coke oven enissions bas been investigated experimentally, by topical application of ariea coke oven main samples to 80 sencar mice ${ }^{4.5}$. The incidence of both skin papillo- 
mas and carcinomas was increased. Experimental inhalation studies also demonstraw ted an increase of lung tumours in mice ${ }^{6,7}$. The human carcinogenic risk of coke owen emissions has recently been reviewed by $\operatorname{IARC}^{8}$.

Several epidemiological studies of coke oven workers have been conducted in the past Table 2). Most epidemiologic studies had a retrospective cohort design. However, this is not true for the first study that was conducted in this field. Kernaway and Kennaway investigated deaths from lung cancer and larymgeal cancer that occurred between 1921 and 1938 in England and Wales ${ }^{9}$. On the death certificates the former occupation was written down. The investigators used national. census data to derive estimates of age-specific occupational distributions in the general population. These estimates were used to calculate the expected number of deaths for a particular occupation. The number of lung cancer deaths in the occupational group of coke oven workers was 2.8 tines higher than expected. In this occupational group mortality from laryngeal cancer was 2.1 times higher than expected. In another study christian ${ }^{10}$ followed a group of workers who had been employed at a coal gasification plant. The production process of coal gasification is quite similar to that of a coke plant. He found a lung cancer mortality rate that was 24 times the rate in the general population. In the same year Reid and Buck $^{11}$ reported the results of an epidemiologic study of a series of deaths that occurred among coke plant workers between 1949 and 1954 . The causes of death were compared with causes of deaths who had been employed in another company. The causes of death among the coke plant workers did not differ from the causes of death in the non-exposed series. The design of this study is quite different from designs that are generally applied in occupational studies, which makes it difficult to assess whether the study was a true negative study or that the design was inappropriate.

In 1967 Japanese investigators reported the results of a retrospective cohort study of workers who had been employed at a coal gasification plant ${ }^{12}$. This study was triggered by earlier case reports of lung cancer deaths in Japanese coal gasification workers ${ }^{13}$. A reference group of workers of the generatorgas plant was also included in the study. Both groups were followed up in a similar fashion. Causes of death were obtained from medical records in local hospital In the exposed population six workers of the coal gasification plant had died from lung cancer, compared to an expected number of 0.18 . The risk of liung cancer increased with duration of exposure and remained high after termination of exposure. The quality of the medical data available for the exposea group was different from that for the non-exposed group, which may imply that the lung cancer cases in the exposed group were more likely to be diagnosed as such. 


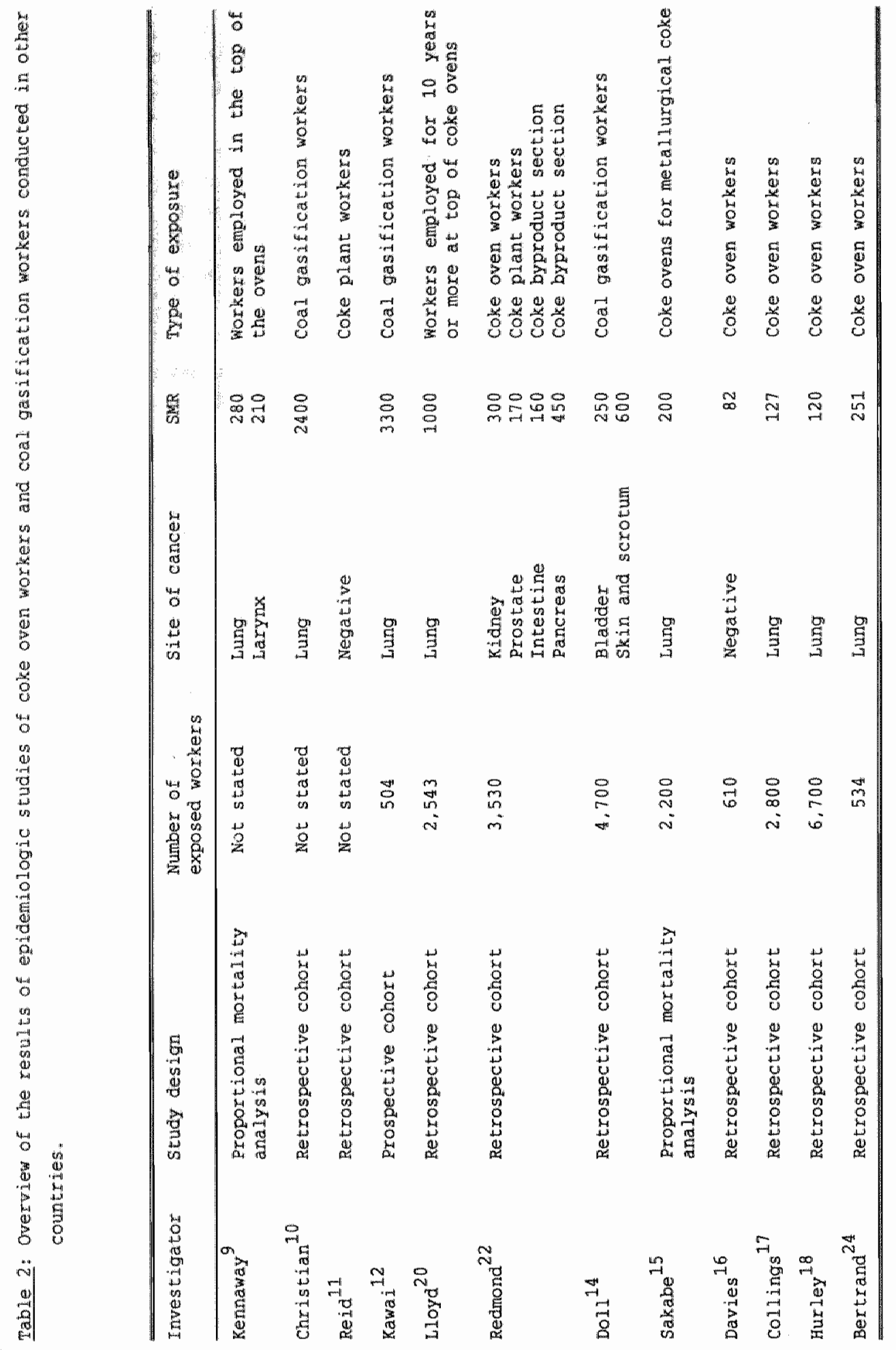


In $1972 \mathrm{Sir}$ Richard Dol1 ${ }^{14}$ reported the results of a retraspective conort study among coal gasification workers in Great Britain. A cohort of 4,700 workers, all exposed on 1 September 1953, was followed until 1965. Only 0.5 of the cohort was last to follow-up. The workers were divided into three exposure groups, that were compared to the mortality rates in the general population. In the group with the highest exposure the risk for bladder cancer was two and a half times that of the general population. Scrotal and skin cancer was six times higher than the background risk. Furthemore the lung cancer rates and mortality from bronchitis were also elevated.

Sakabe ${ }^{15}$ studied the mortality patterns of 2,200 pensionned coke plant workers in Japan, between 1947 and 1973. The study comprised workers of eleven coke plants. The mortality patterns anong these workers resembled those of the general population. However, if the cohort was restricted to coke plants that were a part of a steel company, the lung cancer mortality was twice as high as expected. Davies 16 followed a cohort of 610 coke plant workers in Great Britain ower a period of eleven years. The total mortality in this group was 158 lower than expected. No excess of cancer mortality from any site was noted.

Under the comission of the European Community for coal and steel collings conducted an epidemiologic study of 2,800 workers of 14 British coke plants 17 . A11 workers employed on 1 July 1967 were followed until 1976. The observed causespecific mortality in the cohort was compared with that of unskilied and semiskilled personel in Great Britain. Among coke oven workers who had been employed for five years or more a 27 increase in lung cancer mortality was observed. Later on this study was expanded to 6,767 coke oven workers ${ }^{18}$. This study gave similar results as the previous one.

A similar study of coke plant workers has been carried out in the United states 19-22 by the university of Pittsburgh. The total population consisted of 58,000 steel workers employed in 1953. The workers were followed until 1961. The mortaIity rates of the coke oven workers were compared with those of the steel workers. Redmond ${ }^{22}$ expanded the size of the cohort and the period of follow-up. Among the non-white coke oven workers the lung cancer rates were twice as high as those of other steel workers. Workers employed on the top of the ovens experienced lung cancer rates that were eight times as high as those of the steel. workers. Other cancer types were also elevated among the coke oven workers. These were intestinal cancer, kidney cancer, pancreatic and prostatic cancer. "These results could not be confirmed in a later case-control study of lung cancer ${ }^{23}$. However, this study was restricted to white males only.

Finally an epidemiologic study of 5.34 coke oven workers has been conducted in France $^{24}$ who had retired between 1963 and 1982 . Lung cancer was 2.5 times higher 
than the Iung cancer mortality rates for the general population of France. However, lung cancex mortality rates of the general population in the region in which the study was caried out are significantly higher than those for the total population of France. This difference may account for part of the observed elewated lung cancer risk in the study population. A second weak point is the collection of cases in the cohort. Causes of death were collected from medical flles which may have resulted in a higher ascertainment rate in the exposed group than In the general population.

The specific aims of the study presented here were to investigate if Dutch coke oven workers exposed to coke oven gas have also been at higher risk for lung cancet. and if so, to what extent, and to investigate if Dutch coke oven workers have been at higher risk for other types of cancer than lung cancer. A secondary aim of the study was to investigate if these risks resembled those observed in Great Britain, or those reported from the united states.

\section{THE THREE COKE RLANTS UNDER INVESTIGATION}

Much of the coal exploited in The Netherlands was of a bituminous type which is not suitable for household purposes. In order to make mining of this bituminous coal profitable, it was decided to build large coke plants to produce coke ${ }^{25}$. The first coke from the coke plant Ex wushed in 1919. From the start much attention was given to gas production and the destillation of chemicals. The coke plant E remained in production until 1945. The coke plant thas one of the largest that ever existed in Europe and was taken into production in 1929. Because of poor maintenance during world war II and other technical considerations the coke plant $\mathrm{E}$ was replaced by the modern coke plant $\mathrm{E}^{26}$.

Since much of the profttably exploitable coal was nearly exhausted and becanse of the great natural gas resources that were discovered, it was decided to terminate the coalmining activities in the Netherlands. Consequently the coke plant E2 and $M$ were shut down in 1968. Based on descriptions of the coke plants we concluded that the hygienic conditions were best in the E2-plant, intermediate in the M-plant and poorest in the E-plant. 
In order to detect long term health effects, it is necessary to apply a longitudinal study design. A retrospective cohort design is a generally accepted design. in particular if occupational exposure and a range of potential health effects is under investigation 27 . Usually the observed cause-specific mortality in the exposed population is compared with the cause-specific mortality in the general population.

The influence on mortality of age distribution, length of follow-up and varying background risks in specific time intervals are controlled for by the method of indrect standardisation, resulting in a standardised Mortality Ratio (SMR).

The application of the retrospective cohort design has resulted in a substantial body of knowledge about long term health effects of occupational exposures in particular regarding cancer mortality. However, many results have been difficult to interpret, such as the lower mortality rates of occupational groups, later attributed to the "Healthy Worker Effect" due to a selection into working populations of healthier persons. Therefore it has been suggested to include in the study a non-exposed working population, the reference population. A group of workers employed in the Nitrogen Fixation plant, producing artificial fertilizers. was included in the study as a reference group. An occupational reference group was included to enable an assessment of the Heal thy worker Effect and to avold potential bias due to differences in local cause-specific rnortality rates and national mortality rates. Information about both groups was collected in a similar manner.

The study population consisted of 6,872 male workers who were employed at the ovens of one of the coke plants or the Nitrogen Fixation plant for at least a half year, between 01-01-1945 and 01-01-1969, who held Dutch citizenship and were living in the Nethexlands. The workers included in the comparison group have beer exposed to Nox fertilizer dust. The occupational history, name and adaresis of these 6.872 male workers were available in the personal files of the company. M11 150,000 files of past and present employees were screened to identify workers eligible for the study. From all 1,132 workers employed at the coke overis for more than a half year, information on the occupational history consisted of job and worklace and relating time intervals. The job classification scheme enabled the coding of every job mentioned in the files and included over one hundred spew cific jobs. The list of workplaces in total also contained more than one hundred different places. The screening of the files and collecting the occupational history was done by persons who were trained for this work and who were informed of 
the procedures to be followed. Population registries do not prowide information of individuls to others. However, an exception generally is made if requests are made in the courge of a scientific investigation.

Death certificates thist be filed at the municipal population registry, where the certificates are processed and transferred to the central Bureau of statistics (CBS). At the CBS the death certificates containing information regarding the underlying cause of death are computerized to enable the compilation of the arrual national death rates by cause of death.

Underlying causes of death car be obtained for the purpose of scientific research if permision is granted from the chief Inspectorate of Fublic Health and the CBS. This permission will be granted only if several gtrict conditions are met. A condition strongly restricting the options for epidemiologic research is that the causes of death showld not be tracable to individuals. Thus only cross tabulations of causes of death and exposure groups are provided. This condition renders it impossible to conduct nested case-control studies. Additional agreements mugt be made to acquire access to the original data base for statistical modelling, of course without having access to individual records of the cohort members.

In March 1984 permission of the Chief Inspectorate of Public Health was given to abtain the death certificates. At the end of 1984 the negotiations were started to obtain the causes of death. On April 21.1989 the final cross tabulations of causes of death and exposure groups were received from the CBS. The causes of death had all been coded according to the ICD classification applied in a particular period by trained nosologists of the CBS. The coding was done long before the study was conducted and without any knowledige of the study or exposure categories. Thus no classification difference between the two exposure categories regarding the causes of death is Iikely to have occurred. The various ICD classifications were converted to the ICD-9 version. All causes were grouped into seven mair categories. "rhe main category "neoplasms" was divided into 28 anatomical. is tivers.

The procedure of the follow-up was similar for the exposed and the non-exposed group. From the 6,872 workers eligible for the study number were still enployed by the company, at the end date of the follow-up. These workers were regarded as being alive at the end date of the follow-up, and consequently were not entered into further follow-up procedures. The files of the company's pension fund were searched for study subjects who were receiving retirement benefits at the end date of the follow-up. These subjects were regarded as being alive at the end date of the follow-up. For the remaining study subjects information about their vital status was requested at the municipalities which all keep records of their 
inhabitants. Births, deaths and changes of residence are entered into the mumicipal population registries. These populations registries play an inportant role in the administration of political elections, obligatory military services, tax system and social security system and thus are regarded to be very accurate. Al1 population zegistries that were contacted for information about the vital status of the study subjects participated in the study. For subjects that moved out of one municipality to another, it was necessary to contact the population registry of the municipality to which the person had moved. In some instances it as necessary to contact seven population registries to trace the vital status of a particular worker. Of 6 persons it was not possible to determine the vital status at the end date of the study. In the analyses these 6 were regarded as being alive at the date that they were lost to follow-up. This may have resulted in an underestimation of the true relative risk, because several individuals lost to follow-up may in fact have died. However, in any, the underestimation must be sma11, because only 6 out of 6,872 workers were last to follow-up. The person years of workers who emigrated during the observation period were included into the study up to the emigraton date, since deaths accurring prior to that date also would have been included in the study. The results of the follow-up are shown in Table 3.

Table 3: Wital status of workers enrolled in the coke plant study at 01-01-1984. the end date of follow-up.

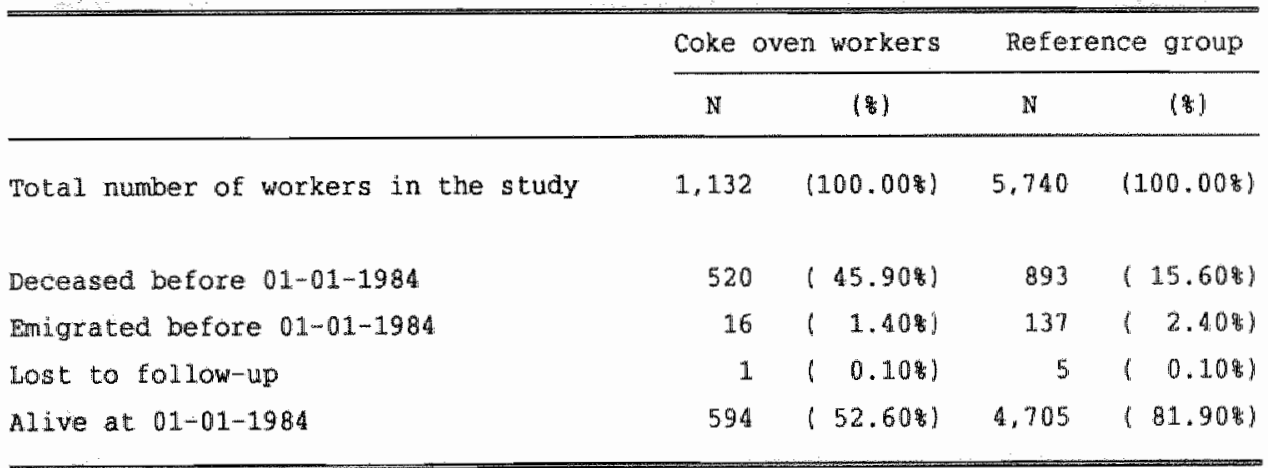

The statistical analysis consisted of a person-time analysis, to correct for differences in age distribution, period of follow-up and the fluctuation of background mortality rates. The person-time analysis was conducted by the computer program designed by $\pi$. Peto 28 . Expected numbers were calculated by means of 
applying the cause-, age- and calender time specific death rates of the total Dutch nale population to the generated person-years of the exposed and non-exposed cohort: This indirect method of standardisation was preferred over a direct method between the exposed and non-exposed group, because of the relative instabitity of these specific rates in the exposed group. For instance, an observed number of 15 deaths from apecific cause of death would still lead to instable Thtes, taking into account the number of cells over which these observed deaths must be diwided. 95 Two-sided confidence limits were calculated as proposed by Brestow and bay ${ }^{29}$. Although non-exposed working cohort was at hand, the basic comparison was with the cause-specific mortality of the total Dutch male populaw tion. Because the individual causes of death are not at our disposal, it has not yet been possible to investigate dose-response relationships by means of statistical modeling. Negotiations are under way with the central Bureau of statistics to carry out additional dose-response analyses on the individual data under their supervision.

\section{RESULTS}

In the reference group the total mortality was lower than expected (see Table 4). 893 Deaths were observed compared to an expected number of 993 . This phenomenon of lower mortality rates in working populations has frequently been observed in cohort studies ard is called the Healthy worker Effect (HWE). HWE can be defined as the manifestation of a deficit in mortality, when the employed population is compared with a general population. It probably originates from selection processes, both prior to employment and during employment. Persons suffering from serious illness are less likely to apply for a job in industry than persons who have no serious iliness. If persons ith a serious iliness apply, they may be found untit tor the job at medical examination.

The total nortality of the exposed cohort coke oven workers was higher than expected $(520$ versus $438, S M R=118,7)$. This increase was statistically significant 1958 confidence Limis of 106.5 and 127.0$)$. Restricting the exposed cohort to those who had ever worked at the oldest plant, the $\mathbb{E}-1$, resulted in a higher SMR of 130.7 (180 versus 137.7 expected, which is statistically significant $195 \%$ confidence limits: $112.3-151.31$. The mortality risks of workers who had only

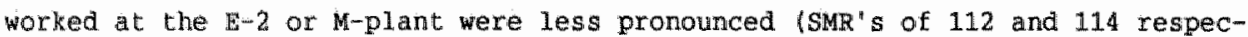
tively). Mortality from respiratory diseases was significantly higher than expected. 
Table 4: Cause-specific mortality in a cohort of coke oven workers and a cohort of non-exposed workers.

\begin{tabular}{|c|c|c|c|c|}
\hline \multirow[t]{2}{*}{ Cause of death } & \multicolumn{2}{|c|}{ Non-exposed group } & \multicolumn{2}{|c|}{ Coke owen workers } \\
\hline & Observed number & SMR & Observed number & SMR \\
\hline \multicolumn{5}{|l|}{ Main categories: } \\
\hline 1. Infectious diseases & 7 & 61 & 4 & 71 \\
\hline 2. Neoplasms & 259 & $85^{*}$ & 160 & $123 *$ \\
\hline 3. Circulatory system & 395 & 99 & 186 & 98 \\
\hline 4. Respiratory system & 57 & 103 & 51 & $166^{*}$ \\
\hline 5. Digestive system & 19 & $57 *$ & 18 & 124 \\
\hline 6. Others & 61 & $60 *$ & 48 & 109 \\
\hline 7. Bxternal causes & 65 & $75^{*}$ & 30 & 131 \\
\hline Unknown & 30 & - & 23 & - \\
\hline \multicolumn{5}{|l|}{ Neoplasms: } \\
\hline Mouth and pharynx & 2 & 59 & 3 & 227 \\
\hline Esophagus & 4 & 84 & 1 & 47 \\
\hline Stomach + small intestine & 27 & 8.8 & 24 & 1.42 \\
\hline Large intestine & 10 & 60 & 6 & 81 \\
\hline Rectum & 15 & 164 & 7 & 153 \\
\hline Iniver and bilary passages & 3 & 5.2 & 8 & $307 *$ \\
\hline Pancreas & 6 & $43^{*}$ & 1 & 18 \\
\hline Nose & 0 & - & - & - \\
\hline Larynx & 1 & 36 & 4 & 329 \\
\hline Trachea + Iung & 107 & 87 & 62 & 129 \\
\hline Bone & 0 & - & 1 & 170 \\
\hline Connective tissue & 3 & 243 & 1. & 279 \\
\hline Skin & 6 & 192 & 0 & 0 \\
\hline Breast & 0 & - & 1 & 671 \\
\hline Prostate & 7 & 55 & 7 & 81. \\
\hline Genital organs & 2 & 87 & 0 & - \\
\hline Bladder & 11 & 6.6 & 7 & 98 \\
\hline Brain & 9 & 120 & 2 & 96 \\
\hline Thyroid gland & 1 & 1.33 & 1 & 353 \\
\hline Lymphatic glands & 0 & - & - & - \\
\hline Lympho-reticular sarcoma & 3 & 86 & 4 & 307 \\
\hline Hodgkin & 2 & 49 & 1 & 104 \\
\hline other lymphoma & 0 & $\dot{-}$ & 1 & 120 \\
\hline Multiple myelona & 2 & 50 & 2 & 118 \\
\hline Leukemia & 13 & 135 & 6 & 163 \\
\hline Benign neoplasms & 4 & 246 & 1 & 166 \\
\hline Wot specified neoplasms & 19 & 140 & 7 & 124 \\
\hline other & 2 & 47 & 2 & 115 \\
\hline Total & 893 & $90 *$ & 520 & 118.7 \\
\hline
\end{tabular}

* $P<0.05$ two-sided 
The sur for regpiratory disease moxtally in the coke oven cohort was 166 (51 observed versus 30.8 expected, which is statistically significant 195 confidence 11mits: $123.4-217.7 \%$. In the coke oven workers cancer mortality from seweral stes were elevated. This was the case for lung cancer (SHR = 129) almost reaching statigtical significance (95\% confidence limitg: $99.0-165.5$ ). gastric and small intestine cancer $(S M R=142)$ not reaching statistical significance $(95 \%$ confidence limits: $91.0-211.4)$ and liver cancer (BMR $=307)$. This sMr was also stakisically stgificant 195 confidence limits: $132.2-604.91$. Coke oven workers of coke plants experienced the highest risk for lung cancer mortality (SMR - 139) nearly reaching statistical significance and mortality from respiratory diseases (SMR $=166$ ) which is statistically significant (95\% confidence limits: $116.6-235.4)$.

Based on job descriptions the coke oven workers were classified as to top workers and side oven workers. In the top workers mortality from respiratory diseases was increased $(\$ M R=175)$, which is statistically significant (95 confidence 1 imits: 106.6 - 269.7). Liver cancer mortality was also elevated (SMR $=664$ ), and was M. so statistically significant (95: confidence limits: $242.6-1,446.3$ ). Side workers experienced elevated Iisks for lung cancer $(S M R=141)$, which is statistically significant (95 confidence limits: 102.7 - 189.7), gastric cancer (SMR $=172$ ). Which is also statistically significant (95\% confidence limits: 103.4 $269.4)$ and laryngeal cancer (SMR $=329)$, which was not statistically significant.

ADJUSTWENT FOR THE HEALTHY WORKER EFFECT

It has been argued that the results of retrospective cohort studies should be corrected for the "Healthy worker Effect" (HWE). "the main explanation for the HWE usualy is regarded to lie in the inappropriate comparison between a working population and the general population ${ }^{30-32}$. The HWE may lead to an underestimation of the relative risk, because it may compensate a part of the excess in observed mortality. Several alternatives have been proposed to adjust the SMR for the HWE. Goldsmith ${ }^{30}$ suggested to introduce one universal adjustment factor of $100 / 90$ for the HWE. Hernberg ${ }^{31}$ on the other hand observed that the HWE is not equal for specific causes of death and may vary from study to study. He noted that the HWE has a tendency to decrease with time and hence to be smaller for diseases that generally occur later in life, such as cancer for instance. The study presented in this paper has the advantage of a non-exposed working popula- 
tion, which enables to make an assessment of the magnitude of the HWE for particular causes of death. For instance, the SMR for Iumg cancer mortallty in the non-exposed group was 87 , meaning that the HWE in this study for lung cancer may have been $100-87=13$ on the assumption that the cause-specific Hw is the same in the exposed and non-exposed groups. If this is also true for the exposed group, than the observed SMR of 129, which is a point estimate, still is an underestimation of the true relative risk and probably by $13 \%$. The SMR of 129 may only be 87 of the true rigk, which brings the estimate of the true sur for lung cancex in the coke oven workers to $129 / 87 \times 100=148$.

\section{DISCUSSION AND CONCLUSIONS}

Dutch coke oven workers have experienced higher mortality rates for several diseases. Lung cancer mortality rates were 298 higher than in the general population if no correction is made for the Healthy worker Effect. Mortality from nonmalignant respiratory diseases was 60 higher than in the general population. The findings in the study presented here are in close agreement with the data from Great Britain. However, they do not support the high risks observed in the United States. Sofar these differences have not been explained. One possible explanation is that exposure to carcinogens for U.S. coke oven workers may have been higher than in Great Britain. Personal air samples taken at U.S. and British coke ovens indicate that this is the case. The samples in the united states had an average of $2.25 \mathrm{mg} / \mathrm{m}^{3}$ of benzene soluble matter, as compared to $1.29 \mathrm{mg} / \mathrm{m}^{3}$ in Britain. Samplies taken in a Dutch coke plant averaged $1.05 \mathrm{mg} / \mathrm{m}^{3}$ of benzene soluble matter 33. However, these samples were taken at another coke plant than those investigated in the study presented here. Probably the exposure in the coke ovens that are subject of the study presented here, have been higher, because they were not as modern as those in which the samples were taken. Two differences between American and European coke plants could be important regarding this issue, namely racial differences and the different working temperatures of the ovens. The American coke ovens have mainly been operated by non-white employees, who may be at higher risk of developing lung cancer than whites, after prolonged exposure to coke oven emissions. American coke oven traditionally have been heated to higher temperatures than many European ovens, since the main purpose of the Amertcan coke plants was to produce metallurgical coke. In Europe the byproducto were also regarded as highiy desirable products. ather factors can be mentioned that may 
be responsble for this difference. The studies in The United states go further back in time ${ }^{19-21}$ when exposures to polycyclic aromatic compounds may have been higher.

other cancer risks noted in the United states were not seen although the excess of Iiwer cancer 1 a reason for concern. It has been suggested that the excess of liver cancer mortality might be related to a higher regional alcohol consumption. This can be true, but it seems rather unlikely, becase this excess was only found in the coke oven workers and not in the non-exposed cohort. Still this funding has not been reported elsewhere and may be a matter of chance. In this study no data were collected regarding smoking habits of the workers. Whus no correction could be made for potential bias by differences in smoking habits. The risk of lung cancer imposed on the workers by means of the occupational exposure to coke oven gas can be put into perspective by making comparisons with other risks.

of the 62 cases of 1 ung cancer among the coke oven workers 48 were expected based on national mortality rates. Thus 14 might be attributed to the working conditiong. It is estimated that 85\% of all lung cancer deaths are caused by personal smoking habits ${ }^{34}$, thus $85 \times 48=41$ of the lung cancer deaths may be attributable to persomal smoking habits. Limiting the risk to lung cancer, the voluntary taken risk related to cigarete smoking is nearly 3 times $(41 / 14=2.93)$ the risk rejated to the occupational exposure of the coke oven workers. The lung cancer risk experienced by the coke oven workers can also be compared to other substances, for instance benzere and vinyl chloride. The mortality risks related to occupational exposures to benzene and vinyl chloride have been estimated by combining the results of epidemiologic studies conducted in these fields. Exposures to bigh concertrations of benzene have been estimated to add 6.9 deaths per, 1,000 deaths to the mortality risks ${ }^{35}$ compared to 28 lung cancer deaths per 1,000 deaths in the coke oven workers. Occupational exposures to vinyl chloride have been estimated to add 16.8 death per 1, 000 deaths to the mortality risk of the exposed workers ${ }^{36}$. Comparing the fects on cancer mortality of these involuntary occupational exposures it can be concluded that the coke oven workers have experienced a greater additional cancer mortaldty risk than workers who have been exposed to high concentrations of benzene or vinyl chloride in the past.

The total mortality anong the cohort of coke oven workers was 520 meaning that per 1,000 deaths approximately 28 additional lung cancer deaths have occurred. This figure is in great excess of 4 additional deaths per 1,000 for the workplace cancer risk.

If the coke ovens subject of this study were still in production, serious improvements in occupational hygiene should have been made. 
Two types of improvement in occupational exposure can be accomplished. The Elist is an exposure reduction by improvements of the equipment and by automatization. Better door - and lid seals will help to reduce emissions. By equipping the charging- and pushing machines with air extracting installations the coke oven gas that inevitably occur at charging and pushing work can be remowed from the workplace and cleaned. These measure will also reduce emissions into the total environment. For several jobs, such as the charger and filler, a further reduction of exposure cam be achieved by providing clean air into the cabins of their machines.

A second type of improvement can be obtained by personal protection and hygiene. Actual exposure to workers can be reduced by about half if the workers wear airstream helmets proper $1 y^{33}$. This by itself is a great improvement and perhaps in combination with technical. changes of the equipment may lead to a reduction of exposure of more than $90 \%$. Taking a linear dose-response relationship, reflecting the assumption that a duplication of the dose will also lead to a duplication of the risk, it can be estimated that a 90 reduction of exposure will lead to at 90\% reduction of the additional risk. Thus, after a $90 \%$ reduction of exposure the adational lung cancer risk left can be estimated to be approximately 3 per 1 , 000 deaths. However, it must be kept in mind that this calculation is based on the lung cancer risk observed in a cohort of coke oven workers, who were not employed as such for their whole working life and that the maximal exposure concentrations. in The Netherlands are based on the risks after having been employed in a part $i$ cular job for the duration of the whole working life. The workers in this study were exposed for an average length of 16 years. Again taking a linear dosemresponse relationship between dose and relative risk to be the most plausible one. it can be estimated that the relative risk of lung cancer mortality in coke oven workers exposed for fourty years will be 2.5 times the relative risk observed in this study, under the assumption that the background risk in the genexal population remains unchanged.

\section{ACKOYOMLEDGEMENT}

We thank the central Bureau of statistics for participating in the project and for providing the causes of death for the workers in study. 


\section{REFEREYCES}

1. W1son DJ, JH We11s. Coal Coke, and Coal Chemicals. McGraw-Hill Book Company* New York; 1950.

2. International Labour Office 1983. Enceclopedia of Occupational Heath and Safety. Genewa.

3. E.P.A. (Enwironmental Protection Agency), 1978. An assessment of the health effects of coke owen emissions. Office of Research and Development, Washington D.C.

4. Nesnow $S$, LL Triplett, TJ Slaga. Comparative tumor initiating activity of complex mixtures from environmental particulate emissions on SENCAR Mouse skin. J. Natl. Cancer Inst. 1982; 68: 829-834.

5. Nesnow 5 , LL Triplett, TJ Slaga. Mouse skin tumor initiation-promotion and complete carcinogenisis bioagsays: Mechanisms and biological activities of emision samples. Environ. Health Persp. 1983; 47: $255-268$.

6. Horton AW, R Tye, KL stemmer. Experimental carcinogenisis of the Iung. Inhalation of gaseous formaldehyde or an aerosol of cal tar by $\mathrm{C}_{3} \mathrm{H}$ mice. J. Nat 1. Cancer Inst. 1963:30:31-43.

7. Tye $R, \mathbb{K L}$ Stemmer. Experimental carcinogenusis of the lung II. Influence of phenols in the production of carcinoma. J. Nat1. Cancer Inst. 1967: 39: 175186.

8. International. Agency for Research on Cancer. IARC Monographs on the evaluation of the carcinogenic risk of chemicals to humans. Polynuclear aromatic Compounds, Part 3. Industriel Exposures in Aluminium Production, Coal Gasificiation, Colse production and Iron and steel Founding, 1984, Vol. 34, Lyon.

9. Kennaway EL. M Kennaway. A further study of the incidence of cancer of the lung and larynx. Brit. J. Cancer 1947: 260-298.

10. Christian HA. Cancer of the lung in employees of a public utility. J. Occup. Med. $1956 ; 14: 133-139$.

11. Rejd Do, C Buck. Cancer in coking plant workers. Br. J. Ind. Med. 1956; 13: $265-269$.

12. Kawaj M, Amamoto, K Harada. Epidemiologic study of occupational lung cancer. Arch. Environ. Health 1967; 14: 859-864.

13. Kuroda $S$. Kawahata. Ober die gewerbliche entstehung des Lungenkreses bei Generatorgasarbeitern. Z. Krebsforschung 1936; 45:36-39.

14. Doll R, MP Vessey, RWR Beasley et al. Mortality of gasworkers. Final report of: prospective study Brit. J. Industr. Med, 1972; 29: 394-406. 
15. Sakabe, Hiroyuki, Kenzaburo, Tsuckiya et al. Lung cancer anong coke oven workers. Industrial Health 1975; 13:57-68.

16. Davies GM. A mortality study of coke oven workers in two south wales integraw ted steelworkers. Br. J. Ind. Ked. 1977; 34: 291-297.

17. Collings PL. Coke workers" mortality, a tine year follow-up in the British Steel Industry. Repoxt prepared by the Statistics Branch. Institute of Occupational Medicine, Edinburgh, Scotland, for the European Coal and Steel Community and the British Steel Corporation. Report no. TM/78/1, 1978.

18. Hurley JF, $\mathbb{R}$ Archibald, PL Collings, DM Fanning, M Jacobsen, $\mathbb{R} C$ Steele. The mortality of coke workers in Britain. Am. J. Ind. Med. 1983; 4: 691-704.

19. Liloyd JW, A Ciocco. Long term mortality study of steelworkers. I. Methodology. J.0.M. 1969; 11: 299-310.

20. Lloyd JW. Long term mortality study of steelworkers. V. Respiratory cancer in coke plant workers. J.O.M. 1971; 13: 53-68.

21. Redmond CKA, JW Ciocco. Long term mortality of steelworkers. IV. Mortality from malignant neoplasms among coke oven workers. J.0.M. 1972; 14: 621-629.

22. Redmond $\mathrm{CK}$, HS Wienand, HE Rockette, $\mathrm{R}$ Sass, $\mathrm{G}$ Weinberg. Long term mortality experience of steelworkers. Report prepared by the University of pittsburgh, pennsylvania, for MIOSH, Cincinnati, Ohio. Contract no. HSM-99-71-32, 1979.

23. Blott WJ, LM Brown, LM Pottern, JB stone, JF Fraumenie. Lung cancer among long-term steel workers. Am. Epidemiol. 1983; 117: 706-716.

24. Bertrand JP, N Clau, A Patris, M Mur et al. Mortality due to respiratory cancers in the coke oven plants of the Lorraine coal mining industry. Brit. J. Ind. Med. 1987; 44:559-565.

25. Merx HJ. Chronologisch overzicht van de geschiedenis van de cokesfabrieken en het gasdistributiebedrijf, 1912 - 1952. DSM, The Netherlands, 1955.

26. Waes van JPM, HE Quanjel. The new "Emma" coking plant of the Netherlands State Mines. Coke and Gas 1956: 83-87.

27. Monson RR. Occupational Epidemiology. CRC Presi, 1980.

28. Peto J. Manyears: A program for computing observed and expected deaths or incidence rates. International Publication. ICRF Cancer unit, oxford, 1980.

29. Breslow NE, NE Day. Statistical methods in cancer research. Vol. II The design and analysis of conort studies. IARC, Lyon, 1987.

30. Goldsmith $\mathbb{J R}$. What do we expect from an occupational cohort? J.0.M. 1975; 17 : $126-127$,

31. Hernberg 5 . Evaluation of epidemiologic studies is assessing the long term effects of occupational noxious agents. Scand. J. Work Environ. Health 11980 ; $6: 163-169$. 


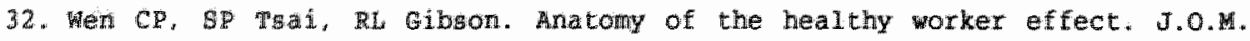
$1983 ; 25: 283-289$.

33. Jager de AG. Het meetbare effect van een antstofhelm op de verlaging van BSH. Mijnegen, 1981 .

34. Schottenfeld D, J Praumeni. Cancer epidemiology and prevention. $\mathrm{w} . \mathrm{B}$. Saunders Compary, 1982 .

35. Swen GM, AEM de Hollander, Kroes. Carcinogenic risk assessment of benzene in outdoor air. In press.

36. Swaen GMH, AEM de Hollander, Rroes. A scientific basis for the risk assessment of winylchoride. Regulatory Toxicology and Fharmacology 1987; $7: 120-$ 127. 


\section{LONG TERM MORTALITY OF FORMER WORRERS OF CORE PLANT}

BY-PRODUCT FACILITIES IN WHE METHERLANDS

G.M.H. Swaen ${ }^{1}$

J.J.M. Slangen ${ }^{1}$

A. Volovics ${ }^{3}$

F. Sturmans ${ }^{2}$

This study was financially supported by grant No. RUL-83-1 of the queen wilhe1mina Fund.

1 Dpt. of Occupational Medicine, University of Limburg. The Netherlands.

2 Dpt. of Epidemiology, University of Limburg, the Netherlands.

3 Dpt. fo Biostatistics, University of Limburg, The Netherlands. 
I. 3

$-50-$ 
In order to assess the long term health effects of occupational exposures present in by-product faclitities of coke plants, a retrospective cohort study was carried out in The Netherlands. A total number of 10,267 workers were selected who had been employed between 01-01-1945 and 01-01-1969 for at least a half year. The exposed cohort consisted of 4,527 workers. The 5,740 non-exposed workers had been employed in a nearby nitrogen fixation plant. For both cohorts standardided mor tality ratios (SMR) were calculated, for which the expected numbers were generated by means of five year cause-specific mortality rates of the general butch population. The cause-specific mortality in the exposed cohort was separately analysed 18 specific departments. The total mortality in the non-exposed cohort was lower than expected. No excess cancer mortality risks were observed in the exposed cohort that were statistically significantly elevated from the expected risks. However, several increased SMR"s were observed under investigation. An elevated SWR for lung cancer was observed in the tar distillery. In the coke shipping department increased risks for gastric cancer and mortality from nonmalignant respiratory diseases were observed. Reports of other risks from the united states could not be confirmed.

\section{INTRODUCTION}

Coke is of vital importance for the production of iron and steel from iron ore. During derivation of cokes from bituminous coal by the process of carbonisation in the absence of oxygen huge quantities of fumes escape from the heated coal. The quantity of coke oven gas produced per ton of coal depends upon the characteristics of the bituminous coal, heating temperature, duration of the cokjng process and several proporties of the ovens. In general per ton of coal $300 \mathrm{~m}^{3}$ coke oven gas is produced ${ }^{1}$. The coke oven gas can be applied for two purposes. It can be used to heat the coke ovens. On the other hand, coke oven gas contains a range of substances that can be distilled from it and sold to customers. Almost all large coke plants are equiped with facilities to recover a number of substances from the coke oven gas, before it is used to heat the coke ovens. The chemical facilities are called the "by-product section" of the coke plant. The by product section usually consists of the following plants: tar distillery, sulfate plant. 
bemzene plant, $H_{2} \$$ plant and generator gas plant. In all of these plants occupational exposures to hazardous substances can occur. The most important are presented in Table 1. Some chemicals can be hazardous to humans and after a longer exposure and latency period have elapsed may increase the risk of cancer. Anecdotal information also confirms that exposures to benzene mut have been substantial. It was comon practice far instance that a worker from the tar distillery would fetch a bucket of benzole (containing a high proportion of benzene) from the benzene plant to clean tar spills at the tardistillery.

Table 1: Overview of the main occupational exposures that accur in the by-product section of coke plant, for ach separate plant.

Facility

Main substances of which occupational exposure can occur

war distillery

Tar, naphthalene, coke oven gas

Sulfate plant

Amonia, sulphuric acid, hydrogen sulfide, hydrogen cyanid, coke oven gas, coal tar, fenol, naphthalene

Benzene plant

Benzene, toluene, xylene, coke oven gas, carbondisulfide

$\mathrm{H}_{2} \mathrm{~S}-\mathrm{plant}$

Coke oven gas, coal tar, naphthalene, hydrogen sulfide, hydrogen cyanide

Generator gas plant

Generator gas

Seweral. workers were known to drench their handkerchiefs in benzole and sniff it up in order to relieve the symptoms of a cold. workers hawe taken home jars and bottles containing benzene, which came in handy for all sorts of minor domestic repairs, for instance at the repair of the inner tubes of bicycle tyres. In the medical department of the coke plant benzole was used to clean laboratory glass. As benzene became suspect of imposing health hazards, all these habits were prohibited.

Coke plants have been object of several epidemiologic investigations. The most extensive study was conducted by Lloyd ${ }^{2}$ and was later expanded by Redmond ${ }^{3}$. A 
review containing nearly all of the evidence for the carcinogenic proporties of exposures occurring in coke plants can be found in volume 34 of the IARC Monographs series on the evaluation of the carcinogenic risk of chemicais to humans 4. As far as exposure to chemicals in the by-product section are concerned there is only limited knowledge about their long term health effects. The only epidemiological study of coke plant workers that dealt with the by-product section as a separate exposure area was the study performed by the pittsburgh group 3.5 . In the workers of the by-product plant excesses of mortality were observed due to kidney cancer, cancer of the large intestine and pancreatic cancer "However, it was not possible to link these excesses to a particular plant or exposure to a particular substance or workplace.

The by-product sections, subject of the epidemiological study partiy presented in this article, were an integrated part of a large coal mining company in the Netherlands. The company has always stressed the vital importance of these byproduct sections because it provided the company of the option to expand into the wide area of coal derivatives production. The first coke plant and its by product section came into production in 1919. In this coke plant the by-product section was small. As it became clear that the chemicals could be sold profitably "more emphasis was given to the by-product section, which was especially the case in the new coke plant built in 1954. Because coal mining had become unprofitable the coal mines together with the coke plants were closed in the late sixties earjy seventies.

The specific aim of the study was to investigate the occurrence of cancex mortality risks among workers who had been employed in the by-product section of Dutch coke plants.

\section{MATERIAL AND METHODS}

This topic has been described extensively in an earlier paper and will only be briefly discussed. Information on personal identification items and job history were collected by searching the 150,000 personal files available at the company. Files of workers eligible for the cohort study we abstracted by standard procedures. For each worker job, workplace and working period were coded " the following eligibility criteria were applied. Only workers with a Dutch nationality were selected because the specific mortality statistics for foreign persons in The Netherlands are in this case not suitable to generate expected numbers. "The 
cohort wist 1 ited to male workers who had worked at least a half year in one of the plants under investigation. A half year was taken as minimal required employmert, because the job history of workers who had worked less, appeared to be vague and unreliable. All workers who had ever worked at the coke ovens were also excluded from the study. Futhermore the cohort was restricted to those workers who were employed between $31-12-1944$ and $01-01-1969$. The reference or non-exposed group consisted of workers of a nearby Nitrogen Fixation plant who met the same elighillty criteria as the exposed cohort. In total 10,267 workers were eligible for the study. of these 5,740 workers were members of the reference group. 4,527 Workers had worked in the by-product section of the coke plants for at least half a year, between 01-01-1945 and 01-01-1969. The total cohort was followed up until 01-01-1984 by means of the pension fund of the company and an active follow-up through the Dutch system of population registries, described in detail in the previous paper. The endpoints as observed in the study are presented in Table 2 .

Table 2: Distribution of endpoints of the follow-up as observed in the study of by-product workers for the exposed cohort and reference cohort.

Reference cohort

N

$5.740 \quad(100.08)$

137

$2.48)$

893

$(15.68)$

4.705

$81.98)$

5

0.18)

5

By-product cohort:

N

(8)

4. 527

$(100.08)$

111

2.58)

854

(18.8\%)

Alive at 01-01-1984

Lost to follow-up

(0.1\%)

3.559

$(78.68)$

$0.18)$

Workers who emigrated were included in the follow-up until their date of emigration since they were at risk of dying and the death being observed by the study urtil that date. The numbers of the death certificates of deceased cohort members were obtained and the central Bureau of statistics was requested to assist in providing information regarding the causes of death. Causes of death had been coded by trained nosologists in the year of death and were converted to the ninth revision of the International Classification of Diseases. Calculation of personyears of observation and standardized Mortality Ratios (SMR's) was done by means of a computer progran especially designed by peto for this purpose" "Two-sided 
95* confidence 1 imits were calculated according to the methods described by Breslow and Day? ${ }^{7}$.

\section{RESULTS}

The results in terms of observed and expected numbers of death are presented in Table 3. The total mortality in the study group was lower than expected. A total of 1.747 deaths were observed and $1,874.4$ were expected based on national mortality rates $(S M R=93.2)$. The SMR for total mortality in the exposed cohort was 97 compared to that of the non-exposed group of 90. A possible explanation for this difference is the longer average period of follow-up of the by-product workers.

The exposed cohort was subdivided into groups of workers who had ever been employed at a particular facility. Among workers who had ever worked at the tar distillery, an elevated SMR of 154 was obserwed for lung cancer, but this SMR was not statistically significant different from 100.

Among workers employed in any of the other chemical facilities no excess of mortality was observed. This was also the case among the 222 workers who had ever been employed in the benzene plant.

The mortality rates of service departments, such as the maintenance department, terrain department, laboratories, coke shipping department, electrical engineering. instrumentation department, construction department and administrative department were also investigated.

In the coke shipping department an increased risk for gastric cancer mortality (SMR $=201$ ) and mortaIity from non-malignant respiratory diseages (SMR $=167)$. However, both SMR" are not statistically significant from 100 (C.I.: 0.8673.966 and $0.863-2.921$ ). 
Table 3: Cause-specific mortalicy in a cohort of coke plant by-product workers and a conort of ron-exposed workers.

\begin{tabular}{|c|c|c|c|c|}
\hline \multirow[t]{2}{*}{ Cause of death } & \multicolumn{2}{|c|}{ Non-exposed group } & \multicolumn{2}{|c|}{ By-product workers } \\
\hline & Observed number & SMR & observed number & SMR \\
\hline \multicolumn{5}{|l|}{ Matn categories: } \\
\hline 1. Infectioug diseases & 7 & 61 & 8 & 79 \\
\hline 2. Neoplasms & 259 & $85 *$ & 282 & 106 \\
\hline 3. circulatory system & 395 & 99 & 338 & 94 \\
\hline 4. Respiratory system & 57 & 102 & 49 & 93 \\
\hline 5. Digestive systern & 19 & $57^{*}$ & 23 & 78 \\
\hline 6. Other & 61 & 60 & 68 & $75^{*}$ \\
\hline 7. External causes & 65 & 75 & 56 & 79 \\
\hline Unknown & 30 & - & 30 & - \\
\hline \multicolumn{5}{|l|}{ Meoplasms: } \\
\hline Mouth and pharynx & 2 & 59 & 3 & 104 \\
\hline Esophagus & 4 & 84 & 2 & 48 \\
\hline stomach * small intestine & 27 & 88 & 31 & 108 \\
\hline Large intestine & 10 & 60 & 13 & 88 \\
\hline Rectoum & 15 & 164 & 10 & 129 \\
\hline Liver and billary passages & 3 & 52 & 5 & 98 \\
\hline Panereas & 6 & $43^{*}$ & 13 & 110 \\
\hline Nose & 0 & - & 0 & - \\
\hline Larynx: & 1 & 36 & 2 & 82 \\
\hline "Trachea + lung & 107 & 87 & 104 & 100 \\
\hline Bone & 0 & - & 1 & 77 \\
\hline Connective tissue & 3 & 243 & 2 & 201 \\
\hline Skin & 6 & 192 & 4 & 155 \\
\hline Breast & 0 & - & 1 & 311 \\
\hline Prostate & 7 & 55 & 15 & 115 \\
\hline Gemital argans & 2 & 87 & 4 & 169 \\
\hline Bladder & 11 & 66 & 20 & 137 \\
\hline Bratin & 9 & 120 & 8 & 134 \\
\hline Thyroid gland & 1. & 133 & 1 & 154 \\
\hline Lymphatic glands & 0 & - & 0 & - \\
\hline Lympho-reticular sarcoma & 3 & 86 & 2 & 67 \\
\hline Hodgk in & 2 & 49 & 6 & 186 \\
\hline other Iymphorach & 0 & - & 4 & 173 \\
\hline Muteiple myeloma & 2 & 50 & 4 & 115 \\
\hline Leukenic & 13 & 135 & 7 & 85 \\
\hline Menign neoplasirs & 4 & 246 & 2 & 145 \\
\hline Not specified neoplasms & 19 & 140 & 11 & 94 \\
\hline other & 2 & 47 & 7 & 187 \\
\hline potal & 893 & $90^{*}$ & 854 & 97 \\
\hline
\end{tabular}

* $\mathrm{P}<0.05$ two-sided 


\section{DISCUSSION}

Epidemiologic studies of coke plant by-product workers conducted in The united states have arawn attention to possible cancer risks, such as intestinal cancer and pancreatic cancer. These results could neither be confirmed in a study carried out by furley et a ${ }^{8}$. In the present study of 4.527 coke plant by-product workers presented here these findings could not be confirmed. If the increased risks for intestinal and pancreatic cancer observed in The United states are true occupationally related risks, these should be concentrated in specific departments of the bymproduct section, since the type of chemicals to which the worker: of the various departments vary greatly. Even after a subdivision of the workers into groups who had ever worked in one of fifteen different departments no trace of these risks were found.

In several specific departments some specific risks were observed. In the tar distillery, where the predominant exposure to polycyclic aromatic carbons was present, an excess of lung cancer was found. However, this excess did not reach statistical significance. In other occupations, where exposure to polycyclic aromatic hydrocarbons occurs, excesses of lung cancer mortality have been noted, for instance in roofers ${ }^{9}$.

In the coke shipping department mortality from non-malignant respiratory disease and gastric cancer was higher than expected. Respiratory disease can posibly be related to the exposure to coke dust that was present in this department. Gastric cancer has been suggested to be elevated in coall miners ${ }^{10,11}$ which may be regarded as biologically plausible, since coal dust, from which coke is derived, has been demonstrated to contain carcinogenic agents ${ }^{12}$. However, in a case-control study of 683 male cases and controls conducted in the area in which this study was also carried out " no evidence was found for a relationship between gastric cancer and coal mining ${ }^{13}$.

Finally the unexpected lack of evidence for an increased risk for leukemia mortality in the benzene plant needs some further attention.

We thank the Central Bureau of statistics for participating in the project and for providing the causes of death for the workers in study. 


\section{BEFERENC:S}

1. Wison PJ, JH Wells JH. Coal, coke and coal chemicals. McGraw-Holl Book Com parny, New York, 1950.

2. Lloyd JW. Long-term mortality study of steelworkers. V Resplratory cancer it coke plant workers. J. Occup. Hed. 1971; 13:53-68.

3. Redmond CKA, JA Ciocco. Long-term mortality of steelworkers. IV Hortalits Erom malignant neoplasms among coke oven workers. $J$. Occup. Med. 1972; 14 ; $621-629$.

4. International Agency for Research on Cancer (IAFC). Monographs on the evlua. tion of the carcinogenic rigk of chemicals to humans: Vol. 34. Polynucleas Aromatic Compounds. Lyon, France, 1984.

5. Redmond CKA, BR strobino, RH Cypes. Cancer experience among coke by-product workers. Ann. N. A. Ac. Sc. 1976; 217: 102-115.

6. Peto J. Manyears: A program for computing observed and expected deaths, on incidence rates. Internal publication, ICRF Cancer Unit, Oxford, 1980.

7. Breslow NE; NE Day. Statistical methods in cancer research. Vol. II The design and analysis of cohort studies. International Agency for Research or Carlcer (IARC), 1987.

8. Hurley JF, RMcL Archibald, PL Collings, DM Fanning, M Jacobson, RC Steele. The mortality of cokeworkers in Britain. Am. J. Ind. Med "1983; 4: 691-704.

9. Hammond EC, J Selikoff, PI, Lawther, H Seidman. Inhalation of benzola)pyrent and cancer in man. Ann. New York Acad. Sc. 1976; 217: 116-124.

10. Enterline PE. Mortality rates among coal miners. An. J. Publ, H. 1964; 54: $758-768$.

1. Rockette HE. Cause-specific mortality of coal miners. J. Occup. Med. 1977; 19: 795-801.

1.2. Tye R, MW Horton, I Rapjen. Benzo(a)pyrene and other aromatic hydrocarbons extractable from biturninous coal. Am. Ind. Hyg. Assoc. J. 1966; 27: 25-31.

13. Swaen GMH, CWHM Aerats, JJM Slangen. Gastric cancer in coal miners: Final Report. Br. J. Ind. Med. 1987; 44:777m779. 


\section{GASTRIC CANCER IN COALMINERS}

\section{FINAL REPORT}

Gerard M.H. Swaen ${ }^{1}$

Collette W.H.M. Aerdts ${ }^{1}$

Jos J.M. Slangen ${ }^{1}$

1 Dpt. of Occupational Medicine, University of Limburg. The Netherlands

Published in British Journal of Industrial Medicine. 
I. 4

$-60-$ 


\section{ABSTRACT}

An epidemiological study was conducted to investigate the risk of gastric cancer in coalminers in the Southern part of Iimburg, The Netherlands. The design that was applied, was that of a matched case control study: 683 Male cases of gastric cancer were identified at the five pathology departments in the area. All cases were histologically confirmed by a pathologist. For each case a comtrol patient, free of gastric cancer, was selected from the same pathology department, matched on date of birth. of the 1,366 patients enrolled in the study an occupational history was collected regarding previous employment in a Dutch coalmine. These occupational histories were analysed by statistical procedures proposed by Mantel and Haenszel. Of the gastric cancer patients 28 had been employed as underground worker in a coalmine, as compared to $25 \%$ of the control group. The odds Ratio for underground coalmining and gastric cancer was 1.15195 confidence 1 imits: 0.89 - 1.47). There was no evidence for the existence of a dose response relationship. It was concluded that the study did not provide support for the hypothesis that underground coalmining increases the risk of gastric cancer.

\section{INTRODUCTION}

Coal is still of great importance to our society as a main source of energy. In. 1983 there were 300,000 miners employed in underground coalmining operations, within the European Comunity ${ }^{1}$. Various carcinogenic substances, such as benz(a)pyrene and benz(a) anthracene derivatives have been identified in coal ${ }^{2}$, but also inorganic carcinogens such as arsenic. cadmium and chromium. It has also been postulated that dust in general is a risk factor for gastric cancer. Inhaled coaldust can reach the gastro-intestinal tract through the pulmonary clearence system.

Some investigators have noted higher incidences of gastric cancer in coalmining areas in $\mathrm{Utah}^{5}$ (but was refuted in a later study ${ }^{6}$, and in Britain ${ }^{7}, 6$. Retrospective cohort studies of coalminers have been carried out by Enteriline" ${ }^{9}$ Rockette 10 and Atuhaire ${ }^{11}$. Enterline reported a standardized mortality ratio of 275 for gastric cancer. In the 30 year follow-up study of men in the Rhondda Fach the mortality rates from gastric cancer were also elevated among underground miners ${ }^{11}$. However, this was also true for the non-miners in the study. Rockette followed-up 
aroup of about 23,000 coalniners in the United states to investigate their mortality pattern ${ }^{10}$. The investigator concluded that "an elevated gastric cancer risk is the third most cons istent mortality finding for coalminers behind accidents and pheumoconiosis mortality". In a recent listing of carcinogenic agents and occupations, coalmining was regarded as an occupation associated with an elevated risk of gastric cancer ${ }^{12}$. It has been suggested that other factors may be of inportance in the relationship between prolonged exposure to coaldust and gastric cancer, such as sociomeconomic status ${ }^{13-15}$. Meyer et al postulated that coalminers who do not have an impaired pulmonary clearance system from smoking are at higher risk of gastric cancer than coalminers who do suffer from an impared pulmonary clearance system ${ }^{16}$. However, there is no evidence to support this hypothesis. Coalmining in the South-East part of The Metherlands has been carried on since the twelf th century. In 1950 over 50,000 workers were employed as underground coalminer in the area of Limburg. At the end of the $1960^{\prime} \mathrm{s}$ the coalmines were closed since they could not compete with foreign coalmining companies. Many different types of coal were mined varying from anthracite to bituminous coals. Coal was mined from depths of 3,000 feet and one of the mines was regarded as the largest two-shaft coalmine in Europe.

Because of the availability of documentation about workers who had been employed in underground coalmining and the frequent occurrence of past occupational exposure to coaldust, we regarded the area as particularly suitable for the conduct of a case-control study to investigate the risk of gastric cancer in coalminers. A preliminary report of this study has been published in this journal ${ }^{17}$.

\section{MATERIAL AND METHODS}

In total 683 cases of gastric cancer, all histologically confirmed, were collecm ted at the five pathology departments located in the area. The histological confirmation took place between 1 January 1973 and 31 December 1983. An age-matched control patient, iree of the disease under investigation was selected for each case at the same pathology department. It was decided to match on age ldate of birth), because the a priori chance of being a coalminer is strongly related to age. "The average difference between the dates of birth of the matched pairs was 62 days. The controls were randomly selected from the total patient population af the particular pathology department. In Table 1 the diagnoses of the controls selected for the study are presented. An underestimation of the true relative 
risk could have occurred if the control group contained many patients whose primary diagnosis for referal to the pathology department was pneumoconiosis How- $^{-}$ ever, none of these patients were selected as controls.

Table 1: Frequency distribution of main disease categories of the controls. selected from the pathology departments.

\begin{tabular}{lrr}
\hline Disease category & $\mathrm{n}$ & \multicolumn{1}{c}{} \\
\hline Circulatory diseases & 27 & 8 \\
Respiratory diseases & 56 & 21 \\
Digestive diseases & 144 & 20 \\
Uragenital diseases & 141 & 15 \\
Diseases of the skin and limbs & 103 & 3 \\
Diseases of internal secretion and sensory organs & 18 & 6 \\
Other diseases & 40 & 23 \\
No abnormality & 154 & 100 \\
\hline Total & 683 & \\
\hline
\end{tabular}

For all 1.366 patients selected for the study information was collected regarding their underground mining work. These data were available at the General Mining Fund, a central agency for all coalmining companies in The Netherlands. Since one of the tasks of the General Mining Fund was to keep records on all coalminers regarding their pension rights an accurate registration existed of all workers who had ever worked underground in a Dutch coalmine. Every coalminer in The Netherlands was obligated to make contributions to the General Mining Fund. The records of these contributions are still avallable for every former coalminer, since they form the basis for the pension benefits to which the contributors are entitled. The filles of the General Mining Fund contain information about name, date of birth, address, date of employment, occupation, and by which coalmine the person was employed. These records were searched in a similar fashion for each of the 1,366 patients enrolled in the study. In this search the date of birth was used as personal identification. If the date of birth of a patient matched with that of a file of the General Mining Fund, name and address were checked to see if the match was correct. For this process it was important to estimate the accuracy of the dates of birth collected at the pathology departments. This was done for the first 500 patients, by comparing the dates of birth of those recorded in the 
Bopulation Registry, of the 500 patients only one turned out to be recorded incorrectly. For the patients enrolled in the study, of whom a file existed at the General Mining Fund, a short occupational history was recorded about employment in a Dutch coalmine. The data collected in this study were analysed by means of a matched pair analysis as described by schlesselman 18 , which is similar to the method proposed by Mantel and Haenszel ${ }^{19}$.

\section{NESLLTS}

For all 1,366 patients the files of the General Mining Fund were searched. 190 of the 683 cases of gastric cancer had arevious occupational history of underground coalmining. In the control group 173 patients had records demonstrating a previous occupational history of underground coalmining (see Table 2). The Odds Ratio for underground coalmining was 1.15 (95* confidence limits $0.89-1.47)$. calculated by applying the Mantel-Haenszel method for matched pairs ${ }^{19}$, suggesting no statistically significant elevated risk of gastric cancer among underground coallminers.

Table 2: Frequency of a accupational history of underground coalmining work among 683 matched pairs of male gastric cancex cases and controls.

\begin{tabular}{lll} 
Controls & \multicolumn{1}{c}{ With history of } \\
\cline { 2 - 4 } & whout history of & Total \\
\hline
\end{tabular}

cases

Witiy history of

underground mining

Without history of underground mining 
In order to study the existence of a dose-response relationship a subanalysis was made by duration of underground coalmining work (see Table 3 ). There was no increase in risk with a longer duration of employment. The average duration of underground coalmining among the controls was 18.0 years and for the cases 18.8 years.

Table 3: Occupational history of underground coalmining work among 683 cases of gastric cancer and 683 age-matched controls by duration of employment in the Dutch coalmines.

\begin{tabular}{|c|c|c|c|c|}
\hline \multirow{2}{*}{$\begin{array}{l}\text { Duration of under- } \\
\text { ground employment } \\
\text { (years) }\end{array}$} & \multicolumn{2}{|c|}{$\begin{array}{l}\text { Cases of gastric cancer } \\
\text { cancer }\end{array}$} & \multicolumn{2}{|c|}{$\begin{array}{l}\text { Controls, tree of } \\
\text { gastric cancer }\end{array}$} \\
\hline & No & * & No & 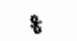 \\
\hline$<1$ & 16 & 8 & 14 & 8 \\
\hline $1-5$ & 30 & 16 & .29 & 17 \\
\hline $5-10$ & 23 & 12 & 22 & 13 \\
\hline $10-20$ & 30 & 16 & 29 & 17 \\
\hline $20-30$ & 42 & 22 & 45 & 26 \\
\hline $30-40$ & 45 & 24 & 30 & 17 \\
\hline$>40$ & 4 & 2 & 4 & 2 \\
\hline Total & 190 & 100 & 173 & 100 \\
\hline
\end{tabular}

DISCUSSIOM

Epidemiological studies, investigating the risk of gastric cancer in coalminers have come up with contradictory results. In some studies an excess of gastrifc cancer was reported and in other studies no excess was found. The results of the study reported here also do not indicate that coalminers are at higher risk for gastric cancer. In the study no adjustments were made for other factors that may be of importance in the development of gastric cancer. Social class is one of the factors that seem to play a rolle in the aetiology of gastric cancer ${ }^{13,20}$. Low social class seems to be related to a higher risk for gastric cancer. It is known that the Dutch coalminers before 1947 as a group earned less than the average 
employee. of the coalminers included in this study 79 thad coalmining experience before 1947 . Thus if social class would have had a confounding effect on our findings, it would likely have resulted in a bias awa from the null hypothesis, resulting in a positive outcome although in reality these may not be an excess risk of gastric cancer among coalminers. It is also postulated that dietary factors may be of importance in the aetiology of gastric cancer ${ }^{21}$. However, the risks involved are small and $i t$ is not likely that these factors have had a conLourding effect in this study.

\section{ACXOWDEDGEMENT}

We thank the stafis of the Pathology Departments of Brunssum, Heerlen, Kerkrade, Mastricht en sittard for their participation in the study and also the "AzL Heerlen" manager of the General Mining Fund for their helpfull instructions during the study. The study was financially supported by The Queen wilhelmina Fund in Arns terdain.

\section{REFERENCES}

1. Coal Eurostatistics Monthly $1984 ; 1: 1-6$.

2. Tye R, AW Horton. I Rapien. Benzo(a)pyrene and other aromatic hydrocarbons extractable from bituminous coa1. Am. Ind. Hyg. Assoc. J. 1966: $27: 25-31$.

3. Braunstein HM, ED Copenhaver, HA Pfuderer. Environmental health and control aspects of coal conversion: An Information Overvier 1977, Vol. 1, Oak Ridge "TN. Oak Ridge National Laboratory.

4. Fox AJ, P Goldblatt, LJ Kinlen. A study of the mortality of Cormish tin miners. Bir. J. Ind. Med. 1981; 38: 378-380.

5. Matolo NM, MR Klaber, WM Gorishek et al. High incidence of gastric carcinoma in a coal mining region. Cancer $1972 ; 27: 733-737$.

6. Klauber MR, JL Iyon. Gastric cancer in a coal mining region. Cancer 1978; 41: $2355-2358$.

7. Ashley BJB. Environmental factors in the aetiology of gastric cancer. Br. J. Prev. Soc. Med. 1969; 23: 187-189. 
B. Stacks $P$. on the death rates from cancer of the stomach and respiratory diseases in 1949 - 1953 among coalminers and other male residents in counties of England and wales. Br. J. Cancer 1962; $16: 592-598$.

9. Enterline PE. Mortality rates among coal miners. Am. J. Public Health 1964: $54:=758-768$.

10. Rockette HE. Cause-specific mortality of coal miners. J. Occup. Med. 1977: 19: $795-801$.

11. Atuhaire LR, MJ Campbe11, AL Cochrane, M Jones, F Moore. Mortality of men in the Rhondda Fack 1950 - 1980. Br. J. Ind. Med. 1985; 42: 741-745.

12. Decouflé P. Occupation in Schottenfeld and Fraumeni. In: Cancer epideniology and prevention. London: WB Saunders Company, 1982.

13. International union against cancer. Stomach cancer. Geneva IUAC, Technical report No. 34, 1978.

14. Ames RG. Gastric cancer in coal miners: some hypotheses for inwestigation. J. Soc. Dccp. Med. 1982; 32:73-81.

15. Creagan ET, RN Hoover, JF Fraumeni. Mortality from stomach cancer in coal. mining regions. Arch.. Environ. Health 1974; 28: 28-30.

16. Meyer MB, GD Luh, JM Sotelo et al. Hypothesis: the rale of the lung in stomach carcinogenesis. Am. Rev. Respir. Dis. 1980; 121: 887-892.

17. Swaen GMH, CWHM Aerdts, F Sturmans, JJM Slangen, P Knipschild. Gastric cancer in coal miners: a case-control study in a coal mining area. Br. J. Ind. Med. 1985: $42: 627-630$.

18. Schlesselman JJ. Case-control studies, design conduct, analysis. oxford university Press 1982: 207-213.

19. Fleis JL. Statistical methods for rates and proportions. New York, John Wiley and Sons 1981: p. 115.

20. Higginson J. Etiological factors in gastro-intestinal cancer in man. JNCI 1966: $37: 527-545$.

21. Bjelke E. Epidemiologic studies of cancer of the stomach, colon and rectum: with special emphasis on the role of diet. Scand. J. Castroenterol 1974; 9, supp1. 31: $42-53$. 
PART II

EPIDEMIOLOGIC METHODS

INVESTIGATING DOSE-RESPONSE RELATIONS IN OCCUPATIONAL MORTALITY STUDIES: SOMETHING TO KEEP IN MIND

THE INFUUENCE OF DESIGN CHARACTERISTICS ON THE OUTCOME OF RETROSPECTIVE COHORT STUDIES

THE INFLUENCE OF DESIGN CHARACTERISTICS ON THE HEALTHY WORKER EFFECT 


\section{INVESTIGATING DOSE-RESPONSE RELATIONSHIPS}

IN OCCUPATIONAL MORTALITY STUDIES

\section{Something to keep in mind}

G.M.H. Swaen ${ }^{1}$

A. Volovics ${ }^{2}$

1 Dpt. of Occupational Medicine, University of Limburg, The Netherlands 2 Dpt. of Biostatistics, University of Limburg, The Netherlands

Published in British Journal of Industrial Medicine. 
II. 1

$-72=$ 
Epideniological cohort studies of mortality are a generally accepted way to study long term health effects of occupational exposures. A routinely conducted subanalysis in this type of research is to investigate the existence of a dose-response relationship. One approach to this sub-analysis is to subaivide the exposed persons into various dose groups by duration of employment and then calculate cause-specific SMR"s for each subgroup separately. In callculating the SMR's for the separate subgroups the investigator should be aware of the subject discussed in this article. Ignoring this issue will result in biased estimates of the SMR " $\mathrm{s}$ in the separate exposure groups. The SMR's of the short exposure group will be overestimated and the SMR's of the long exposure groups will tend to be underesitimated.

\section{INTRODUCTION}

Many epidemiological studies assessing the long term health effects of occupational (or non-occupatiomaly exposures have used the design of a non-concurrent prospective or cohort study ${ }^{2}, 3$. In this type of study a group of workers, exposed in the past. is identified and followed through time to determine the age- and time-specific mortality rates for a number of different causes of death..

The statistical analysis usually consists of a person-time analysis, resulting in a standardised Mortality Ratio (SMR). The purpose of applying the person-time analysis in cohort studies is to account for differences in distribution of each age- and time pexiad. The person-years in each cell are multiplied by the death. rates of the general population for that particular age group and time period giving an "expected number of deaths" "The sum of the expected numbers for all the cells combined is the number of expected deaths in the total group. The SMR is calculated by dividing the observed number of deaths by the expected number. multiplied by 100 . 
DOSE-AESPOHSE RELATONSHIPS

In aralogy to experimental study designs, epidemiologists have often tried to quantify dose-response relationships. The existence of a dose-response relationship is considered to be strong evidence for an actual causal association ${ }^{4}$. Since the actual level of exposure experienced by the individul study subjects usually is not known, another quantitative measure of exposure is duration of employment. one of the underlying assumptions is, that the longer a person has worked in a particular occupation, the higher the dose that he has experienced. Based on this assumption specific dose groups can be distinguished by defining subgroups of workers by length of exposure period, which usually coincides with duration of employment. After having defined various dose groups an obvious way to compare the $r$ iks of dying of a particular disease is to calculate the cause-specific SMR's for each particular group. The apparent way to do this is to regard the particular dose groups as independent groups and to conduct a person-time analysis for each separate dose-group. The examples of cohort studies in the literature in which analyses of this type of dose-response relationships are described are abundant. Unfortunately these articles hardly ever contain information on how exactly the analysis of dose-response was carried out. Therefore it can not be checked how the SWR's for each particular dose group were calculated.

\section{An example}

An example may help clarify the issue. Suppose a cohort study has been conducted of a group of 10 workers (A to J) who all started working in a particular factory in 1960 . They have been followed up until 1980 .

Two workers (A and $B$ ) died in 1963, one (C) died in 1968 and two (D and $E$ ) in 1975. Two workers (F and $G$ ) left the company in 1963 and were alive at the end of the study. The remaining three (H, I and J) were still employed in the factory in 1980. The person-years of the individual workers are displayed in Figure 1. The total study group can be divided into two subgroups, having less than 10 years of exposure or more than 10 years of exposure. Subjects $A, B, C, F$ and $G$ fall into the subgroup with less then 10 years of exposure. The other workers have all experienced nore than 10 years of exposure. The number of persion-years in the short exposure group add up to 54 and in the long exposure group to 90 . including the first 10 years under observation. 
Figure 1: Person-years of 10 workers enrolled in the hypothetical cohort study.

\begin{tabular}{|c|c|c|c|c|}
\hline & & Accumulated & exson-years & Total \\
\hline & & $\begin{array}{l}\text { In short ex- } \\
\text { posure group }\end{array}$ & $\begin{array}{l}\text { In long ex- } \\
\text { posure group }\end{array}$ & \\
\hline A & 000 & 3 & & 3 \\
\hline B & 00 of & 3 & & 3 \\
\hline C & 000000000 & 曲 & & $B$ \\
\hline D & $-\ldots-\ldots-\ldots--\cdots$ & & 15 & 15 \\
\hline E & $-\ldots-\ldots-\cdots-\cdots$ & & 15 & 1.5 \\
\hline F & 00000000000000000000 & 20 & & 20 \\
\hline G & 00000000000000000000 & 20 & & 20 \\
\hline H. & $-\ldots-\cdots--\cdots-\cdots-\cdots$ & & 20 & 20 \\
\hline I & $-\cdots-\ldots-\ldots-\ldots-\cdots,-$ & & 20 & 20 \\
\hline J & 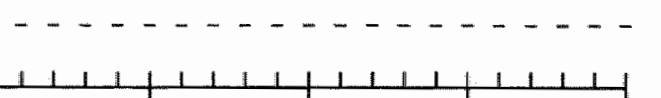 & & 20 & 20 \\
\hline 1960 & 1970 & 54 & 90 & 144 \\
\hline
\end{tabular}

Handing the person-years under observation

The hypothetical cohort study presented above and the division of study subjects into two exposure groups is the generally accepted way to evaluate the existence of dose-response relationships. However it must be clear that the two workers who died after three years of exposure (A and $B$ ) were forced into the short exposure group as a result of the independent or outcome variable of the $s$ tudy. On the other hand in the first 10 person-years of the workers in the $10^{+}$-exposure group mo deaths can have occurred, since if death would have occurred the worker would have been categorised in the short exposure group. Counting the deaths in the short exposure group and the living in the long exposure group will artifically result in a higher SMR 1 in the short exposure group and a lower SMR in the long exposure group. One alternative to deal with this problem would be to disregard 
II. 1

those person-years of obsexvation prior to the moment that enough exposure time could have been accumulated to be entered into the long exposure group. In this way events related to the study outcome (mortality) wil not influence the subdivision into the two exposure groups. However, the person-years of all the workers accumuled in the first 10 years of observation should be added into the short exposure group.

Figure 2: Person-years of 10 workers enrolled in the hypothetical cohort study by exposure group in which the person-years are counted.

\begin{tabular}{|c|c|c|c|c|}
\hline & & Accumulated & exson-years & Total \\
\hline & & $\begin{array}{l}\text { In short ex- } \\
\text { posure group }\end{array}$ & $\begin{array}{l}\text { In long ex- } \\
\text { posure group }\end{array}$ & \\
\hline A & 00 of & 3 & & 3 \\
\hline B & a o of & 3 & & 3 \\
\hline C & 0000000 ot & 8 & & 8. \\
\hline D & $0000000000 \ldots \ldots+$ & 10 & 5 & 15 \\
\hline $\mathrm{E}$ & $0000000000 \ldots \ldots+t$ & 10 & 5 & 15 \\
\hline 1 & 00000000000000000000 & 20 & & 20 \\
\hline G & 00000000000000000000 & 20 & & 20 \\
\hline H & $0000000000 \ldots \ldots \ldots \ldots$ & 10 & 1,0 & 20 \\
\hline $\mathbb{1}$ & $0000000000 \ldots \ldots \ldots \ldots \ldots$ & 10 & 10 & 20 \\
\hline$\pi$ & 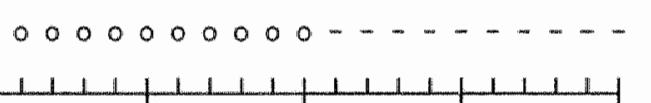 & 10 & 10 & 20 \\
\hline 196 & $0 \quad 1970 \quad 1980$ & 104 & 40 & 144 \\
\hline
\end{tabular}

Then after the first 10 years of observation actual person-years AT RISK can be accumulated by those workers who have been exposed for more than ten years. The first ten years of observation even for those who are categorised into the long exposure group must be counted in the low exposure group since they were at risk of dying and ending up in the low exposure group. The proposed analysis of the person-years is presented in Figure 2. 
By this way of handing the data workers switch to the long exposure group after actually having accumulated 10 years of exposure. The scope of this article is limited to handing simple dose-response relationship. other issues, such as latency have not been addressed.

\section{CONCLUSION}

Retrospective cohort studies of occupational groups have greatly expanded the knowledge about long term health effects of the occupational evironment. One subanalysis that is generally conducted in these type of studies is the investigation of dose-response relationships. keadily available computer programs have facilitated the conduct of the persontime analysis. These prograns can also be used to calculate SMR"s for particular subgroups, for example dose group defined by length of employment. If these dose groups are analysed in this way an error may be made. It must be kept in mind that the subgroups are not independent. One correct way to handle this is to add all person-years into the short duration group that were accumulated prior to achieving the eligibility criterion of the long duration group. We also recommend authors of retrospective cohort studies to provide a detaled discription of how the statistical analysis was conducted, in particular the analysis of dose-response relationships.

In the literature we have found one article in which this was done and from which could be concluded that the analysis of the dose-response relationship was handied correctiy ${ }^{1}$.

Finaly we suggest that epidemiologists who wish to publish results of cohort studies and intend to present dose-response relationships, may provide more information about the procedures that were conducted during the calculation of these dose-response relationships.

\section{REFERENCES}

1. Cole $p$, MB Goldman. Occupation. In: Fraumeni JF, ed. Persong at high risk of cancer. New York, Academic Fress, 1975. 
2. Decoufle P. Occupation. In: Schottenfeld D, Fraumeni JF, eds. Cancer epidemio$109 y$ and prevention. London, Saunders Company, 1982.

3. LILenfeld $A, D E$ Lilienfeld. Poundations of epidemiology. New Tork, Oxford University press, 1900 : pp. 309.

4. Bufler RA, 5 wood, C Elfler, L Suarez, DJ Kilian. Mortality experience of workers in a vinylchloride monomer production plant. J. Occup. Med. 1979; 21: $195-203$. 
THE INFLUENCE OF DESIGN CHARACTERISTICS ON THE OUTCONE OF RETROSPECTIVE COHORT STUDIES

\section{A review of the literature}

Gerard M.H. Swaen ${ }^{1}$

Jan M.M. Meijers ${ }^{1}$

1 Dpt. of Occupational Medicine, Uniwersity of Limburg, The Netherlands

Published in British Journal of Industrial Medicine.

$1988 ; 45: 624-629$ 
III. 2

$-80-$ 
Retrospective cohort studies are increasingly more being applied in the field of accupational health. In order to describe and further investigate this type of studies, 179 published retraspective cohort studies were reviewed. All 179 were published in six scientific journals between 1975 and 1985 inclusive. A description of the 179 reviewed articles was made and relationships between investigator oriented variables, design characteristics and the outcome of the study were investigated. Retrospective cohort studies focussing on exposures in the chemical industry appeared to yield most negative findings, which may be party explained by the relationship between the affiliation of the investigator and study outcome. Studies requiring a minimal latency period, applying an occupational reference group and abtaining a low percentage of last follow-up tended to have higher chance of a positive finding. Study size however, did not appear to be related to the outcome.

\section{INTRODUCTION}

Epidemiologic studies have become one of the generally recognized tools to inwestigate long term health effects of the occupational environnent. This is particularly true for retrospective cohort studies " or non-concurrent prospective studies. A retrospective cohort study can be defined as an epidemiological study in which a group of persons has been identified, who ali have experienced a particular event (occupational exposure) in the past and are followed through time to determine the occurrence of disease or mortality. From a reference population an expected number of deaths for specific diagnoses can be culculated, by means of indirect standarisation. The obserwed number of deaths, divided by the expected number, multiplied with 100 gives a standardized Mortality Ratio (SMR) which can be regarded as a measure of the relative risk for the exposed group to die of a particular aisease, as compared to that risk in the reference population. Retrom spective cohort studies represent a very powerful tool. for detecting long term health effects of particular exposures, despite their observational character ${ }^{1}$. Retrospective cohort studies are expensive to carry out and wowlly take long time to complete ${ }^{2}$. They are particularly effective in case of a specific exposure that may play an etiologic role in various diseases, if the problem to be dealt 
With is of the type: Does exposure to substance $A$ lead to a higher risk of cancer and if so, what type of cancer?

Retrosective cohort studies are observational studies, and thus have been subject to extensive criticism, because they do not have an experimental design ${ }^{3}, 4$. Usually incorrect reference populations are applied, resulting in a Healthy Horker $\mathbb{E} f$ fect. The classical statistical procedure, the SMR analysis, has also been subject to elaborate criticism 10 . However, it must be clear that there is no alternatiwe yet to retrospective cohort studies and therefore priority should be given to the improvement of existing methods, the policies by which these studies are conducted and the results are published. Retrospective cohort studies are wavlly expensive and difficult to carry out. It is essential to take sufficient care in collecting and interpreting the data to eliminate the passible effects of bias, confounding and chance that may lead to contradictory outcomes ${ }^{10}$. Furthernore, the design characteristics (e.g. number of persons at risk, exposure definition) may influence the results of cohort studies to a great extent.

Methodological issues in epidemiological studies can be investigated in a number of ways. One can take theoretical considerations as a basis and deduct the empirical effects of design characteristics ${ }^{4,12}$. Wang and Miettinen for instance have argued on theoretical grounds that applying the mortality rates of the general population as the reference in retrospective cohort studies, is erroneous. Another example of this approach is the statement that in retrospective cohort studies the Healthy worker effect wll fade out after a longer period of employment or a longex period of follow-up. After a longer period of employment the initial healthier population at the time of first employment has had enough time to develop diseases that have not been picked up at the medical examination at first employment. This theoretical approach however, misses the potential to actually quantify the effects of design characteristics on the outcome of a study or provide evidence that such effects occur in reality.

A second aproach to investigate the effects of design characteristics on the outcome of a study is by simulation. Ar actual conducted study can be re-analyzed after articicla modification of a design characteristic. For instance one can take a study with a long follow-up, in which no kealthy worker Effect was observed and artificlaliy shorten the period of follow-up. If, after decreasing the length of follow-up, a Healthy worker Effect is observed, evidence is presented that a Hedithy worker Effect occurs more frequenty in retrospective cohort studies with a short period of follow-up. Such an approach for instance was taken by Koskela et $1^{13}$ "By analyzing the data of a large cohort study in various ways the investigators demonstrated that in that particular study, the cohort formation criteria had an effect on the outcome of the study. McMichael ${ }^{6}$ also used 
simulation to show how the Healthy worker Effect varled within different subgroups and with the use of different design characteristics in retrospective cohort studies.

A thira possible approach is taken in this review in which 179 articles of retrospective cohort studies about occupational exposures in an elewen year period have been abstracted and analyzed. Each article has been regarded as an independent entity, comprising information about the effects of investigator or lented variables (e.g. conntry, authors affiliation and financers) and design characteristics (e.g. expected deaths, exposure definition, duration of follow-upl on the outcone of the retrospective cohort study. The investigator oriented variables and design characteristics were considered as the incependent variables in this review. The dependent variable consisted of the outcome of the study: A negative study was defined as a study of which the investigators concluded that it did not give enough evidence for the existence of an dincreased risk of dying of a particular disease. "Non conclusive studies" were also categorlized as negative studies.

In this article, the research methods, the investigator-oriented wariables and design characteristics are described and it is reported whether or not these independent variables are related to the outcome of the studies. It is certain that the review reported here does not cover all occupational retrospective cohort studies reported in the literature in the period of elewen years (1975 - 1985). In order to estimate the coverage we looked at the references given in the review article on occupation and cancer by Decoufle $e^{14}$ and noted that 66 of the retrospective cohort studies cited in that article, were published in journals covered by this survey.

\section{MATERIAL AND METHODS}

Six scientific journals were searched, from 1975 to 1985 inclusive. whe journals selected for this review were:

- The American Journal of Epidemiology;

- American Journal of Public Health;

- British Journal of Industrial Medicine;

- International Journal of Epidemiology;

- Journal of Occupational Medicine;

- Scandinavian Journal of work, Enviroment and Health. 
Every article reporting an occupational retrospective cohort study was abstracted. If the outcome was cancer incidence, registered in a cancer registry, the toudy was included on the condition that comparable follow-up and analytic procedures were used in mortality studies. In these instances the standardized incldence tatio of the total number of cancers was taken as SMa of the total number of deaths. If more than one article was written reporting a particular study. only one article was included in the review. However, updates were regarded as separate sutues.

In Apperidix 1 all the variables collected in this rewiew are displayed, with the categories that were used. All the articles were abstracted by one of us after specific agreenents were made about how the items should be classified. The folHowng guidelines were applied in the abstraction work: For the investigator orlented wariables the first author of the publication was decisive. If no men tion was made concerning the financial sources available to the retrospective cohort study it was assuned to be similar to the affiliation of the first author. For each study minimat and maximal latency were calculated using the cohort definition and the endctate of the follow-up. For instance if all the workers employed between 1945 and 1960 were followed up until 1986 the minimal latency was 26 years and the maximal latency was 41 years. If all exposed workers employed after 1945 were followed until 1986, the minimal latency was 0 years (since a person who started working on 30 December 1985 was stili eligible for follow-up) and the maximal latency was 41 years. In total 179 retrospective cohort studies were abstracted.

The data collected in this review have been analyzed by statistical procedures generally applied in case-control studies. Odds Ratios and two-sided $95 \%$ confidence limits were calculated, as described by schlesselman ${ }^{15}$.

\section{RESULTS}

In total 179 retrospective cohort studies were found from 1975 up to 1985 inclusive. 12 of these were "updates". The British Journal of Industrial Medicine and Journal of Occupational Medicine combined, published 74 of the total number of occupational cohort studies in the given period, followed by the scancinavian Journad of Work. Environment and Health (14). Typical epidemiological periodicals play no substantial part in the publication of occupational cohort studies. In the American Journal of Public Health not one study eligible for this review 
was published. From 1975 on to 1985 there was a consistent increase in the number of cohort studies published: In 1975 only 5 articles vere found in the jourmals under investigation as compared to 34 in 1985.

45t of the studies have been carried out in the united staces. 21. In Great Britain and 19 in Scandinavia, the remainder in a wide variety of countries in and outside Europe. These results show that the United states "Britain and Scandinavia are the leading countries in publishing this type of studies.

\section{Investigator oriented variables}

A number of variables regarding the investigator were studied in relation to the outcome of the retrospective cohort studies. The cohort studies performed by epidemiologists employed by governmental agencies had the highest percentage of positive results. 76 of the studies executed by them were positive as compared to only $36 \%$ of the cohort studies performed by epidemiologists employed by industry (Appendix 2). Similar differences were observed regarding the financial resources available to the cohort studies. About 77 of the studies funded by governmental agencies or universities were positive, compared to 53 of the studies financed by industry (Appendix 2 ). The outcome of the study also varied by type of occupational exposure in industry that was under investigation (Appendix 2 ). The only exposures in wich more negative than positive outcomes were reported were those in the chemical industry. Wherefore the relationship between the affiliation of the principle investigator and the outcome of the cohort studies may be explained by the fact that epidemiologists employed by industry mainly work in the chemical inaustry, an area in which less positive results seem to be expected. The analysis was repeated after omission of ald the studies conducted by epidemiologists affiliated with industry and private agencies. The tendency remained that proportionally most negative study-outcomes were reported in the chemical industry. In fact there was no significant change in order of substances under investigation in respect of the proportion of positive studies after the omission of studies conducted by epidemiologists employed by industry of private agencies. However, if the analysis was restricted to the reported studies that focussed on accupational exposures in the chemical industry the difference in outcome between studies conducted by epidemiologists from industry itself and other epidemiologists was apparent. Only $32 \%$ of the studies in the chemical industry performed by epidemiologists employed by industry were positive, compared to 598 of those studies conducted by ather epidemiologists. Although the number of studies is small, this difference is statistically significant $(\mathrm{P}<0.05)$. 
Another Investigator oriented variable that appeared to be related to the outcome of the cohort studies, was the country in which the study was conducted (Appendix 2). Restricting the analysis to the three geographical areas that contributed mogt retrospective cohort studies (The United States, Great Britain and the Scandinavian countries), the highest proportion of positive studies was reported from the scandinavian countries (826). The lowest proportion of positive studies was reported from the united $\$$ tates, being 52\%. This difference was statistically significant $(\mathrm{P}<0.005)$. The proportion of positive outcomes of Scandinavian studies was also statistically significant higher than in all other studies combined $(\mathrm{P}<0.005)$. This difference remained after omitting cohort studies conducted in the chemical industry, due to their unequal distribution over the countries and their subsequent potentiai confounding effect.

\section{Degign characteristics}

There appeared to be no relationship between the size of the exposed cohort and the study outcome (Appendix 21. Of the studies with less than 5,000 workers 65\% were positive, as compared to 66: of the studies with 5,000 or more workers. Only a weak relationship was found between the total number of expected deaths, the total person-years of follow-up and the outcome of the study (Appendix 2). We investigated if the application of minimal exposure period as eligibility criterion had an effect on the outcome of the retrospective cohort studies. No significant difference was observed in respect of the outcome between studies that had no minimal exposure period and studies that did (Appendix 2). However among the studies in which the exposed cohort was restricted to workers who at least had experienced one year of exposure, there were more positive outcomes than among the studies in which no minimal latency was set. The odds ratio of a positive outcome in relation to the presence of minimal latency period of one year was $1.9(95 \%$ confidence limits: $0.99-2.85)$.

It has frequently been argued that comparing occupational cohorts with the mortaIty rates of the general population is inappropriate ${ }^{5,15}$, since occupational cohorts differ from the general population in aspects as education, socio-economic status and health. Therefore we investigated the outcomes of retrospective cohort studies in which a specific, working comparison group was applied and cohort studies in which this was not done. There were only 26 studies in which a specific accupational comparison group was used. These studies did appear to have more positive outcomes 177 than the studies ith no specific comparison group $(63 \%)$. The odds ratio of a positive outcome was 1.9 in retrospective cohort 
studies in which a specific comparison group was used 195 contidence limits: $0.97-2.891$.

One of the concerns regarding the interpretation of results of retrospective cohort studies has always been if and in what way cohort members lost to follow up influence the outcome of the study. In order to investigate this, we divided the studies reporting the percentage of last to follow-up into studies with less than one percent of the cohort lost to follow-up and studies with one percent or more lost to follow-up. In studies with less than one percent lost to follow-up the odds ratio of a positive outcome was $2.66195 \%$ confidence limits: $1.96-$ 3.36).

only a weak and not statistically significant association was found between duration of follow-up and the outcome of the study. Duration of follow-up was defined as the time between the first and last year of follow-up. In studies having thirty years or more of follow-wp the odds ratio of a positive outcome was 1.3 in the retrospective cohort studies with less than thirty years of follow-up 195 confidence limits: $0.69-1.93$ ).

\section{DISCUSSION}

Usually articles concerning the influence of methodological issues on the outcome of retrospective cohort studies consist of theoretical considerations or simulation examples. In this report another perspective was chosen. The relationships between the investigator background, design characteristics and study outcome were analyzed for 179 accupational retrospective cohort studies on the basis of structured abstracts. The outcome was defined in terms of positive or negative outcome in the eyes of the investigators. However, there are pitfalis. When by cross-tabulations of the overall distribution of independent and dependent variables correlations are found, these may as well be influenced by other, confouding variables (e.g. the exposure under study). It must also be kept in mind that the conclusions are drawn from non-experimental design and therefore it can not be studied whether or not a relationship is a causal one.

In this review it was found that retrospective cohort studies conducted by epidemiologists employed by industry had proportionally more negative results than those conducted by govermental agencies or universities 165 versus respectively $24 \%$ and $32 \%$. A part of the difference could be explained by the fact that industrial research workers mainly investigated exposures in the chemical industry and 
this topic may priori lead to more negative findings. However, when only considerlng exposures in the chemical industry, a tendency remaned for industrially enployed epideniologists to conduct proportionaly more studies with a negative outcome. One possible explanation for this finding may be that those industries who employ epldenlologists are also more aware of the potential risks involved and have put great effort into the improvement of the occupational environment. Anothex hypothesis may be that the background of the investigators influences their lnterpretation of the results. Epidemiologists employed and financed by industies have a more dependent relation to their study-objects than epideniologists working at uniwersities or governments. Perhaps this could be reflected by a diferent interpretation of health risks.

Scandinavian studies reported significantly more positive findings (82) than studieg from other countries; studies from the United states significantly less 15231, even after omitting exposures to chemicals in the chemical industry, because of their contounding potentials. It follows that next to the affiliation and financial sources of the authors, the country also seems to be related to the study results. Different exposure-levels at the workplace due to various preventive measures and other production methods perhaps can explain the geagraphical varition. It is also possible that political and economical differences shape the interpretation of the outcomes.

No obvious relationship was found between design characteristics concerning the size of cohort studies and a positive or negative outcome. The total number of exposed workers, expected deaths and total person-years of follow-up did not seem to influence the results. This was a somewhat surprising result, and it may indicate that power calculations should not be the sole ground in deciding wether or not a planned study is worthwile to pursue. Some other design characteristics appeared to be related to the outcome of the study. studies in which a high conpleteness of follow-up was achieved were more likely to be positive. This was also true for studies in which an industrial reference group was used.

In occupational cohort studies it is desirable to determine the vital status at the end of follow-up for as many persons under investigation as possible. visual1y. however, this is not totally feasible. Therefore in almost every study the lost to follow-up problem has to be dealt with. Interpretation of the 179 articlas learned that the lost to follow up percentages were related to the outcome. In studies wth less than one percent lost to follow-up the odds ratio of positive outcome was 2.66 . It is not obvious that these differences are caused by the vital wetus of persons who are lost to follow-up; it is more plausible that the guality of a study is expressed by the of the pexcentage lost to follow-up. But then again it is not clear how the relation between this variable and the outconies must be understood. 
With this survey we hope to have made a contribution to a better understanding of methodological issues regarding retrospective cohort studes in occupational epidemiology and a more objective assessment of the relevance of their results.

\section{REFERENCES}

1. Friediman GD. Primer of Epidemiology. New York, McGraw-Hill Book Company, 1980: pp. 122 .

2. Lilienfeld AM, DE Lilienfeld. Foundations of Epidemiology. New York: Oxford Unïversity Press, 1980 : pp. 247.

3. Enterline PE. Pitfalls in Epidemiological Research, and Examination of the Asbestos Literature. J. Occup. Med. 1976:18: 150-156.

4. Wang $J$, O Miettinen. Occupational mortality studies. Scand. J. Work Environ. Hea 1th $1982 ; 8: 153-158$.

5. Fox AJ, PF Collier. Low martality rates in industrial cohort studies due to selection for work and survival in the industry. Brit. J. Prev. soc. Med. $1976 ; 30: 225-230$.

6. McMicheal AJ. Standardized mortality ratios and the Healthy worker Effect: Scratching beneath the surface. J. Occup. Med. $1976 ; 18: 165-168$.

7. Shinde11 S. RF Weisberg, $\mathbb{E E}$ Giefer. The "healthy worker effect" - fact or artifact. J. Occup. Med. 1978; 20: 807-811.

8. Bel1 CMJ, DA Coleman. Predicted mortality patterns in cohort study popula tions exposed to different types of hazard: can SMR's show a dose-resonse? Statistics in Medicine 1983; 2: 363-371.

9. Gaffey WR. A Critique of the standardized mortality ratio. J. Occup "Med. $1976 ; 18: 157-160$.

10. Wong $\mathrm{a}, \mathrm{P}$ Decouflé. Methodological is sues involving the standardized mortaity ratio and proportionate mortality ratio in occupational studies. J. OCcup. Med. 1982; $24: 299-304$.

11. Dol1 $\mathbb{R}$. Occupational Cancer: Problem in interpreting Human Evidence. Anm., Occup. Hyg. 1984; $28: 291-305$.

12. Hernberg $S$. "Negative" regults in cohort studies - how to recognize rallacies. Scand. J. Work Environ. Health 1981; 7, suppl. 4: 121-126.

13. Koskela $\mathrm{x}, \mathrm{E}$ Järvinen, $\mathrm{p}$ Kolari. Effect of cohort definition and follow wp length on occupational martality rates. Scand. J. Work Environ. Health 1984; 10: $311-316$. 
14. Decouflé P. dccupation. In Schottenfeld and Frameni, Ed. Cancer epidemiology and prewention. London, Saunder company, 1982: pp. 318-335.

15. Schlesselman JJ. Case-control sudies, design conduct analysis, oxford university Press, 1982 .

Appendix 2: Fresentation of the variables of which information was collected for the 179 retrospective cohort situdies included in the survey.

Dependent variable:

- Positive or negative study.

Independent variables, investigator orjented:

- Year of publication (from 1975 to 1985 inclusive).

- Afiliation (government, university, industry, other).

- Resources (goverment, university, industry, ather).

- Country (United states, Canada, Great Britain, Scandinavia, rest Burope, rest world).

Independent variables, methadologically oriented:

- Number of exposed workers (mumerical).

- Definition of exposure (total industry, particular workplace, particular job, bothl.

- Minimal exposure period (non, < halfyear, (one year, longer).

- Reterence group (Yes, no), size if applicable.

- Number of person-years of follow-up (numerical).

- Minimal and maximal observed latency.

- Adustment (smoking, other variablesi).

- First and last year of follow-up.

- Number of deaths expected in the exposed group.

- percentage loge to follow-up.

- Number of years between enddate of follow-up and year in which the article was published. 
Appendix 2: Crosstabulations of investigator oriented variables, design characteristics and the outcomes of 179 retrospective occupational cohort studies published betweer 1975 and 1986 .

\begin{tabular}{|c|c|c|c|c|c|c|c|c|c|}
\hline & \multicolumn{2}{|c|}{ Positive } & \multicolumn{2}{|c|}{ Wegative } & & \multicolumn{2}{|c|}{ Posutive } & \multicolumn{2}{|c|}{ Negative } \\
\hline & (\%) & $|n|$ & $(8)$ & $(n)$ & & (8) & $(n)$ & $18)$ & $(n)$ \\
\hline \multicolumn{5}{|l|}{ Affiliation } & \multicolumn{5}{|l|}{ Number of workers } \\
\hline University & $(68.4)$ & $(52)$ & $(31.6)$ & $(24)$ & $0-999$ & $(64.5)$ & $(40)$ & $(35.5)$ & $(22)$ \\
\hline Government & $(76.1)$ & (51) & $(23.9)$ & $(16)$ & $1,000-4,999$ & $(65.2)$ & $(43)$ & $(34.8)$ & $(23)$ \\
\hline Industry & $(35.5)$ & (11) & $(64.5)$ & $(20)$ & $5,000-9,999$ & $(73.9)$ & (17) & $(26.1)^{\prime}$ & $(6)$ \\
\hline private & $(60.0)$ & (3) & $(40.0)$ & $(2)$ & $>10,000$ & $(53.3)$ & $(16)$ & $(40.7)$ & (11) \\
\hline Total & $|65.4|$ & (117) & $(34.6)$ & $(62)$ & Total & $(65.4)$ & $(116)$ & $(34.6)$ & (62) \\
\hline \multicolumn{5}{|l|}{ Financial } & \multicolumn{5}{|l|}{ Minimal exposure } \\
\hline \multicolumn{5}{|l|}{ resources } & \multicolumn{5}{|l|}{ period } \\
\hline Gowernment & $(76.7)$ & $(56)$ & $(23.3)$ & (17) & None & $(66.3)$ & $(67)$ & $(33.7)$ & (34) \\
\hline Industry & $(52.8)$ & $(38)$ & $(47.2)$ & (34) & \& hidf year & $(57.9)$ & (11) & $(42.1)$ & (8) \\
\hline University & $\mid 77.81$ & $\{21\}$ & $(22.2)$ & $(6)$ & Half year - year & $(55.2)$ & $(16)$ & $(44.8)$ & (13) \\
\hline Private & $(28.6)$ & (2) & $(71.4)$ & $(5)$ & $>$ year & $(78.6)$ & $(22)$ & $(21.4)$ & $(6)$ \\
\hline Total & $(65.4)$ & $\{117\}$ & $(34.6)$ & $(62)$ & Total & $(65.5)$ & $(116\rangle$ & $(34.5)$ & (61) \\
\hline \multicolumn{5}{|l|}{ Exposure under } & \multicolumn{5}{|l|}{ Number of expec- } \\
\hline \multicolumn{5}{|l|}{ investigation } & \multicolumn{5}{|l|}{ ted deaths } \\
\hline Chemicals & $(48.6)$ & $(36)$ & $(51.4\rangle$ & $(38)$ & $<100$ & $(59.6)$ & (28) & $(40.4)$ & (19) \\
\hline Metals & $(83.3)$ & 301 & $(16.4)$ & $(6)$ & $100-499$ & $(65.6)$ & $(42)$ & $(34.4)$ & (22) \\
\hline Asbestos & $(76.2)$ & $(16)$ & $(23.8)$ & $(5)$ & $500-$ & $(64.0)$ & $(16)$ & $(36.0)$ & (9) \\
\hline Dust & $(66.7)$ & $(12)$ & $(33.3)$ & $(6)$ & $>1,000$ & $(71.4)$ & $(30)$ & $(28.6)$ & (12) \\
\hline Radioactivity & $(62.5)$ & (5) & $(37.5)$ & $(3)$ & Total & $(65.5)$ & $(116)$ & 34.51 & (61) \\
\hline Mining & $(85.7)$ & (6) & $(14.3)$ & (1) & & & & & \\
\hline others & $(80.0)$ & (12) & $(20.0)$ & $(3)$ & Percentage lost & & & & \\
\hline Total & $(65.4)$ & (117) & $(34.6)$ & (62) & to follow-up & & & & \\
\hline \multirow{2}{*}{\multicolumn{5}{|c|}{ Country of }} & $<1 \%$ & $(77.9)$ & $(53)$ & $\{22.1\}$ & (15) \\
\hline & & & & & $1-4.9 \%$ & $(56.7)$ & $(34)$ & $(43.3)$ & $(26)$ \\
\hline \multicolumn{5}{|l|}{ investigation } & $5-9.9 *$ & $(50.0)$ & $(16)$ & $(50.0)$ & (16) \\
\hline United states & $(51.9)$ & $(42)$ & $(48.1)$ & (39) & $>10$ & $(87.5)$ & (7) & $(12.5)$ & (1) \\
\hline Great Britain & $(65.8)$ & $(25)$ & $(34.2)$ & (13) & Total & $(65.5)$ & $(120)$ & $(34.5)$ & (58) \\
\hline Scandinavia & $(82.4)$ & $(28)$ & $(17.6)$ & $(6)$ & & & & & \\
\hline Canada & $(90.91)$ & $(10)$ & $(9.1)$ & (1) & \multicolumn{5}{|l|}{ Length of follow- } \\
\hline Rest of Europe & $(80.01$ & $(81$ & $(20.0)$ & $(2)$ & up (years) & & & & \\
\hline others & $(80.0)$ & 4) & $(20.0)$ & (1) & $0-9$ & $(83.3)$ & $(10)$ & $116.7)$ & $(2)$ \\
\hline \multirow[t]{2}{*}{ Trotal } & $(65.4)$ & (117) & $(34.6)$ & $(62)$ & $10-19$ & $(60.0)$ & $(18)$ & $140.0)$ & $(12)$ \\
\hline & & & & & $20-29$ & $(59.6)$ & $(34)$ & $(40.4)$ & (23) \\
\hline Journa 1 & & & & & $30-39$ & $(66.0)$ & $(35)$ & $(34.0)$ & (18) \\
\hline J. Occup. Med. & $(53.7)$ & $(36)$ & $(46.3)$ & $(31)$ & $40-49$ & $(78.9)$ & $(15)$ & $(21.1)$ & (4) \\
\hline Br. I. Ind. Med. & $(61.5)$ & $40)$ & $(38.5)$ & (25) & $>50$ & $(62.5)$ & 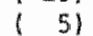 & $(37.5)$ & (3) \\
\hline Scand. J. Work & & & & & Total & $(65.5)$ & $(117)$ & $(34.5)$ & $(62)$ \\
\hline Env. H. & $(96.0)$ & $(24)$ & $(4,0)$ & $(1)$ & & & & & \\
\hline Am. J. Epidem. & $(64.3)$ & (9) & $(35.7)$ & (5) & & & & & \\
\hline Int. J. Epidem. & $(100.0)$ & $(8)$ & 0) & $(0)$ & & & & & \\
\hline An. I. Public & & & & & & & & & \\
\hline Health & a) & (10) & 0) & $(0)$ & & & & & \\
\hline Total & $(65.4)$ & $(117)$ & $(34.6)$ & (62) & & & & & \\
\hline
\end{tabular}




$$
\text { II. } 2
$$


OCCUPATIONAL COHORT STUDIES:

\section{THE INFLUENCE OF DESIGN CHARACTERISTTCS}

ON THE HEALTHY WORKER EFFECT

Jan M.M. Meijers ${ }^{1}$

Gerard M.H. Swaen $^{1}$

Kees van viet

"Dpt, of Occupational Medicine, University of Limburg, The Netherlands

Accepted for publication in International Journal of Epidemiology. 
II. 3 


\section{ABSTRACT}

A cross-sectional analysis of the relation between the healthy worker effect (HWE), defined as a total Standardized Mortality Ratio (SMR) Iower than 100, and relevant design characteristics in 270 published retrospective occupational cohort studies is presented. The majority of the reviewed studies showed a HWE, varying in SMR from 50 to 99 (mean: 83). The HWE seemed to influence the final outcomes of the studies to a great extent. A positive relation between the sudy size, in terms of the number of exposed workers and total number of person-years of follow-up, and the HWE emerged. But no clear relation between the length of the follow-up period and the HWE could be detected. Fixed cohorts also did not show a stronger HWE than dynamic cohorts. Studies about chemical exposures revealed four times more a HWE than other studies.

\section{INTRODUCTION}

Retrospective cohort studies with mortality as endpoint are lncreasingly applied in occupational epidemiology and have turned out to be very useful in detecting long term health risks ${ }^{1}$. They also can serve as tools in risk assessments of occupational exposures. The Standardized Mortality Ratio (SMR) can be regarded as a measure of the relative risk for the exposed group to die from a particular disease as compared to the risk in the reference population. However, the SMR suffers from several methodological deficiencies. Gaffey argued that the SMr is a biased estimate of the relative risk, because the relative risk is defined in terms of probabilities of death. While the SMR is defined in terms of mortality rates $^{2}$. He pointed out that the SMR overestimates the relative risk and that the wextend oferestimation increases as the probability of death increases. He also argued that if an excess mortality risk really exigis in a population, the cumulative SMR will tend to drop to 100 as the period of follow-up increases.

There are many pitfalls in the design and conduct of an appropriate cohort mortality study: The sample size may be too smal1; the exposure categorization of workers can be incorrect; the follow-up period may be too short in order to detect diseases with long latency (e.g. cancer); the follow wp may be incomplete and the statistical methods that are used may be insensitive or even wrong ${ }^{3}$. One issue that has received considerable attention in the past, is the healthy worker 
erect (HWE). mhe WW ig defined as the manifestation of a deficit in mortality. wher the enployed population is compared with a general population ${ }^{41}$. The HWE originates from the fact that an employed group is usualy healthier than the general population. Ag weed in his historical analysis recently showed, this phenomenon was already known to several foumders of occupational epidemiology ${ }^{12}$. The Wh was first denominated as a discrete entity in $1974^{4}$ and since then many epidemiologists have contributed to elicit its origin.

It is presumed that selection processes life at the core of the whe ${ }^{13}$. Primary selection refers to processes at time of hire. Persons who apply for a job usualIy undergo dichedical examination and are refused if their health is not sufficient to meet the job requirement. Secondary selection refers to processes during employment. Hamful factors in the work environment cam lead to heal th complaints and diseases which nay force workers to leave their occupation and this indirect1 y casues survival of healthier persons in inastry 12 . The HWE is mot a static quantity. Its magnitude varies and is thought to be affected by many variables, such as: race; sex; cconomic status and sociall class; follow-up pexiod; physical workload; cross-sectional or open study character; occupational exposures. and may vary between specific diseases $6,9,13-16$. In fact the general population is heterogeneous, not completely free from the exposure under investigation and $1 t$ rarely represents the same social stratum as the study cohort. Therefore, it does not fulfili the elementary requirements of comparison validity ${ }^{7} 8$. The only way to overcome the HWE is to avoid comparisons with the general population. Howewer. this solution is not feasible in many instances. Usually, it is extrenely difficult to find and compile a large ad hoc working reference cohort with the same characteristies as the study group, only differing in the fact that these is no exposure to the fuctor under study.

secause of practical, financial and methodological reasons general reference populations have not yet lost their popularity in occupational cohort studies. The interphetation of standardiged Mortarity Ratio's in these studies is seriously complicated, becase of the existing healthy worker efect: An sme lower than Ino does not recessarily mean that no excess mortality risk exists in the studied population. In order to clear the way for future standardization for the Hwe, it remains important to discover and describe al the variables that determine the magnitude of the eftect. Many investigators have tackled this problem by using simlation models. rhey re-analyzed actual conducted studies by axtificial modification of design characteristics, such as age distribution, follow-up- and latercy period, the proportion of active workers and different exposure subgroups $2,10,11,13,17,18$

A diferent aproach is taken in this review, which presents a cross-sectional 
analysis of the relation between the total SHR, and thus HW, of 270 published retrospective cohort studies about occupational exposures and relevant design characteristics. The articles, published in a thirteen year period in seven scientific journals, were regarded as separate entities, comprising information about the design characteristics as independent wariables and the outcomes in terms of SMR"s as dependent variables. It was presumed that a totall sMR lower than 100 represented the accurrence of a HWE. With a cross-sectional description it is not passible to analyse exact cause-effect relations between study characteristics and the HWE. However, in order to obtain an overall impression of the distribution of the HWE in a sample of occupational cohort studies the method can be useful.

The main objective of this paper is, whether there are consistent correlations between design characteristics on one hand, and the HWE and its magnitude on the other. More specific, the following questions are dealt with:

- What is the average magnitude of the HWE?

- Does the occurrence and magnitude of a HWE change with the size of the study in terms of the number of exposed persons, the person-years of follow-up and the expected deaths?

- Does a connection between the HWE and the length of follow-up exist?

- Is there a relation between the exposure definition and the HWE?

- Is there a relation between the completeness of the study in terms of the "lost to follow-up" percentage and the HWE?

\section{MATERIAL AND METRODS}

Seven scientific journals were systematically searched fran 1975 or, if later, the first year of publication to 1987 inclusive. Each article, reporting an occipational retrospective cohort study in which the total sMr for the total exposed population regardless of cause of death was given, was abstracted. If more than one article was written reporting the same study, only one article was included in this review. However, updates were regarded as separate studies. The number of selected articles per journal amounted to:

- The American Journal of Epidemiology ( $n=17)$;

- American Journal of Industrial Medicine $(\mathrm{n}=28)$;

- British Journal of Industrial Medicine ( $n=91$ ):

- International Archives of Occupational and Environmental Health $(n=1):$ 
- Trterntional Journal of epidemiology $\ln =91$;

- Tounal of Dccupational Hedicine $(n=77)$;

- Scandinawan Journal of work, Enviroment and Health $(\mathrm{n}=47)$.

In Appendix I the relevant wariables collected for this review are displayed together with the categories that were used. Each article was abstracted after detalied, specific guidelines were developed for the classification of the items. As "country" was chosen the nation or combination of nations, where the exposed workers were selected. The nature of exposure was determined by the specific compounds, but for "mining" a separate category was reserved because almost all studies in this fjeld did not tocus on a particular exposure but on the health risk of mining itself.

For each study minimal and maximal latency period were calculated using the cohort definition and the enddate of the follow-up. For instance, if all the workers employed between 1950 and 1960 were followed up until 1988, the minimal latency was 28 years and the maximal 1 atency was 38 years. On the other hand, if al1 exposed workers employed after 1950 were followed until 1988, the minimal latency was 0 years since a person who started working on 30 December 1987 was sLld eligible for follow up.

The final outcome of each study was determined by the conclusion of the author $(s)$. A negative study was defined as a study of which the investigators explicitely concluded that it did not provide evidence for the existence of an increased relative risk due to an occupational exposure. "Non conclusive"studies were also categorized as negative studies. The total SMR for the exposed group was regarded as an estimate of the HWE, the strength of the HWE reflected by the calculation: $(100$ - total SMR). If the total SMR amounted to 100 or more, a HWE was considered not to exist.

cross tables between the design characteristics and the HWE were computed and the data were further analyed by statistical procedures generally appiced in casecontrol studies. odds ratios and two-sided 95 confidence limits were calculated. ans described by schlesselman. ${ }^{19}$.

\section{RESULTS}

The unweighted mean SMR for the 270 studies amounted to 96.4, 172 studies showed a HWE, with an average SMR of 83.7 . In only 29.7 of all studies concerning occu- 
pational exposures to asbestos and in the mining industry a HWe occurred, agalnst 69.1 of other exposures. It is widely known that the asbestos and mining industry in the past imposed serous health risks upon the labourers (e.g. asbestosis. mesothellom, silicosis, accidents, lung cancer), which expresses itself by elem wated total SMR" $s$ in retrospective cohort studies 20,21 . As a consequence, in these exposure categories the total SMR is no reliable measure for the HWE. Theresore we decided not to include the studies conducted in the asbestos and mining industry ( $n=37)$ in further analyses of the data.

Thus the review was restricted to 233 studies, of which 161 (69.12) showed a HWE. The distribution of studies with a HWE over the selected design characteristics is displayed in Table 1. Although the awareness about the flaw of the HWE in cohort studies is growing, it can be seen that the proportion of studies with a $H W E$ has increased in recent years. The odds ratio of the proportion of studies with a HWE published after 1981 in relation to earlier studies yields 1.54, which is not statistically significant (Table 2). Studies carried out in scandinavian countries differed from those conducted in North America and Great Britain in the low percentage of BWE. The odds ratio of BWE in studies in other regions was almost two times as high, and nearly reached statistical sugnificance (Table 2 ). With regard to the occupational exposure under investigation in studies concerning chemical substances, a comparatively strong HWE occurred. Almost 83 of all studies of chemical exposures showed a total SMR of less than 100. with an odds ratio of 4.1 (statistically significant).

Table 1 shows that as the number of exposed workers in occupational cohort $s$ tudies increases, the chance to encounter a FWE also increases. 81 of the studies with 10,000 or more workers reported a total SMR smaller than 100, compared to 608 of the studies with less than 1,000 exposed workers. The odds ratio of 1 inding a HWE in a study with more than 5.000 exposed persons was 1.94 times that of a study with less than 5,000 (statistically significant) (Table 2). A similar telationship was found in respect of the number of person-years of follow up accumulated in the study. Studies with 50,000 person-years or more had an oddy ratio of 2.36 of observing a HWE as compared to studies with less than 50,000 person-years (Table 2). However, this correlation disappeared looking at the expected number of deaths in the entire cohorts. The tendency of an odds ratio of 1.47 for an SMa smaller than 100 in studies with 200 expected deaths or more did not reach statistical significance (Table 2). 
Table 1. Dastribution of studies with a healthy worker fect per design characteristic in 233 retrospective occupational cohort studies fall exposures except mining and asbestos).

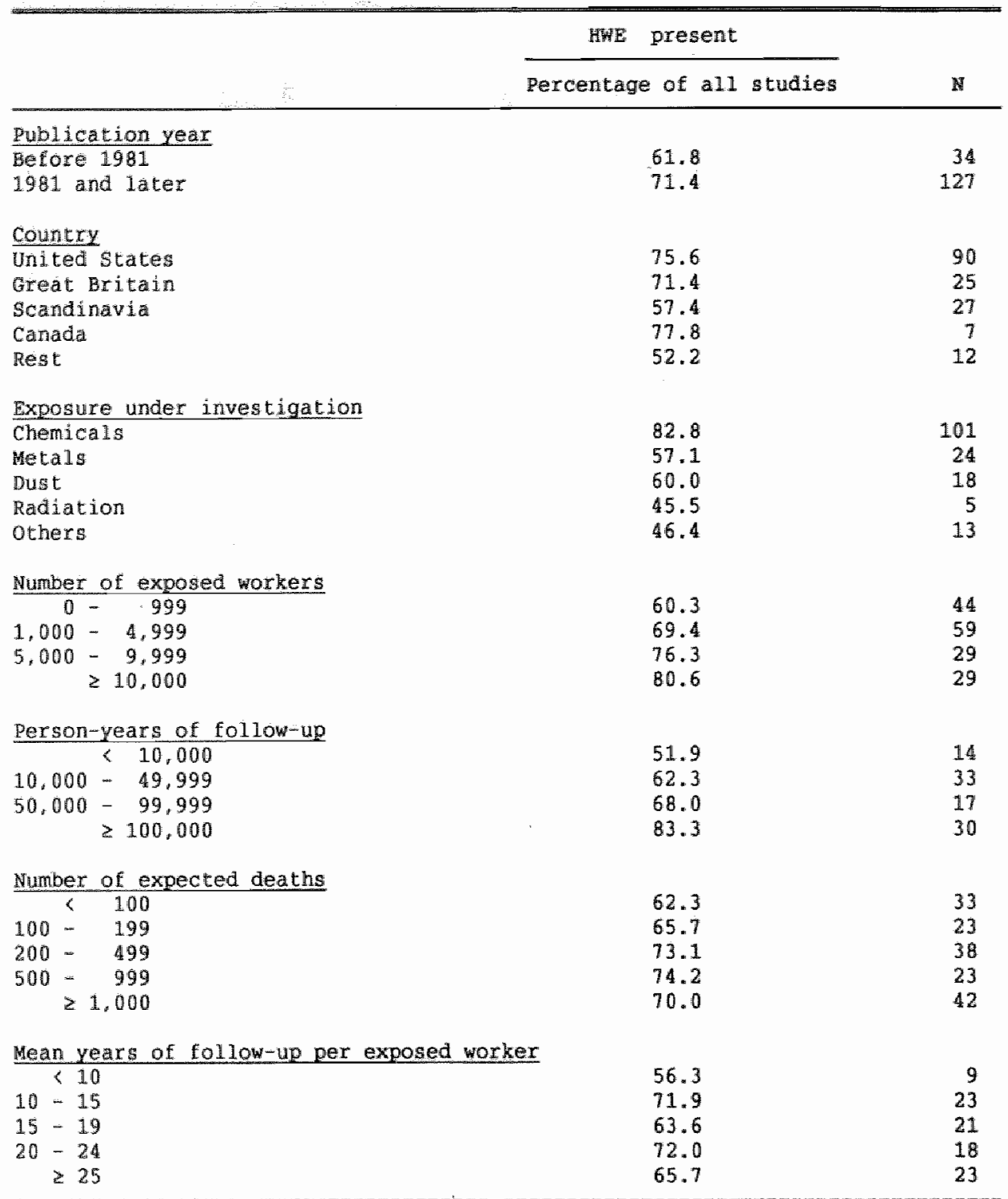

Cont irued... 


\begin{tabular}{|c|c|c|}
\hline & HWe present: & \\
\hline & Percentage of 11 studies & $\mathrm{N}$ \\
\hline \multicolumn{3}{|c|}{ Length of follow-up (years) } \\
\hline $0-19$ & 70.9 & 39 \\
\hline $20-29$ & 75.0 & 54 \\
\hline $30-39$ & 65.8 & 50 \\
\hline$\geq 40$ & 58.6 & 17 \\
\hline \multicolumn{3}{|c|}{ Minimal observed latency (years) } \\
\hline $1-9$ & 75.0 & 45 \\
\hline $10-19$ & 60.3 & 38 \\
\hline$\geq 20$ & 52.0 & 13 \\
\hline \multicolumn{3}{|l|}{ Cohort definition } \\
\hline Cross-section & 71.0 & 22 \\
\hline Period & 68.8 & $\mathbb{1 3 9}$ \\
\hline \multicolumn{3}{|c|}{ Minimal exposure period } \\
\hline None & 64.8 & 79 \\
\hline$<$ Half year & 73.1 & 19 \\
\hline Half year - year & 73.3 & 33 \\
\hline$>$ Year & 75.7 & 28 \\
\hline \multicolumn{3}{|c|}{ Percentage lost to follow-up } \\
\hline$<1$ & 62.1 & 54 \\
\hline $1-1.9$ & 75.8 & 25 \\
\hline $2-4.9$ & 76.3 & 45 \\
\hline$\geq 5$ & 68.5 & 37 \\
\hline \multicolumn{3}{|l|}{ Study outcome } \\
\hline Positive & 57.4 & 81 \\
\hline Negative & 86.0 & 80 \\
\hline
\end{tabular}

If the average number of years of follow-up per exposed worker, defined as the quotient of the total number of person-years of follow-up and the number of expom sed workers, were taken into account, no consistent relation between follow-up duration and the HWE emerged (Table 2 \%. In fact, as the length of the follow period of a study, given by the difference between the last and first year of follow-up, increased, the chance that a HWE pccurred seemed to diminish: the odds ratio of a HWE in studies with a follow-up period of less than 30 years was 1.55 tumes that in studies with a longer follow-up. Hevertheless this difference was: not statistically significant (Table 2). The minimal observed latency period presented the same picture (Table 1). As the minimal latency period increased, the proportion of studies with HWE diminished. The chance to find a HWE in studies with minimal latency of less than ten years is 2.18 times that in situdies with a longer latency, which is statistically significant (Table 2 ). 
Male 2: 0ads ratios for the HWe in gelected design characteristics 1233 occupathona 1 collort studies!.

\begin{tabular}{|c|c|c|c|}
\hline Design characteristic & Distribution & odds ratio & $\begin{array}{l}\text { Confidence } \\
\operatorname{limits} \\
(\alpha=0.05]\end{array}$ \\
\hline Fuld ication yedr & 1981 and 1ater ws before 1981 & 1.54 & $0.82-2.9$ \\
\hline Country/Region & others ws scandinavia & 1.91 & $0.99-3.7$ \\
\hline $\begin{array}{l}\text { Exposure under inves- } \\
\text { Ejgation }\end{array}$ & Chemicals vs others & 4.1 & $2.25-7.47$ \\
\hline Number exposed workers & 25.000 vs $<5.000$ & 1.94 & $1.02-3.69$ \\
\hline $\begin{array}{l}\text { Rerson-years of } \\
\text { follow-up }\end{array}$ & $\geq 50,000$ vs $<50,000$ & 2.36 & $1.12-4.97$ \\
\hline $\begin{array}{l}\text { Number of expected } \\
\text { deaths }\end{array}$ & $\geq 200$ vs $<200$ & 1.47 & $0.83-2.59$ \\
\hline $\begin{array}{l}\text { Mean follow-up years } \\
\text { per person }\end{array}$ & $\geq 15 \mathrm{vs}<15$ & 1 & $0.48-2.09$ \\
\hline $\begin{array}{l}\text { Length of follow-up } \\
\text { (years) }\end{array}$ & $<30 \mathrm{va} \geq 30$ & 1.55 & $0.89-2.71$ \\
\hline $\begin{array}{l}\text { Mnimal observed } \\
\text { latency (years) }\end{array}$ & $<10$ vs $\geq 10$ & 2.18 & $1.05-4.55$ \\
\hline Cohort definition & Fixed vs dynamic & 1.11 & $0.48-2.55$ \\
\hline Minimal exposure period & $\geq 1$ year vs $<1$ year & 1.47 & $0.72-6.20$ \\
\hline $\begin{array}{l}\text { percentage lost to } \\
\text { tollow-up }\end{array}$ & $\geq 1 \mathrm{vs}<1$ & 1.68 & $0.95-2.96$ \\
\hline Study outconte & Megative us positive & 4.48 & $2.88-8.8$ \\
\hline
\end{tabular}

More detailed andyseg of the relation between the size of the cohort studies in terms of the number of exposed workers and tatal person-years of follow-up and the mean and total follow-up period and minimal latency presented the fallowing picture: Iarger sudies (more than 5,000 exposed workers, more than 50,000 person-years of follow-up) did not show a significant, consistent difference in follow up period in relation to smaller sudies. But in studies with more than 5.000 workers, the chance to find a study with a short mean follow-up period per person of legs than 15 years was 1.5 times that in studies with less than 5.000 
workers 195 confidence Iimits: $0.70-3.2)$. In these larger studies, the odds ratio for a minimal latency time of less than 10 years was 2.4 times that of smaller studies (95 contidence limits: $1.15-5.1)$. The same trend was discovew red according to the total person-years of follow-up. The odds ratio to find a minimal latency time of less than 10 years for studies with more than 50,000 follow-up years versus less years of follow-up amounted to 1.94 195: contidence limits: $0.78-4.8$.

With regard to the studies concerning chemical exposures no other design characteristics studied in this review could explain the differences between the occurrence of the HWE in studies about chemicals and other occupational exposures.

Perhaps sone selection criteria used to define a cohort play a role in the occurrence of a $\mathrm{HWE}^{16}$. In this descriptiwe study the odids ratio of a $\mathbb{H W E}_{\mathrm{E}}$ for ixed cohorts amourted to 1.11 in comparison to dynmic colvorts, constructed during a longer period (not significant) (Table 2). When a minimal exposure period of more than one year was used before a worker was selected for the cohort, the adds ratio for a HWE was 1.47 (not significant) (Table 2).

The highest proportion of studies with a $\mathbb{W}$ was found in studies with a percentage lost to follow-up of one percent or more (OR: 1.68) (Tables 1.2). At last, there emerged a very strong relation between the study outcome and the occurrence of a HWE. The odds ratio for a HWE was 4.48 (Table 2 ).

\section{DISCUSSTON}

Because simulation examples about the influence of methodological issues on the FWE are restricted to a particular study, they can not give a comprenensive in sight in the overall wfect of methodological variables to the WW in occupatiow nal cohort studies. In this review we report the results of a different approach. The crossmsectional investigation of selected design variables and tota 1 SMR" of 270 cohort studies was used for a descriptive analys of the genera 1 impact of methodological entities upon the $W_{W E}$.

Wevertheless there are some pitfalls. In the first place total SMR's were used as estimates for the HWE. But it is also possible for specific occupational exposures that a substantial excess mortality due to one or more specific death-cases expresses itself in an increase of the total SMR, which will cover up an existing HWE. To overcome this problem we excluded the exposures for which this could pro- 
bably happen, asbestos and mining. Becondly, If by cross-tabulation of the owerall distribution of degign charactexistics and the WWe correlations are found, these may as well be influenced by other, confounding variables. It must also be kept in mind that the conclusions are drawn from a cross-section and non-experimental design, and therefore it is impossible to investigate whether or not a relationship is a casal one. But this method can be of good use in developing nesw hypotheses according to the origin and existence of the HWE.

In this review it was found that majority of occupational cohort studies, after mituting exposures to asbestos and mining, suffer from a we varying in sMR from 50 to 99 with a mean of 83 . It has been argued that it would be a reasonable approach to apply a general correction factor of approximately 90 of total male mortality across al ages and causes, to rule out the wwe 5 . The results of this study, nevertheless, show that the HWE is not a stable entity and may wary widely between cohort studies. Thus, in agreement with Hernberg ${ }^{3}$, it would be an oversimplification to introduce a uniform adjustment factor. As the data show, more recent retrospective studies are not better equiped to deal with confounding because of the HWE than former studies.

A relation between the size of the studies and the occurrence of a HWE emerged: As the number of exposed workers and the total person-years of follow-up increased, the chance to find a HWE increased too. Numerous authors have demonstrated that the HWE diminishes as the follow-up periot for an occupational cohort grows $^{2,11,15,16}$. This review seems to confirm their experiences. There was an inverse, although not significant, relationship between the followmp period of a situdy and the HWE. But how could the possitive correlation between the study size and HWE be explained? we investigated if the larger studies showed a shorter follow-up period. This seemed not to be the case.

A factor that great $I Y$ influenced the occurrence of a HWE was the minimal latency time, defined by the time between the endiate of cohort compilation and the enddate of follow-up: The longer the minimal latency period, the smaller the chance to find a study with a HE.

"The differences in minimal latency were able to elucidate the increased occurrence of the HWE in cohorts with a large study size to a certain extend. A possible explanation for this phenomeron could be the fact that as the latency period increases the initial healthier working population looses its health benefit. which results in a higher SMR.

3 tudies concerning chemical substances experienced a four times higher chance to reveal a HW than other studies. As far as the authors know, this has never been mentioned in other reports and it is not at all clear which underlying factors can explain this important difference. Maybe workers in the chemical sector have 
to pass a stronger health selection before they are admitted to the job the health selection during employment is stronger or they have higher social status than the general population, which results in a higher total SMR.

koskela et al concluded from a simulation study that crass-sectional cohorts had a lower SMR than open cohorts, due to the health selection during employment ${ }^{16}$. This effect increases as the health selection for certain professional groups (e.g. workers with heavy fysical efforts) becomes more important. Although this review shows a slight tendency in the direction of an increased HwE in crosssectional cohorts, it could not statistical significant confirm the findings of koskela et al.

Studies incorporating workers with an exposure of more than one year had a chance of 1.5 to reveal a HWE than studies with a less stringent criterion. Although this outcone was not significant, it contains an interesting hypothesis that needs further investigation. Epidemiologists often debate the necessity of introducing a minimal exposure definition. If a higher exposure definition leads to a healthier study population in relation to the reference group, for instance through a greater health selection in that period, it would be advisable not to introduce such a criterion.

We investigated the relation between the percentages last to follow-up, as surrogate for the quality of the studies and total SMR"s. As the lost to followmp fractions rose, the chance to detect a $\mathrm{HWE}$ also increased. Although we do not know what exactly causes this relation, it stresses once more the need for an accurate and complete gathering of vital information. The importance of the $\mathbb{H W E}$ in interpreting accupational cohort studies appears from the fact that a study containing a HWE has far more less chance to be considered as a positive study. regardless the exposure under investigation. It thus emerges that the conclusions based on historical cohort studies are directly related to the selection of an inaccurate reference population.

The HWE is an intriguing and complex methodological issue, that affects almost every occupational cohort study. As long as no feasible alternative for the gereral population as referent group exists, it is important to classify the variables that determine the HWE. With this cross-sectional review "we hope to have shed more light on the overall distribution of the HWE over cohort studies and the methodological issues influencing the HWE. Many of them need further explanation. 


\section{PEFERETCES}

1. Friedman GD. Primer of Epldemiology. Wew York, McGraw - Hill Book Company. 1980.

2. Gaffey WR A critique of the Standardized Mortality Ratio. J. Occup. Med. $1976 ; 18: 157-160$.

3. Hernberg S. Evaluation of epidemiologic studies in assessing the long term effects of occupational noxious agents. Scand. J. Work Environ. Mealth 1980; $6: 263-169$.

4. McMichael AJ, R Spritas, LL Kupper. An epidemiologic study of mortality within a cohort of rubber workers, 1964-1972. J. Occup. Med. 2974; 16: 458-464.

5. Goldsmith $J$. What do expect from an occupational cohort? $J$ "Occup. Med. 1975: $17: 126-127$.

6. Fox AJ, PF Colliex. Low mortality rates in industrial cohort studies due to selection for work and survival in the industry. Br. J. Prew. Soc. Med. 1976: $3: 225-230$.

7. Hermberg $s$. "Wegative" results in cohort studies - How to recognize fallacies. Scand. J. Work Environ. Health 1981; 7: 121-126.

8. Wang $\mathrm{DD}$, os Miettinen. Occupational mortality studies. Principles of walidity. Scand. J. Work Environ. Health 1982; 8: 153-158.

9. Koskella RS. Occupational mortality and mortality in relation to selective turnover. Scand. J. Work Environ. Health 1982; 8; supl. 1: 34-39..

10. Wen CP, SP Isai, RL Gibson. Anatomy of the healthy worker effect: a critical review. J. Occup. Med. 1983; 25: 283-289.

11. Monson RR. Olservations on the healthy worker effect $J$. Occup. Med. 1986: 28: $425-437$.

12. Weed DL. Historical roots of the healthy worker effect. $\pi$. Occup. Med. 1986: $28: 343-347$.

13. Weed DL, HA Tyroler, C Shy. The healthy worker effect in actively working communications workers. J. Occup. Med. 1987; $29: 335-339$.

14. McMichae1 AJ, SG Haynes, HA dyroler. Observations on the evaluation of occupational mortality data. J. Occup. Med. $1975 ; 17: 128-131$.

15. McMichael AJ : Standardized Mortality Ratios and the "health worker effect": Scratching beneath the surface. 3. Occup. Med. 1976; 18: 165-168.

16. Koskela RS, E Järvinen, PJ Kolari. Effect of cohort definition and followup length on occupational mortality rates. Scand. I. Work Environ. Health $1984 ; 10: 311-316$. 
17. Pearce $\mathbb{N}_{n}$ H Checkoway, $C$ Shy . Time-related factors as potential confounders and effect modifiers in studies based on an occupational cohort. Scand. J. Hork Environ. Health 1986; $12: 97-107$.

18. Sterling TD, JJ weinkam. Extent, persistence and constancy of the healthy worker or healthy person effect by all and selected causes of death. J. occup. Med. 1986; $28: 348-353$.

19. Schlesselman JJ. Case contral studies, design conduct analysis. Oxford. Oxford University Press, 1982.

20. Atuhaire LK, MJ Campbel1, AL Cochrane, M Jones, Foore. Mortality of men in the Rhondda Fach 1950-1980. Br. J. Ind. Med. 1985; 42: 741-745.

21. Cotes JE. J steel. Work-related lung disorders. Oxford. Blackwell Scientific publications, 1987.

Appendix 1: Presentation of the variables of which information was collected for the retrospective cohort studies.

- Year of publication (from 1975 to 1987 inclusive).

- Country (United States, Canada, Great Britain, Scandinavia, rest Europe, rest wor 1d).

- Nature of the occupational exposure (chemical, metal, asbest "mining, organic and mineral dust other than asbest, radiation, rest).

- Number of exposed workers.

- Minimal exposure period "non, < half year, < one year, longer"l.

- Cohort definition (cross-section or period).

- Number of person-years of follow-up.

- Minimal and maximal observed latency.

- First and last year of collow-up.

- Number of deaths expected in the exposed group.

- Percentage lost to followmu.

- Possitive or negative study.

- Total SMR of the exposed group. 
II. 3 


\section{PART III}

\section{ENVIRONMENTAL RISK ASSESSMENT}

THE USE OF EPIDEMIOLOGICAL DATA IN RISK ASSESSMENT

A SCIENTIFIC BASIS FOR THE RISK ASSESSMENT OF VINYL CHLORIDE CARCINOGENIC RISK ASSESSMENT OF BENZENE IN OUTDOOR AIR 
$-110-$ 
THE USE OF ERIDEMTOLOGICAL DATA

IN RISK ASSESSMENT

Gerard M.H. Swaen $^{1}$

1 Dpt. of Occupational Medicine, University of Limburg, The Netherlands

Published in Regulatory Toxicology and Eharmacology.

1988: 8:422-430 
II. 1

$-112-$ 
Next to toxicological data, epidemiological studies form the scientific basis for risk assessment. Both approaches have their particular advantages and limitations. The most important limitation of epidemiological studies is the lack of exact data on past exposures. Their most important advantage is that they study the actual occurrence of diseases in humans. Epidemiological and experimental data should be regarded as complementary and should be used in clase conjunction in the process of risk assessment. Apart from these advantages and limitations several specific issues are adaressed in this paper, such as study population of particular interest, the problem of low dose extrapolation, the interpretation of negative results "derivation of no-efect levels from epidemiologic studies and the application of safety factors for epidemiological studies.

\section{INTRODUCTION}

Since one of the specific aims of epidemiology is to study the role that factors play in the occurrence of morbidity and mortality. it is redundant to postulate that epidemiologic research should be of great importance in the process of $\mathrm{risk}$ assessment. Yet it can be debated if this is actually the case and if the significance of epidemiological evidence is accurately assessed on its merits and limitations.

What should experts irvolved in the process of risk assessment expect from the scientific body of knowledge on health effects from exposure to chemicals that is gradually being formed by epidemiologists throughout the world? This is the hain issue that 111 be addressed in this paper. In contrast to toxicological research epidemiologists can hardly ever apply experimental study designs in their quest for knowledge concerning the causes of diseases. This introduces several limitations in the conclusions to be drawn from epidemiological studies. It also determines to a great extent the credibility of epidemiology in the eyes of scientists from other disciplins. Still the number of epidemiologists involved in the process of risk assessment is smill, especially as compared to the number of experimental toxicologists. This is particularly the case in European countries.

Epidemiologists in the field of occupational and environmental health have histo- 
rically been interested in the long term health effects of exposures. Especially in occupational epidemiology a major effect parameter has been nortality and in particular cancer mortaity. Partly this is attributable to the measurability of this effect and the avaliability of data about the "natural or background mortality in the general population. Thus, although this workshop is focussed on the risk assesgment for human exposure to non-carcinogenic substances, the Iiberty has been taken to illustrate several issues by means of examples from carcinagenic risk assessment. The field of $\mathrm{risk}$ assessment and the contribution of epidemiological data is quite extensive. However, this paper will only elaborate upon a few issues that seem to be particular suitable for discussion at the monent. These issues will be preceded by two paragraphs on the advantages and limitations of epidemiological data in the process of risk assessment. The epidemiological studies subject of this paper are of the retrospective and prospective cohort type, in which a group of exposed persons and group of non-exposed persons is followed through time to determine the occurrence of health effects. If statements about other study designs such as case/control studies or human experiments are made, this will be specifically mentioned. Expert comittees in the field of enwiromental health frequently are confronted with the situation that an advice or recommendation is required meaning that the option of not formulating any recommendation at all for a particular substance is not realistic. Thus a recommendation is required even if the body of knowledge is Iimited.

\section{ADVANTAGES OF EPIDENIOLOGICAL DATA}

Obvious Iy the greatest advantage of epidemiological data over animal data is that it provides evidence on the actual occurrence of health effects of exposure to chemicals in humans. Subsequently there is no need for animal to human extrapolation. This widely accepted advantage increases the credibility and acceptability of the eventual exvironmental standards to be proposed by expert combittees.

A second advantage is that the human populations object of epidemiologic investigation nearly always are comprised of subjects with great genetic variation, often but not always randomly distributed over the exposed and non-exposed groups. The genetic variation more or less guarantees that individuals particularly susceptible to the exposure of interest are also inciuded in the study. In animal experiments the use of highly inbred strains is preferred because it warrants homogenic and comparable base populations. This also should erable con- 
firmation of the experiments by scientists throughout the world. Another advantage of epidemiology is that it studies humans in their natural. environment, in which they smoke, drink, take medication etcetera. Thus interactions between these parameters and the exposure under inwestigation wil also contribute to the occurrence of morbidity. An interesting example of this is the multiplicative effect of cigarette smoking and exposure to asbestos on the relative risk for of cancer ${ }^{1}$. Because of this interaction animal studies investigating the risks of asbestos exposure in absence of exposure to cigarette smoke would lead to an underestimation if extrapolated to smoking humans.

Another related advantage is that usually cohorts studied by epidemiologists also contain a proportion of already impaired humans, who may be at higher isk to develop health effects following a particular exposure. As an extreme example the epidemiologist may even select a high risk population on an impairment criterion. For instance the epidemiologist may select asthmatic patients for his study and observe the incidence of asthmatic complaunts during an episode of increased air pollution.

\section{LIMITATIONS OF EPIDEMIOLOGICAL DATA}

Inherent to the empirical nature of epidemiological research it is only possible to investigate health effects of exposures as they occur or have already occurred in reality. An exception to this rule is experimental human research in which reversible health effects are ethically acceptable. These experimental human studies or human volunteer studies can be of great significance for a better understanding of the underlying mechanisms. A better understanding of human metabolism will enable a more precise comparison between humans and test animals, which may provide a more solid basis for interspecies extrapolation.

Aside from this exception epidemiological studies are Iimited to the occurrence of exposure of a sizable human population to a certain chemical. "Thus "the risk. assessment of irreversible health effects of new substances that are about to be introduced will be a toxicological affair.

Unfortunately in reality human exposures to chemicals do not occur separately. In areas where $\mathrm{SO}_{2}$ ambient air concentrations are high usually high concentrations of $\mathrm{CO}$ and $\mathrm{NO}_{\mathrm{x}}$ are also present. This concurrence of exposures limits the possibilities to attribute health effects to one of the particular substances. In such cases epidemiologic research can only provide data on the health effects 
of these concurent conglomeration of exposures. If toxicological data do not provide enough insight in the effects of each substance separately. these epidemologic whafe wil not contribute much to the risk assessment of these individud chemicals. In this ramework the statement can be made that the risk assessment for individual substaces better concurs with experimental toxicology than with epidemiology. Experimental studies permit the health effects of one substance to be evaluated, whereas epidemiology can only study the combinations of expostres that occur in real 1 ife. A good example can be found in an epidemiologal study of ar pollution in the Netherlands ${ }^{2}$. In this longitudinal study a comparison was made between the decrease of vital pulmonary capacity and FEV, of a population living in a heawily polluted area and a population living in a rural area. The results clearly indicated that air poldution was related to a decrease in pulanary function. Athough it is not clear which particular agent contributed to this effect and to what extent, evidence was presented that the accurring combination of agents aid contribute to the decrease in lung function. Thus the resuts of these studies will not be quite informative regarding the risk assessment of one particular pollutant. However, they are very useful to check the standards to be set for exposure to these individual substances.

other limitations of epidemiological research are attributable to difficulties in observation and quantification of exposure and health effects. In many retrospective cohort studies there are no quantitative data available about exposures that occurred in the past. If the only information on exposure is that the study population has definitely been exposed to a certain chemical in the past, the results of such a study wijl only be a contribution to qualitative risk assessment and risk identj.fication and not to quantitative risk assessment.

The results of epidemiological studies have frequently been drawn into doubt because it was not possible to rule ouc bias due to differences regarding other factors between the exposed and non-exposed groups. For example an increased $x$ isk for lung cancer in an occupationally exposed group could still be a result of elevated snoking habits in this group. Gradualy the time has come to replace this type reasoning by a nore careful and realistic consideration. The possibility of bias due to uneven distribution of other exposures should only be considered if data indicate that such an uneven distribution has been present.

Another limitation is the difficulty to deal with effects that are not expressed in terms of mortality. If an epidemiologist intends to investigate the effects of say "urban air pollution" on pulmonary function, and wishes to do this in a proper prospective manner, he/she will embark upon such a great undertaking that it requires great quantities of courage and perseverance, let alone financial and human resources. In such a study not only information about "urban air pollu- 
tion" and the longitudinal development of pulmonary function must be collected but also specific information on smoking and other factors that many have the potency to induce pulmonary impairment. Now, in this eriof increasing pressure on scientists to increase output measured in number of articles published and their impact factors, it becomes even more hazardous to embark upon a vast scientific undertaking that will not yield results in the first few years.

It must be clear that several limitations that apply to experimental toxicology also apply to epidemiology. Especially the investigation of small risk increases is limited because these studies require large populations. which in tems of financial resources and logistics are difficult to conduct.

\section{STUDY POPULATIONS OF PARTICULAR INTEREST AND THEIR IIMITATIONS}

Epidemiological studies of occupational exposures have greatly enlarged our knowledge of long term human health effects of chemical exposures. Retrospective cohort studies have demonstrated to be a particularly useful and efficient study design in the evaluation of these long term health hazards. Several characteris tics of these studies impose restrictions on the applicability of the results for environmental risk assessment. First of all the nature of occupational exposures differs from the nature of the enviromental exposures of which the health $\mathrm{r}$ isks are to be assessed. Occupational exposures may occur during a working life in daily intervals of eight hours and usually healthy males are involwed. Thus generalization to continuous life time exposure, general lalso including diseased persons) male and female populations introduces a great deal of uncertainty. Especially the fact that occupational exposure in general does not start hefore the age of fifteen and now even twenty makes it difficult to extrapolate tho results to exposure starting at date of birth or even before birth. Subseguently human biotransformation may be capable of handing eight hour intermittant exposures whereas continuous exposures of similar concentrationg may lead to build up of chemicals in human tissue.

occupational exposures may be mixed and exposure to one particular agent usually is accompanied by exposure to other agents, thus complicating the attributability of observed effects. In such a case it is not sufficient just to mention the mere possibility of co-exposures, but the presence of these co-exposures must be made likely. Confounding by co-exposures needs only to be taken seriously if there ig evidence that these particulax co-exposures may contribute to the abserved ef- 
wects. For instance if the ain of a study is to evaluate the effect of exposure X on the liver and for co-exposure 4 the only known health effects concerns a dectease in lung function, than co-exposure to y does not have to be regarded as a confounding wariable.

whe most inportant shortconing of occupational cohort studies is the lack of information about the magnitude of past exposure. This type of information is nearly always lacking and imposes great dificulties for quantitative risk assessment but not so much for gualitative risk assegment. However, one should not disregard these studies in the process of quantitative $r i$ sk assessment, but one should try to estimate past exposures with the best possible means.

What developments can be expected in the field of occupational studies? And how wil these alfect risk assessment? First of all a substantial decrease in the magritude of occupational exposures has faken place in the western world. Exposures that may occur at present in many instances are 100 to 1000 times lower than say forty years ago. Thus in twenty years from now any long term health effects of these low exposures may occur and can be studied in an epidemiological. manner, wich may provide more knowledge of long term health effects of low exposure, prowided that the study populations are large enough to warrant reliable conclusions. Furthermore a trend can be noted in occupational epidemiology to conduct updates of already investigated cohorts. This may result in confirmation of earlier findings and a better understanding of the concept of latency. Also these cohorts nay prove to be interesting to investigate if risks decrease after conslderable or complete elimination of exposure.

Another development to be expected is a rapid increase in studies focussed on morbidity. Many industrial corporations have set up comprehensive morbidity registries. These are very helpful for future studies, but here again, highy exposed groups will become rare and accordingly there may be increasingly more negative studies. It also implies that positive studies conducted in this era may not be replicated. Therefore at the moment special attention should be given to accurate and complete documentation of the exposures under investigation.

\section{THE PROBLEM OF LOW DOSE EXTRAPOLATION}

Just as in experimental toxicology, the epidemiological approach requires large populations to study smali risk increases from low exposures. The sample sizes reguired to investigate the occurrence of health effects of exposures in the 
range of general amient air concentrations and the advised are so large, that these studies are wery difficult to conduct. Although in some instances epldeniologists have observed specific dose response relationships the lowest observed concentrations were still much higher than the finally adwised limit values. A Inear dose response relationship in the region of high exposures does not imply that there also exist a linear dose response relationship in the low exposure range. Several models have been proposed for low dose extrapolation" However, epidemiological verification or falsification of these models will require even much larger sample sizes than already necessary to observe an effect after low dose exposures. Probably the most sound and effective criterion to distinguish between models awailable for low dose extrapolation is biological plausibility. If there is not enough knowledge about underlying biological mechanisms, an arbitrary choice could be made in favor of a linear extrapolation in case of carcinogenic substances. The advantage of a linear extrapolation is that is a compromise between two extremes, the s-curve and parabolic curve. For biological effects the s-curve may be more likely than the parabolic curve, so that a linear extrapolation represents a conservative model, rather overestimating the $r i s k$ at low concentrations. Other models implicitely suggest that very sophisticated data were available on which basis a very careful evaluation could be made. However, this was not the case, at best it was intelligent guesswork of the expert, something that should always be explicitely stated. Perhaps intuitively the best way to proceed is to apply various models and see what sort of exposure standards they suggest. If the various standards are all in the same order of magnitude one can be confident that the choice of extrapolation model has not introduced a great deal of uncertainty. It should not be expected that epidemiological studies will solve the problem of low dose extrapolation. The most practicle data to be expected to contribute progress in this field may very well be an increase in knowledge of bilological mechanisms in the low dose range from both human and animal (experimental) studies. The models mentionned abovic do not apply to non-carcinagenic substances. because they do not take into account any threghold level: below which no adwerse health effects will occur.

\section{INAERPRETATION OF NEGATIVE RESULTS}

A negative result, that is a study in which no increased risk is observed, can be a reflection of two issues. First, it is possible that the investigated expo- 
Wure sitution in fact does not impose a health risk. Secondly, it is possible that the sample size of the study is too small to detect the effect or that the effect does not show up in the study group because of random variation. Suppose there is 50 basis to expect that for a particular substance there is no threshold level. Wher how can al negative study be applied in risk assessment? one approach is to distegrd negatrve results and only use positive results as a basis for rigk assesment. Mnother approach is to regard such a study as an "unfortunate sample" but stil capable of providing evidence about the magnitude of the risk that may exist in real jife. confidence linits can be calculated around the negative results that provide the range in which the actual risk will be located, giver a pre-determined degree of uncertainty. The use of the upper limit then provides a basis for a conserwative extrapolation to lower concentrations. An example in which this method has been applied is the carcinogenic risk assessment of benzene" Epidemiological sudies of workers exposed to high concentrations of benzene (3 $200 \mathrm{pm}$ ) have indicated that these workers are at increased risk of developing leukemia. These findings are generally accepted. However, epidemalogical atudies of workers exposed to low concentrations $(<10$ ppm) have consistertly been negative. Toxicological ewidence suggests a mechanism of action, which is in agreement with a non-threshold level approach. Thus the problem was raised that the negative findings did not fit into a non-threshold approach indicater by the toxicological evidence. raking an additional lifetime risk of $1 \times$ $10^{-6}$ as accepted the positive occupational studies with high exposure to benzene were Inearly extrapolated downard, resulting in a init value of $0.55 \mu \mathrm{ng} / \mathrm{m}^{3}$. The negative studies were combined and around the combined standardized MortaHity Ratio (SMR) of 100 a two-sided 95 confidence limit was calculated. Although it is not likely that benzene exposure may decrease the risk of leukemia twosided contidence interwal was calculated because this is the approach generaldy taken in occupational. mortality studies. Next, the upper limit was taken as a congervative estimate of the relative risk and was also ineariy extrapolated dowiswards. This approach resulted in a limit value of $1.4 \mu g / \mathrm{m}^{3}$. The two approam ches yield quite similar regults, leading only to a doublimg of the $1 \mathrm{imit}$.

\section{THE APPLICATION OF SAFEY FACTORS FOR EPIDEMIOLOGICAL STUDIES}

In the process of risk assessment it is common practice to use safety factors to account for uncertainties. Usually a safety factor of 10 is applied for the 
extrapolation from animals to man and also in order to account for the intraspeeles varlation ${ }^{5}$. These safety factors do not apply to risk assessnent based on eplatemiologic studies. On the other hand epidemiologic studies are non experimental and sensitive to bias or other impurities. Usually exposure to other agents can not be ruled out, measurement errors can easilY occur and non-response rates in the study groups can affect the credibility of the results. Furthermore, the most informative studies involve occupationally exposed groups which may have a different composition than the general population.

Impaired persons are less likely to apply to jobs that demand a great deal of physical strain. Astmathics are less likely to be hired for dusty jobs. Occupational groups subject of epidemiologic investigations usually consist of males. This makes it difficult to generalize the results to the general population which also consists of young persons, females and elderly. Furthermore, occupational exposures occur in eight howr intervals, which may give the exposed workers the opportunity to recuperate. The use of safety factors for epidemiologic studies seems warranted, but it is obvious that these safety factors can be smaller than those applied to animal studies. Perhaps a sensible way to go is to drop the safety factor of 10 for animal to human extrapolation and divide the remaining safety factor of 10 into two components. One component can depend upon a general consensus about the strenghts and weaknesses of the study, having a maximal value of 2.5 under the condition that epidemiologic studies with severe shortcomings are completely disregarded. Some justification for this number can be found in the general epidemiological rule that a relative $x$ isk of 2 or greater is unlikely to be the result of bias or confounding, but will generally be regarded to represent an actually existing relative risk. The second component of 4 can be introduced for uncertainties regarding the extrapolation of occupational groups to the general population. The size of this component is also quite arbitrary. The component should be regarded as a reasonable estimate of the Healthy Worker Effect for non-neoplastic diseases. It should be interpreted as meaning that the general population may be four times more sensitive for a paricular exposure after hawing experienced a similar dose.

\section{DERIVATION OF NO-EFFECT LEVELS FROM EPIDEMIOLOGIC STUDIES}

In epildemiologic studies exact concentrations are hardly ever available, which makes a quantitative evaluation quite difficult. But suppose, these are available 
or can be satisfactorily estimated, how can a non-effect level be derived from epidemiologic studies? One approach that can be taken is to analyse the existence of dose-response relationship between the exposure concentration and a predetermined health effect. Parallel to the approach applied in animal data, a linear downard extrapolation w11. give an estimate of the non-effect level at the intercept with the horizontal axis, which then can be subjected to a certain safety factor. In theory this is very straight forward approach. In practice several problems will have to be dealt with, such as, what were the exposure levels in the past, what do we define as a health effect, and is a linear extrapolation model appropriate.

perhaps human volunteer studies can be of great value in this field, by atudying the occurrence of early reversible effects at low exposure levels.

\section{CONCLUDING REMARKS}

In the last twenty years epidemiologists have accumulated a fair body of knowledge about factors that play a role in the occurrence of disease. At the moment an upward trend can be observed regarding the impact of epidemiologic knowledge in the process of risk assessment. Given this trend, it is of great importance that experts involwed in the process of risk assessment are aware of both the advantages and limitations of epidemiologic research. Most advantages and limitations cam be brought back to the nature of epidemiologic studies. The great advantages are that epidemiologists attempts to investigate health effect in humans and that populations usually are studied in their "natural enwironment". Several Iimitations apply just as well to experimental toxicology as to epidemiology, fow instance the problem of low dose extrapolation and the determination of no-effect levels. In these fields it should not be expected that epidemiological data wil greatly expand our understanding. Models for low dose extrapolation may very well remain to be based on toxicological knowledge about the underlying buological mechanismis.

It is clear that a further refinement of epidemiologic studies is necessary. This implies to health effect parameters as to exposure parameters. Perhaps in some cases biological monitoring can be used to retrospectively estimate the exposures in the past, if sufficient knowledge is available of the biological fate of the chemicals under investigation. 
The greatest contributions of epidemiology in the process of enwironinental risk assessment can be achieved in cases where there is toxicological knowledge about the underlying biological mechanisms, in other words as active symbiosis of these two sciences. One thing that epidemiologists should do to improve the impact of their studies is to put more effort into an as accurate as possible quantifucation of past exposures. The application of safety factors has partly been justified because of uncertainties in animal to man extrapolation. Even if humans prove to be just as sensitive as experimemtal animals, standards for environmental exposures based on epidemiologic studies may turn out to be a factor 10 higher than if they wauld be solely based on animal studies.

\section{REFERENCES}

1. Steenland $\mathrm{K}, \mathrm{M}$ Thun. Interaction between tobacco smoking and occupational exposures in the causation of lung cancer. J.0.M., 1986:28:110-118.

2. Lende van der R, "TJ Kok, R Pesetreigh, PHH Quanjer, JP Schouten, NGM Orie. Decreases in VC and FEV, with time as indicators of effects of smoking and air pollution. Bull. European Physiopath. Resp., 1985; vol. 17: 775-792.

3. Clayson DB, D Krewski, I Munro. Toxicological risk assessment. CRC Press, Boca Raton, Florida " 1985.

4. Health Council of The Netherlands. Benzene, appraisal of a criteria document and proposal for a risk-evaluation, 1987.

5. Health Council of The Netherlands. Establishment of health based recominendations for setting standards, 1985: 28 . 
III

$-124-$ 


\section{A SCIENTIFIC BASIS FOR THE RISK ASSESSMENT OF" VINYL CHLORTDE}

- Swaen, G.M.H. Dpt. of Occupational Medicine, University of Imimburg, Mastricht, The Netherlands.

- Hollander de, A.E.M., Secretary. Health Council of The Netherlands, The Hague, The Netherlands.

- Kroes, R., chairman of the Comittee and Director of the National Institute of Public Health, Bilthoven, The Netherlands.

- Engelse den, L. Dutch Cancer Institute, Amsterdam, The Netherlands.

- Feron, V.J. TNo-CTVO, Toxicology and Nutrition Institute, zeist, The Netherlands.

- Mulder, G.J. Dpt. of Toxicology, University of Leiden, Leiden, The Netherlands.

- Verbeek, A.L.M. Dpt. of Sacial Medicine, University of Nijmegen, Nijmegen, The Netherlands.

- Verschuuren, H.G. Dow Chemical Europe, Horgen, Switserland.

- Vogel, E.W. Dpt. of Radiation Genetics, University of Leiden, Leiden, The Netherlands.

- Welen wan der, A.W. Ministry of Housing, Physical Planning and Environment, The Netherlands.

The authors are members of the commitee on the Evaluation of Carcinogenic Substances of the National Health Council of the Netherlands.

Published in Regulatory Toxicology and Pharmacology. 
In July 1984 the Minister of Welfare, Public Health and Culture, representing the Dutch government sent a request to the Health Council of the Netherlands to advise on the health risks presented by environmental exposure to several carcinogenic substances. One of these substances was vinyl chloride (vC). On the basis of a working document prepared by the wational Institute of Public Health and Environmental Hygiene, a comittee of the Health Council of the Netherlands prepared a report concerning a health risk assessment of which was published in May 1986.

In this article a short review is presented of the available data and the considerations that formed the basis for the risk assessment of the carcinogenicity of vC to man. The advise was mainly based on human data from epidemiological studies of workers occupationally exposed to VC. The comittee concludes that a continuous exposure to $0.001 \mathrm{mg} / \mathrm{m}^{3}$ vc corresponds with an additional cancer morta1 ity risk of $10^{-6}$ per person life-time. The Dutch government considers this additional risk to the general population to be acceptable.

\section{INTRODUCTION}

Man is continuous $1 \mathrm{y}$ exposed to multitude of substances that are present in the environment he lives in. A number of these substances possess the capability of inducing malignant tumors im animals, humans or both. Some carcinogens are naturally accurring chemicals and exposure to these can hardly be prevented. others are man-made, emitted into the environment as a congeguence of human activities and thus exposure can, at least in principle, be reduced to an acceptable level. Reduction of emission of carcinogens can be achieved by govermental regulation. one of the instruments for such regulation is to set upper limits for pollutants in the enviromment, that may not be exceeded. These Iimits are in principle based on qualitative and quantitative information about the carcinogenicity of the specific substance. A particular health risk is then defined as an acceptable $r i g k$, for which frequently is taken one additional cancer death per one million lives, after life-time continuous exposure. This risk will further be referred to as the $10^{-6}$ risk level. The actual low exposure levels that result in this $x$ isk can not be directly determined and must therefore be estimated by extrapolation. The ex- 
trapolation of tumor incidence at high exposure levels to the incidence at low exposure levels is one of the principle problems connected with carcinogenic risk assessment. Several mathematic models have been developed to describe the relacionahp beween the lewel of exposure to a carcinogen and the probability of developing cancer, none of which has been verified in real life circumstances. In principle two types of data can be used in an extrapolation model for carcimogenic risk assegsment:

- Data on carcinogenic response in other species than man from experiments with animals exposed to high levels of a carcinogen.

- Data on carcinogenic response in humans, circumstantially exposed to high levels of a carcinogen, e.g, industrial epidemiologic studies.

Animal studies should be performed in a rigorously controlled environment and thus ideally are not necessarilly subject to bias or confounding by extraneous influences. However, the results must be extrapolated from the animal model to man, which introduces a considerable degree of uncertainty.

Epidemiology can only study the health effects of environmental or occupational exposures as they actulily occur or have occurred. Moreover, epidemiological studies are more likely to be subject to bias or confounding due to uncontrolled differences that have not been investigated between the exposed and non-exposed groups. In addition epidemiological studies generally lack precision in respect of exposure data. However, they have the advantage to be on actual health effects in humans, and thus could prowide more relevant information for human risk assessment.

Relatively high human exposures to carcinogens may occur in the accupational environment. Epidemiological studies that evaluate the carcinogenic effects of occupational exposure to particular substances may provide the most significant human data for carcinogenic risk assessment ${ }^{1,2}$. The purpose of this article is to compare the two approaches for carcinogenic xisk assessment th each other. tuking exposure to vinyl chloride $(W C)$ as the exposure of interest. Long term health effects of occupational exposure to vC have been extensively studied. Thus VC is a chemical for which a good comparison can be made between the two approaches. An extensive review on the health hazards of VC has been compiled by the Dutch National Institute of Public Health and Environmental Hygiene ${ }^{3}$. We will first assess the carcinogenic risk of VC on the basis of animal data. Then we will conduct a risk assessment for $\mathrm{pc}$ using human data, collected by means of epidemiological studies of workers occupationally exposed to $\mathrm{VC}$. In both types of risk assessment a linear dose-response model has been applied. A linear doseresponse relationship is supported by the one hit stochastic model for carcino- 
genisis, recommended by the American Food and Drug Administration and by the Dutch National Health Council ${ }^{5}$. It was also preferred, because the analysis by warious dose groups of workers in terms of duration of exposure and exposure level to vc performed by weber, suggests a Inear dose-response relationship. The phamacokinetics of VC in animals or humans are st 111 not well enough understood to incorporate an estimation of the "biological effective dose" - based on a pharmacokinetic model for saturable metabolism - in the dose-response extrapolation model, as was proposed by Gehring et a ${ }^{7}$ " 8 . Thus this model was not taken into account in the risk assessment of $\mathrm{VC}$.

\section{RISK ASSESSMENT BASED ON ANIMAL DATA}

VC is a procarcinogen which requires metabolic activation through the cytochrome P-450 system to exert genotoxic properties ${ }^{9}$. Mutagenic activity of vc has been demonstrated both in in vitro and in vivo assays ${ }^{1} \cdot 11$. In several animal studies the animals exposed to vC after oral application developed more tumors than the control populations ${ }^{12,13}$. There can be no doubt that vc is carcinogenic in amimals. In several studies with mice and rats a clear dose-response relationship was noted between the vC-exposure and the frequency of angiosarcomas of the liwer. The series of studies with Sprague Dawley rats performed by Maltoni et al ${ }^{11}$ were selected to form the scientitic basis for the risk assesment based on animal data, because in these studies VC was applied by means of inhalation and because the results suggested a clear dose-response relationship for angiosarcomas of the liver. In Table 1 the results are presented of the experiments with mice and rats conducted by Maltoni. A linear, non-threshold model was applied for risk extrapolation to lower dose levels.

The result: of each separate dose experiment were combined by taking the arithmatic mean of the incidences per $\mathrm{mg} / \mathrm{m}^{3}$ of $\mathrm{vc}$ applied in each experiment. "lhe arituthetic mean of the ratios was 29, which indicates that in order to increase the uncidence of angiosarcoma by one percent an additional concentration of 29 pprm vc must be applied, which equals $74 \mathrm{mg} / \mathrm{m}^{3} \mathrm{vc}$. 
Mable 1: Incidences of angiosarcomas" in Maltoni"s experiments with spraque Dawley rats after various concentrations of $\mathrm{vc}^{11}$.

\begin{tabular}{lccc}
\hline Experinent & $\begin{array}{l}\text { WC concentration } \\
\text { (In ppon) }\end{array}$ & $\begin{array}{l}\text { Incidence of angio- } \\
\text { Sarcomas* }\end{array}$ & $\begin{array}{c}\text { Ratio concentra- } \\
\text { tion/incidence }\end{array}$ \\
\hline BT 1 & 250 & 8.5 & 29 \\
BT 2 & 200 & 10.8 & 19 \\
BT 2 & 150 & 5.0 & 30 \\
BT 2 & 100 & 0.8 & 125 \\
BT 1 & 50 & 3.4 & 15 \\
BT 9 & 50 & 7.9 & 6 \\
BT 15 & 25 & 4.2 & 6 \\
BT 15 & 10 & 2.5 & 4 \\
\hline
\end{tabular}

* Hepatic and extrahepatic angiosarcomas

Taking the inverse of this ratio it can be concluded that an average increase of risk of 0.000135 of angiosarcoma per animal will be the result of an increase of $1 \mathrm{mg} / \mathrm{m}^{3}$ vc. In order to adapt the experimental situation to human life-time exposure, two conversion factors were introduced. The animals in the experiment were exposed to VC during 20 hours a week. Human exposiure to environmental concentrations of VC occur during 168 hours per week, giving a conversion factor of $168 / 20=8.4$. The second conversion factor was necessary because the rats were not exposed during 143 weeks, the average lifespan of a:rat, but only 52 weeks, giving a conwersion factor of $143 / 52=2.75$.

The additional risk of angiosarcoma per $\mathrm{mg} / \mathrm{m}^{3}$ WC concentration for a continuous life-time exposure for one individual was-calculated to be $0.000135 \times 8.4 \times 2.75$ $=0.0031 \mathrm{per} \mathrm{mg} / \mathrm{m}^{3} \mathrm{VC}$. The proposed maximum level for environmental exposure to a particular carcinogen as formulated by the committee is one additional death of cancer per one million lives, giving a life-time environmental exposure of $0.00032 \mathrm{mg} / \mathrm{m}^{3}$ vC $\left(10^{-6} / 0.0031\right)$.

Thus the comittee would consider an environmental exposure to $0.00032 \mathrm{mg} / \mathrm{m}^{3} \mathrm{vC}$ to correspond to $10^{-6}$ risk level on the basis of animal data. 
The isk for humans of accupational exposure to VC in industry has been investigated by epldemiologists for groups of workers. All studies used the design of a retrospective cohort study. A group of workers exposed to vo in the past was identified and followed through time to observe the accurrence of cancer in the exposed group. Based on national statistics an expected number of deaths from a particular disease was calculated, taking into account the age distribution, length of follow-up and calender-period. By dividing the observed number by the expected number, the standardized Mortality Ratio (SMR) was calculated, which is a measure of the relative risk for a particular cause of death resulting from ve-exposure.

Table 2 summarises the results of the seven iargest epidemiological studies on workers exposed to VC. All studies except one indicate an excess mortality from cancer of the Iiver and in particular of angiosarcoma of the liver (ASL). Other types of cancer also showed a tendency to be increased in incidence, but these increases are not consistent. Total cancer mortality however is higher in four out of the seven stucies. In order to carry out a risk assessment the results of these epidemiological studies had to be combined to obtain an overall estimate of the relative risk. prior to combining the results, the studies indicating the highest and the lowest relative risk were omitted, because these studies were considered to be extreme results due to ramdom variation. The remaining three studies were regarded as unbiased estimates of the true standardized Mortality Ratio (SMR). Although the cohort studied by waxweiler was probably completely included in the study conducted by Tabershaw, both studies were regarded as being independent estimates of the risk of liver cancer after exposure to VC. An alternative analysis after omission of the study conducted by waxweller revealed similar conclusions. Since the three studies were not of the same size, a weight was given to each study according to its size, based on the standard error of the observed SMR. Phis weight was the expected number squared, divided by the observed number, being the inverse of the variance. The overall SMR was subsequently calculated by dividing the sum of the products of the individual weight and the SMR by the total sum of the weights. The overall SMR for liver cancer mortality obtained in this manner is 13.07, meaning that workers occupationally exposed to VC experienced a 13.07 fold $r i s k$ to die of liver cancer. The overali $3 M R$ for total cancer mortality is 1.14 . 
Table 2: Results of seven occupational mortality of workers with past exposure to WC.

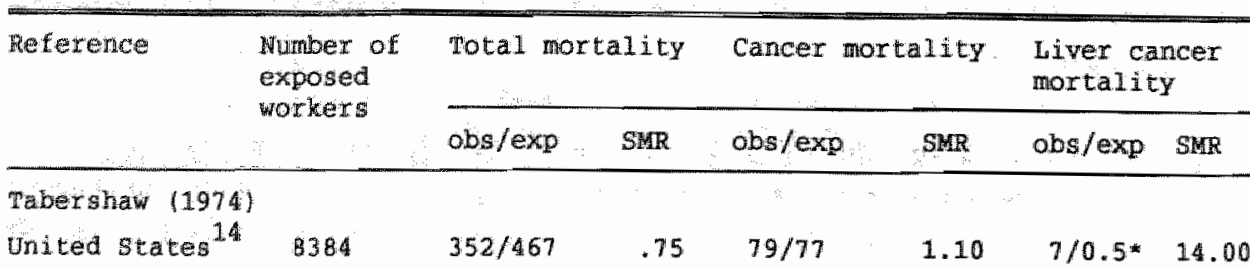

Meber (1981)

West Germany 6

7021

$4.1435 .7 \quad .95$

$94 / 90.6$

1. 12

$12 / 0.09 \quad 15.23$

Pox $\{1977\}$

United Kinganon

7717

$393 / 521$

$.75 \quad 115 / 127$

.91

$4 / 1.64$

2.44

Waxweiler (1976)

united states 16

1294

$136 / 126$

1.08

$35 / 23.5$

1.49

$7 / 0.6$

11.55

att (1975)

Inited states ${ }^{17}$

594

$89 / 100$

.89

$20 / 17.9$

1. 12

$0 / 0$

1.00

Theriaul: (1981)

Canada $^{18}$

451

$59 / 55$

1.07

$20 / 13.5$

1. 48

$8 / 0.14$

57.14

Wicholson (1984)

United States 19 257

$80 / 85.6$ .93

$28 / 19.7$ 1. 42 $10 / 0.42 \quad 23.80$

*estintated

vC-concentrations that have occurred at the workplace have varied greatly through time. Barnes retrospectively estimated these exposures to have been approximately 1,000 ppm between 1945 and 1955, between 400 and $500 \mathrm{ppm}$, from 1955 to 1965 , between 300 and 400 from 1966 to 1972,150 ppm by 1973 and 5 ppm after $1975^{20}$. Based on these number a time weighted average of 500 ppm for the total exposure period was applied in the risk assessment.

An important aspect of the exposure to VC is the duration of exposure or employment. For the study conducted in the united states the average employment period was 8.7 years ${ }^{13}$. The comittee decided that for the risk assessment for the duration of exposure of all three cohort 8.7 years would be taken. In sumary, epide- 
miologtcal studies of workers occupationally exposed to an verage concentration of 500 ppm at an average duration of 8,7 years indicated that these workers experienced a 13 fold risk of liver cancer as compared to the general population. Total cancer mortaltiy was 1.14 times the cancer mortality in the general population.

\section{Extrapolation to ife-time, continuous exposure}

A number of steps must be taken before the existing risks for workers exposed to $500 \mathrm{ppm}$ VC for a period of 8.7 years can be converted into estimated risks of Iife-time continuous exposure to low concentrations. The first step is to convert: the intermittent exposure accurring for eight hours on a working day to a continuous life-time exposure. A working week usually consists of 40 working hours, whereas a total week consists of 168 hours. Therefore a conversion factor of $168 / 40=4$ must be applied. This means that an exposure encountered only at the workplace corresponds with one fourth of the dose resulting from a continuous exposure of the same concentration.

The second step is the conversion factor for the duration of the time limited wCexposure experienced by the workers to life-time exposure to ambient air concentrations of VC. The workers studied by epidemiological methods were exposed for an average duration of 8.7 years. Given an average lifetime of 70 years, ifetime exposure results in a $70 / 8.7=8$ fold higher dose at equal concentrations. The conversion from $500 \mathrm{ppm}$ during 40 hours per week, for 8.7 years $1500 \times 1 / 4$ $\times 1 / 8 \mathrm{ppm}$ ) leads to a life-time exposure of 15.6 ppm. An estimated SMR of 13.07 will result from life-time exposure to $15.6 \mathrm{ppm}$.

Extrapolation to the $10^{-6}$ risk level.

Extrapolating the effects of high exposures down to low concentrations can only be done if certain assumptions are made regarding the doseresponse relationship. We will assume a linear dose-response relationship. This straight line is defined by 2 points. Having identified two points on the straight line it is possible to express this line by means of the mathematical equation as: $S M R=1+b x c$ (an which $c$ is the life-time exposure concentration) and calculate $b$ :

the model: $S M R=1+b \times c$

if $c=15.6$ and $S M R=13.07$, then

Thus, $b=0.774$. The dose-response relationship is $S M R=1+0.774 \times c$ 
The naxt step $1 \mathrm{~s}$ to express the $10^{-6}$ xisk level in terms of an SMR. The accepted risk is expressed as one additional death by cancer per one milion lives. In the Wetherlands 1,484 per milion deaths die of liver cancer ${ }^{21}$. With one additional case this would be 1,485, giving an SMR of 1,485/1,484=1.00067. BY means of the above equation for the Iinear dose-response relationship the concentration of vc for life-time exposure can be calculated resulting in this SMR of 1.00067: SWR $=1+b \times c \quad c=0.0008$ ppin

Aife-time exposure to a concentration of $0.0008 \mathrm{ppm}=0.002 \mathrm{mg} / \mathrm{m}^{3} \mathrm{vc}$ is expected to lead to an additional $10^{-6}$ risk. However, it can not be excluded that there are othex cancer types related to vc-exposure, or perhaps cancer unrelated to specific sites. In fact four of the seven epidemiological studies presented in Table 1 showed an elevated cancer mortality.

The owerall sMR of the three studies used earlier for cancer mortality is 1.14 for all types of cancer. The Iife-time exposure concentration remains 15.6 ppm.

$\operatorname{SMR}=1+\mathrm{b} \times \mathrm{c}$

if $c=15.6$ and $S M R=1.4$, then

$\mathrm{b}=0.009$ giving SMR $=1+0.009 \times \mathrm{c}$

In the Netherlands about 250,000 per one million deaths are due to cancer ${ }^{14}$. One additional death then will result in an SMR of

250.001

$\frac{250.001}{2.000004}$

250,000

$\mathrm{SMR}=1+0.009 \times \mathrm{C}$

thus, $c=\frac{0.000004}{0.009}=0.00044 \mathrm{ppm}=0.001 \mathrm{mg} / \mathrm{m}^{3} \mathrm{vC}$

It was concluded that a Iife-time exposure to $0.001 \mathrm{mg} / \mathrm{m}^{3} \mathrm{vc}$ results in an additional risk to the general population of 1 death per million lives.

\section{DISCUSSION}

Epidemiological. data have rarely been applied in enviromental risk assessment. Extrapolation on the basis of experimental data as well as epidemiological data both suffer crom a number of short-comings. The main uncertainty of a risk 
assessment based on animal experiments is the extrapolation to man. Differences in body-size, metabol ism, DNA-repair mechanisms and immunological responses can lead to differences in response to exposures to carcinogens between animals and man. As pointed out by many researchers on many occastons the 1 inear, non-threshold aose-response model is Iikely to be an oversimplification of a complex process of carcinogenisis. Howewer, no ideal model, incorporating relevant blological mechanisms is (yet) available, or will be in the near future. Therefore a simple model of a conservative nature was considered to be most appropriate for emirommental carcinogen risk assessment of vc.

The main uncertainty of a risk assessment based on human data is the lack of exact information with respect to the actual past exposures. Application of linear extrapolation to these two different types of data resulted in two aifferemt environmental exposure limits, being $0.00032 \mathrm{mg} / \mathrm{m}^{3} \mathrm{VC}$ based on the experimental data and $0.001 \mathrm{mg} / \mathrm{m}^{3}$ vC based on human data, which only differ by a factor of 3. Because of the existence of extensive human data the committee decided to base its risk assessment on human data. Consecutively the Dutch Government was advised to take $0.001 \mathrm{mg} / \mathrm{m}^{3}$ VC as an exposure corresponding to an additional risk of one death per million life-time exposed individuals as the scientific basis for the development of air quality standards.

\section{REFERENCES}

1. Cook RR. The role of epidemiology in rigk assessment. Drug Metabolism reviews $1982 ; 13,5: 913-923$.

2. Day NE. Epldemiological methods for the assessment of human cancer risk. In: Toxicological rísk assessment, Vol. II, by Clayson pB, Krewsil $D$, Munro $I$. Cre press Boca Raton Florida, 1985.

3. State Institute of Public Health and Enviromental Hyiene. Criteriadocument over Vinul chloride, Lucht, 34. Staatsdrukkerij Den Haag, 1984.

4. Food and Drug Administration Advisory Comittee on Protocols for Safety wa luation. Panel on carcinogenes is report on cancer testing in the safety eva luation of food additives and pesticides. Toxicol, appl. Pharmacol. 1971; 20: $419-438$.

5. Dutch National Health Council (Gezondheidsraad). Advies inzake de beoordeling van carcinogeniteit wan chemische stoffen. No. 1978/19, Rijswijk, 1978.

6. Weber H, Reinl, E Greiser, German investigation on morbidity and mortality 
of workers exposed to vinyl chloride. Enw. Health Persp. 1981; 41: 95-99.

7. Rehring PJ, FG Matanabe, CN Park. Resolution of dose-response toxicity data for chenicals requiring metabolic activation: Example winyl chloride. Toxicol. App1. Pharmacoi, 1978; 4: 581-591.

8. Geling PJ, PG Watanabe, CN Park. Risk of angiosarcama in workers exposed to vinyl chloride as predicted from studies in rats. Toxicol. Appl. Pharmacol. 1979; 49: 15-21.

9. Iwanetich $\mathrm{K}, \mathrm{I}$ Aronson, ID Katz. The interaction of vinyl chioride with rat hepatic microsomal cytochrome p-450 in vitro. Biochem. Biophys. Res. Commun 1977; 74: 1411-1418.

10. Bartschin H, Montesano. Mutagenic and carcinogenic effects of vinyl chloride. Mutat. Mes. 1975:32:93-114.

11. TARC. Monographs on the evaluation of the carcinogenic risk of chemicals to humans 19, $377-348$. Int. Agency for research on Cancer, Lyon, France, 1979.

12. Maltoni C, G Lefemine. A Ciliberti, G Cotti, D Caretti. Carcinogenicity bioassays of vinyl chloride monomer. A model of risk assessment on an experimental basis. Environ. Health Perspec. 1981; 41: 3-29.

13. Feron $V_{J}$, CWM Hendriksen, AJ Speek, HP Til, BJ Spit. Life-span oral toxicity study of vinyl chloride in rats. Food. Cosmet Toxico1. 1981: 19: 317-333.

14. Tabershaw IR, WR Gaffrey WR. Mortality study of workers in the manufacture of vinyl chloride and its polymers. J. Occup. Med. 1974; 16:509-51B.

15. Fox Au, PF Collier. Mortality experience of workers exposed to vinyl chloride monomer in the manufacture of polyvinyl chloride in Great-Britain. Brit. J. Ind. Med. $1977 ; 34: 1-10$.

16. Waxweiler RJ, W stringer, Jk Wagoner, J Joners, H Falk, C Carter. Neoplastic risk among workers exposed to vinyl chloride. Ann. NY ACad. Sci. 1976; 271: $40-48$.

17. Ott $M G_{*}$ RR Langener, BB Holder. Vinyl chloride exposure in a controlled industrial environment. Arch. Environ. Health 1975; 30: 333-339.

18. Ther ialt $G, \mathbb{P} A 1$ ard. Cancer mortality of a group of canadian workers exposed to vinylchloride monomers. J. Occup. med. 1981; 23: 671-676.

19. Nicholson WJ, PK Henneberger. Trends in cancer mortality among workers in the synthetic polymers industry. Prog. Clin. Biol. Res. 1984; 141: 65-78.

20. Barnes Aw. Vinyl chloride and the production of PVC. Proc. R. Soc. Med. 1976; $69: 277-281$.

21. Ces (Centraal Bureau voor de Statistiek). Atlas van de Kankersterfte in Nederland. Statsuitgeverij Den Haag, 1980. 


\section{CARCINOGENIC RISK ASSESSMEMI" OF BEN\&ENE}

IN OUTDOOR AIR

Developed jointly by the Members of the Comittee on the Evaluation of Carcinogenic Substances. Health Council of the Netherlands ${ }^{1}$

1

Committee on the Evaluation of Carcinogenic Substances. G.M.H. Swaen, Department of Occupational Medicine, University of Limburg, PO Box 616, 6200 MD Maastricht, The Netherlands (to whom correspondence should be addressed): A.E.M. de Mollander, Secretary, Health Council of The Netherlands, The Hague; R. Kroes, Chajman of the Committee, National Institute of Public Health and Environmental Hygiene, Bilthoven; L, den Engelse, The Netherlands Cancer Institute, Amsterdani: W.J. Feron, TNo-CIVo, Toxicology and Nutrition Institute, Zeist; G.J. Mulder, Department of Toxicology, University of Leiden, Leiden; A.L.M. Verbeek, Department of Epidemiology, University of Nijmegen, Nijmegen; H.G. Verschuuren, Dow Chemical Europe, Horgen, Switzerland; E. Woge1, Department of Radiation Genetics. University of Leiden, Leiden: A. E, van der wielen. Ministry of Housing, Physical planning and Environment, the Hague.

Published in Regulatory Toxicology and Pharmacology. 
III.3 


\section{ABSTRACE}

Based on a working document reviewing benzene toxicity data prepared by the Wational Institute of Public Health and Environmental Hygiene of The Netherlands a committee of the Health Council of The Netherlands prepared a report regarding a health risk assessment of benzene in ambient air. A short review is presented of the available data on the health effects of benzene. Two risk evaluations based on epidemulological studies of humans exposed to benzene are presiented and incorporated in the overall risk assessment. Together with these evaluations and the fact that there is no strong evidence for the existence of a stochastic working mechanism of action the committee advised to increase the result of the risk assessment presented by the National Institute of Public Health and Environmental Hygiene of The Netherlands by two orders of magnitude.

\section{INTRODUCTION}

As part of a programme instigated by the Dutch government in order to arrive at environmental quality standards for a series of dangerous substances, the National Institute of Public Health and Environmental Hygiene received instructions. to compile, in consultation with other research institutes and with the participation of industry experts, integrated criteria documents on these substances. A comittee of the Health Council of The Wetherlands was appointed to appraise scientifically the integrated criteria documents, in particular the assessment of risks connected with environmental exposure to carcinogens. The present paper deals with the carcinogenic risk assessment of benzene and is based on the initial advice prepared by the committee for the Dutch goverment. Several ribk assessments of benzene have already been made ${ }^{1-3}$.

Benzene $\left(\mathrm{C}_{6} \mathrm{H}_{6}\right)$ has a half-life in air of approximately 5.3 days . Ambient air concentrations show substantial geographical variation. In Dutch urban areas benzene concentrations varying from 2 to $185 \mathrm{\mu g} / \mathrm{m}^{3}$ have been measured ${ }^{3}$. A number of publications report benzene concentrations in the breath of nom-smoking, not occupationally-exposed persons that exceed the outdoor benzene concentration of the environment in which they 1 ive ${ }^{4-6}$. These studies reported mean concentrations between $5-20 \mu \mathrm{g} / \mathrm{m}^{3}$ in the breath of the non-smokers examined; sometimes values of 60 to $200 \mu \mathrm{g} / \mathrm{m}^{3}$ were found. Benzene concentration in the breath of smokers 
was generally gignificantly higher (by "factor of 2 to 3 ) than of non-smokers. The EPA estimated that a $10^{-6}$ Iife time ribk can be expected at life time beraene exposure leveld of $0.147 \mathrm{pg} / \mathrm{m}^{3}$ air. Using a linear non-threshold model on epidemiologic data, white et all estimated that this risk would arise at a benzene concentration of $0.12 \mathrm{jg} / \mathrm{m}^{3}$ air. This latter estimate was agreed upon by the Dutch National Inatitute of Public Health (Rrva) ${ }^{3}$.

Frst the evidence avilable to the comittee indicating the carcinogenic potency of berizene will be presiented. Next several approaches for a guantitative risk assessment will be described. Fully these approaches are combined into a compreherisive line of reasoning.

\section{DNA-interactions and mutagenicity}

When mice and rats were exposed to radioactively labeled benzene, some radioactivity was incorporated into $\mathrm{DNA}^{7-9}$. Since in none of these experiments the chemical nature of this incorporated radioactivity has been adequately investigated, they do not permit the straight-forward conclusion that benzene is capable of direct interaction with the DNA in the cell nucleus.

More recent publications by Rushmore et a $1^{10}$ and Kalf et al ${ }^{11}$ have made the capacity for covalent binding of benzene metabolites to DNA more plausible. However, these investigations concerned DNA of isolated bone marrow mitochondria. The question is to what extent the resules of these in vitro investigations are relevant to in wivo genotoxicity. In the mitochondria, enzymatic activation of benzene through the cytochrome P450-system has been shown to accur. In the rucleus such an activation system probably does not exist. Studies on the influence of benzene on DNA-repair-activity and unscheduled DNA-synthesis in mammalian cell cultures ${ }^{12-15}$ and in bacteria ${ }^{3}$ have not yielded any evidence of interaction with DNA.

Despite extensive research it has not been established that benzene is capable of inducing gene mutations. This conclusion was lso drawn in an international investigation, sponsored by the "International Programme on Chemical Safety" (IPCS), into the value of short-term testing in carcinogenicity prediction rollaborative study on short-Term Tests ${ }^{16}$. As far as gene mutations were concemed, benzene was negative in test systems with bacteria, yeasts, Drosophila and mamalian celis. The few divergent results were produced mainly in tests which did not discriminate between gene mutations and recombinations. The lack of proof for this specific mutagenic activity (induction of gene mutations) could indicate that exposure to benzene either does not produce any DNA modi- 
fication, or only a type of modification that results in chromosome aberrations but not in gene mutations.

\section{Clastogenic effects}

A great number of experiments show that benzene is capable of inducing chromow some aberrations in yeasts, fungi, plants, insects and somatic manmalian cel1s, including human 1 ymphocytes. Chromosome aberrations were found in mamalian cells due to exposure to benzene, both in vitro and in vivo. These concerned chromosome breakage phenomena such as translocations and micronuclei. as well as sister-chromatid exchanges and aneuploidy. The mechanism of the clastogenic effect of benzene has not yet been explained.

The results of some investigations indicate an interaction of benzene metabolites with protein structures of the cell skeleton that play a role in cell division, particularly the microtubules which are important in the arrangement of chromosomes at cell division ${ }^{17-20}$. It is possible that interactions of this type are responsible for the ameuploidy observed in the experiments.

A survey of the available experimental data ${ }^{3}$ shows that no significantly increased incidence of chromosome aberrations was obserwed in in vivo experiments with exposure to ambient benzene concentrations below $32.5 \mathrm{mg} / \mathrm{m}^{3}$. Erexon et a $1^{21}$ found indications of lower tolerance levels in laboratory animals that had been selected for their sensitivity to the induction of clastogenic effects. Rats exposed to $3.2 \mathrm{mg} / \mathrm{m}^{3}$ benzene showed a marginal increase in the incidence of micronuclei in polychromatic erythrocytes and sister-chromatid exchange. Higher dosages $\left(>9.6 \mathrm{mg} / \mathrm{m}^{3}\right.$ ) produced a decrease in mitotic activity.

The results of a number of in vivo experiments indicate that the sensitivity of laboratory animals to the clastogenic ef fects of benzerie on blood cells and bone marrow cells decreases with continuing exposure $22-24$. In a number of experiments the incidence of chromosome aberrations atter repeated or continuous exposure of laboratory animals was not significantly higher than after a single exposure to the same benzene concentration. This suggests that the pattern of exposure (peak concentrations versus continuous low concentrations) is significant; this has also been noted by cronkite et al ${ }^{25}$ with reference to haematotoxic effects.

Epidemiological research among workers inaicated that exposure to comparativeIy high benzene concentrations results in sometimes persistent chromosome aberrations in bone marrow cells or peripheral lymphocytes. The interpretation 
of these data is diffeult because of important shortcomings in the composition of the control groups and because of inadequately registered exposure.

\section{Weoplastic trans formation}

Benzene has been tested for neoplastic transformation in a variety of test systems, but only in experiments with syxian hamster cells it was possible to observe an increase in the incidence of trans formed cell clones ${ }^{26,27}$. A posgible explanation for this observation is a difference in metabolism between embryonal celis compared to that in the non-embryonal cells of the other test systems $^{24}$.

\section{Carcinogenicity in anima1 experiments}

Especially in oral experiments with chronic administration, benzene has proven to be multipotent carcinogen. In particular, a dose related incidence of tumors in zymbal's glands, a comparatively rare organ for tumor formation in laboratory animals, according to a clear dose-response pattern indicates that this is not just a promotion effect.

\section{Carcinogenicity in human populations}

It is generally accepted that exposure of humans to high benzene concentrations entails an increased risk of developing acute non-lymphatic leukaemia. This knowledge is based on case reports and on results of epidemiological wudies of occupationally-exposed populations. What follows is a description of the most relevant studies of the risk of acute non-lymphatic leukaemia (ANL) resulting from exposure to high benzene concentrations (see Table 1 ). 
Table 1: Survey of the results of epidemialogical studies of the incidence of leukaemia in workers exposed to benzene.

\begin{tabular}{|c|c|c|c|c|c|c|}
\hline Author & $\begin{array}{l}\text { Type af } \\
\text { exposure }\end{array}$ & $\begin{array}{l}\text { Mumber } \\
\text { of } \\
\text { people }\end{array}$ & $\begin{array}{l}\text { Highest } \\
\text { exposure }\end{array}$ & $\begin{array}{l}\text { Number of } \\
\text { cases of } \\
\text { leukaemia }\end{array}$ & Type & SMR \\
\hline $\begin{array}{l}\text { Axsoy } \\
1974\end{array}$ & $\begin{array}{l}\text { Turkish } \\
\text { shoe- } \\
\text { makers }\end{array}$ & $*$ & $\begin{array}{l}670-2073 \\
\mathrm{mg} / \mathrm{m}^{3} \\
200 \mathrm{mg} / \mathrm{m}^{3}\end{array}$ & 26 & $\begin{array}{l}\text { acute mon- } \\
\text { Iymphatic }\end{array}$ & 200 \\
\hline $\begin{array}{l}\text { Infante } 29 \\
1977\end{array}$ & $\begin{array}{l}\text { Chemical } \\
\text { plant in } \\
\text { USA }\end{array}$ & 748 & $\begin{array}{l}\mathrm{TWA} \\
\mathrm{mg} / \mathrm{m}^{3}\end{array}$ & 9 & $\begin{array}{l}\text { acute non- } \\
\text { lymphatic } \\
7 / 0.7\end{array}$ & 1000 \\
\hline $\begin{array}{l}\text { att } \\
1978\end{array}$ & $\begin{array}{l}\text { Dow } \\
\text { Chemical }\end{array}$ & 5,94 & $\frac{0}{m^{3}} 300 \mathrm{mg} /$ & 3 & $\begin{array}{l}\text { acute non- } \\
\text { lymphatic } \\
3 / 0.8\end{array}$ & 375 \\
\hline $\begin{array}{l}\text { Thorpe } \\
1974\end{array}$ & $\begin{array}{l}\text { Petro- } \\
\text { chemical } \\
\text { industry }\end{array}$ & 38,000 & low & 18 & negative & 200 \\
\hline $\begin{array}{l}\text { Rinski } \\
1987\end{array}$ & $\begin{array}{l}\text { Chemical } \\
\text { plant }\end{array}$ & 748 & $\mathrm{mg} / \mathrm{m}^{3} 128$ & 8 & $\begin{array}{l}\text { acute non- } \\
\text { lymphatic } \\
8 / 1.71\end{array}$ & 470 \\
\hline $\begin{array}{l}\text { Paganimi } \\
1980\end{array}$ & $\begin{array}{l}\text { Graphic } \\
\text { industry }\end{array}$ & 1,361 & & 7 & $\begin{array}{l}\text { total leu- } \\
\text { kaemia } 7 / 2.8\end{array}$ & 250 \\
\hline $\begin{array}{l}\text { Monson } \\
1978\end{array}$ & $\begin{array}{l}\text { Rubber } \\
\text { industry }\end{array}$ & 13,570 & & 40 & $\begin{array}{l}1 \text { ymphatic } \\
40 / 16.4\end{array}$ & 240 \\
\hline $\begin{array}{l}\text { Yin } \\
1987\end{array}$ & $\begin{array}{l}\text { Various } \\
\text { industries }\end{array}$ & 28,460 & $5 \mathrm{~m}^{3}-500 \mathrm{mg} /$ & 25 & $\begin{array}{l}\text { total leu- } \\
\text { kaemia }\end{array}$ & 574 \\
\hline $\begin{array}{l}\text { Parkes } 36 \\
1982\end{array}$ & $\begin{array}{l}\text { Rubber } \\
\text { industry }\end{array}$ & 33,815 & low & 31 & negative & \\
\hline $\begin{array}{l}\text { Rushton } \\
1900\end{array}$ & $\begin{array}{l}\text { petrow } \\
\text { chemical } \\
\text { indus try }\end{array}$ & 34,781 & low & 30 & negative & \\
\hline
\end{tabular}

* Not known

One of the first indications of an increased risk of developing leukaemia resulting from exposure to benzene came from Turkey. Aksoy reported a rimber of cases of ANL in people employed in the shoe industry ${ }^{38}$. In many patients the illness was preceded by an episode of aplastic anaemia. Similar obserwations were also made in other countries. Exposure to benzene in the Turikish shoe industry must have been wery high, in many cases around $640 \mathrm{mg} / \mathrm{m}^{3}(200$ ppm. Aksoy attempted to quantify the risk more closely. He did so by estima. 
ting the number of expected leukawia cases among the 28,000 workers in the shoe industry. He estimated the expected number at 6 per 100,000 man-years, while actually observing 13 per 100,000 man-yaars. On this basis he concluded that in workers in the Turkish shoe industry leukaemia was 2.2 times more prevalent than in the general population ${ }^{38}$.

other epidemiological studies have been conducted in the chemical industry. The sudy which 18 considered nost relevant is the cohort study among 748 workers in a factory in ohio producing Pliofilm. Infante was the first to examine this group ${ }^{29}$. However, he was unable to establish the vital-status for 25 of the workers at the end of the follow-up period. Binski 32 examined the same 748 workers and was able to establish the vital-status for $98 \%$ of the cohort. Rinski observed cases of leukaemia while expecting 1.71 , which is equal to a standardized mortality ratio (SMR) of 470. All cases involwed concerned acute non-lymphatic leukaemia. Classification according to duration of exposure showed the existence of a dowe-response relation. In the group exposed for longer than 5 years, SMR was 2100 . The benzene exposure of the 748 Pliofilm workers was estimated at a time-weighted average of $128 \mathrm{mg} / \mathrm{m}^{3}$ by white ${ }^{1}$. $o t^{30}$ identified 594 workers at Dow chemical who had all been exposed to benzene in the past. Three workers instead of the expected 0.8 had died of acute non-Iymphatic leukaemia $(S M R=375)$. Time-weighted mean exposure would probably also have been of the order of $128 \mathrm{mg} / \mathrm{m}^{3}$.

In 1980 paganini reported the results of a cohort study among 1,361 workers in the graphic industry. The vital-status of $9 \%$ of the workers could not be established. Instead of the 2.8 expected cases, the researcher abserved 7 cases of leukaemia mortality (SMR $=250$ ). Many of the workers had been exposed for over 20 years.

With the aid of detailed estimates of past exposure levels Rinski et a ${ }^{32}$ found a clear association between cumulative exposure and the incidence of leukania in a group of exposed workers Imainly the above-mentioned pliofilm cohorty. In groups of workers with a cumulatiwe exposure of respectively less than 40 ppm years, 40 to 199 ppm years, 200 to 399 ppm-years and over 400 ppmyears the SMR for leukaemia was $109,322,1186$ and 6637 respectively. The SMR ror the whole cohort was 337, a little lower than had been observed in a previous "update" of a part of the cohort. Besides an increased incidence of leukdemi. Ringki et al found an increase in the number of cases of multiple myem lona, albeit in low numbers $(4$ against 1.0 expected, SMR $=409$ ). Three of the four cases belonged to the group with the lowest cumulative exposure.

In the people"s Republic of China, $Y$ in et al compared the fate of 28.460 workers exposed to benzene in warious industries (concentrations: $50-500 \mathrm{mg} / \mathrm{m}^{3}$ ) 
will that of 28,257 workers without benzene exposure. They found 25 cases of mainly acute non-1ymphatic leukaemia in the first group compared to only four in the last group $(S M R=574)(1987)$.

So far, the results of the epidemiological studies described are roughly compatible. Some deviant findings have also been reported. wonson ${ }^{34}$ followed up 13,570 workers in the American rubber industry. Part of this cohort had been exposed to benzene in the past. There was indeed an excess leukaemia mortality $(40$ cases observed, $S M=240)$, but this concerned mortality due to 1ymphatic leukaemia, while the other studies had only shown an assaciation between mon lymphatic leukaemia and benzene exposure.

In another cohort study, by parkes et al ${ }^{36}$, among 33,815 workers in the Bri- $^{3}$ tish rubber industry no excess leukaemia mortality was observed at all 130 leukaemia cases observed, 32 expected). Thorpe ${ }^{31}$ too found no excess leukaemia mortality among 38,000 workers in the petrochemical industry 118 cases observed, 23 expected). All workers came from production plants. Rushton et a $1^{37}$ examined nortality in 8 British oul refineries of 34,871 workers and they also found no indication of increased leukaemia mortality 131 cases found, 28 expected). No data on the magnitude of past exposures to benzene were available.

Despite this shortcoming the conclusion seems justified that the incidence of leukaemia in workers exposed to low mean concentrations $\left(630 \mathrm{mg} / \mathrm{m}^{3}\right)$ is not different from the incidence in the general population. The statistical power of these studies is too small to be able to say with any certainty that an effect threshold does exist; but the data do not contradict this possibility. Epidemiological data do not leave doubt that high exposures to benzene impose an increase in risk for acute non-lymphatic leukaemia. The results indicate that workers exposed to benzene concentrations of around $128 \mathrm{mg} / \mathrm{m}^{3}$ have experienced ANL leukaemia mortality that may have been five times the background risk $(S M R=500)$. All studies of low benzene exposure have been negative. The committee agreed on the statement that the epidemiological data car not justify any judgement on whether or not there is a threshold level for carcinogenicity. As a consequence of the availability of human data, it was decided to give priority to a risk assessment mainly based on epidemiological evidence of the carcinogenic effects of benzene exposure. 


\section{EISK ASEESSHEWT BASED ON POSTTIVE EETDEMOLOGTCAL STUDIES}

Fron the positive studieg of workers exposed to high benzene concentrations the Connittee concluded that a cen year occupational exposure to $128 \mathrm{mg} / \mathrm{m}^{3}$ benzene increasies the risk of ANL leukaenia by a factor 5. Occupational exposure occurs only duxing 40 hours per week, whereas continuous exposure during 168 hours per week occupational exposure of 10 years approximates a continuous exposure of 2.5 years in dose. Mn average human 1ife will be approximately to 70 years, so that a continuous life-time exposure of $2.5 / 70 \times 128 \mathrm{mg} / \mathrm{m}^{3}=4.57 \mathrm{mg} / \mathrm{m}^{3}$ is considered to be comparable in total dose to the occupational expasure leading to a fivefold increase of ANL leukaemia mortality.

A linear dosewesponse model can be expressed as:

SMR $=100 * \mathrm{~b}$.

where the SMR is the standardized mortality ratio, b indicates the steepmess of the slope and $x$ is the life-time benzene concentration.

By application of the results of the occupational cohort studies to the linear mode 1 , b can be calculated as follows:

$$
\begin{aligned}
& 500=100+b \times 4.57 \\
& 400 / 4.57=b \rightarrow=87.5
\end{aligned}
$$

Mortality due to acute non-lymphatic leukaemia (ANM) in the vetherlands in the period from 1969 to 1978 was 1.6 per 100,000 men and 1.3 per 100,000 women, standardized according to age steucture. Total mortality was 923.2 per 100,000 men and 731.5 per 100,000 women, standardized according to age structure. This corresponds to a figure of 1.755 deaths due to ANL per million deaths in The Netherlands. Taking a $1 \times 10^{-6}$ infe-time risk as accepted in the Netherlands, the $S M R$ should not exceed $1,756 / 1,755 \times 100=100.057$.

Application of the linear model to these number yields the concentration corresponding to an additional risk of $10^{-6}$ at 1 ife-long exposure:

$$
\begin{aligned}
& 100.057=100+87.5 \times x \\
& x=0.057 / 87.5=0.00065 \mathrm{mg} / \mathrm{m}^{3}=0.65 \mu \mathrm{g} / \mathrm{m}^{3}
\end{aligned}
$$


The three negative studies by Thorpe ${ }^{31}$, parkes $^{36}$ and Rushton ${ }^{37}$ can also serve as basis for risk assessment. These three studies combined investigated the morta1ity in a group of about 90,000 workers. Since no data on actual benzene concentrations are available, the comittee made an estimate of the average concentrations. It was decided to take an average concentration of $16 \mathrm{mg} / \mathrm{m}^{3} \quad(=5 \mathrm{ppm})$ during ten years of work as a realistic reflection of the experienced benzene exposure. In the three negative studies fewer leukaemia deaths were observed than expected, suggesting a protective effect of benzene. However, such an effect is unlikely and the comittee regarded the leukaemia defecit to be attributable to random variation. Hence a SMR of 100 was taken as the most reasonable sHk for the three negative studies combined. A two sided $95 \%$ confidence interval implicates that the section of the interval smalier than SMR = 100 has some biological meaning. This was not the apinion of the committee, but the procedure was preferred because it is generally accepted in occupational cohort studies. The $95 \%$ confi-

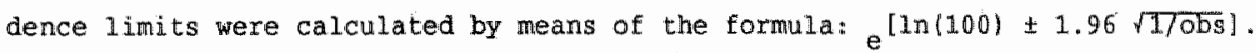
This gave a value of 1.23 for the upper limit $($ SMR $=123)$, meaning that there is only a chance of 2.5 that the actual SMR is higher than 123 .

The conversion of a ten year occupational exposure of $16 \mathrm{mg} / \mathrm{m}^{3}$ to continuous Iife-time exposure leads to a continuous life-time exposure of $16 / 4 \times 10 / 70=$ $0.57 \mathrm{mg} / \mathrm{m}^{3}$. On these figure the linear extrapolation model can be applied, taking $1 \times 10^{-6}$ as an accepted risk (SMR $\left.=100.057\right)$ :

$$
\begin{aligned}
\text { SMR } & =100+b \times \\
123 & =100+b \times 0.57 \mathrm{mg} / \mathrm{m}^{3} \\
b & =23 / 0.57=40.35
\end{aligned}
$$

An SMR of 100.057 is accepted:

$$
\begin{aligned}
100.057 & =100+40.35 \times \mathrm{x} \\
\mathrm{x} & =0.057 / 40.35=1.4 \mathrm{Hg} / \mathrm{m}^{3}
\end{aligned}
$$

On the basis of the highest risk which might hawe exighed given the negative results of the studies, assuming a 95 confidence interval, one can calculate that ife-long exposure to a mean airborne benzene concentration of $1.4 \mathrm{\mu g} / \mathrm{m}^{3}$ means a maximum risk of one additional death due to acute non-lymphatic leukamia per one million deaths. 
A limitation of this rigk assessment based on megative studies, is, that the confidence limits are greatly influenced by the size of the conducted cohort studies. The comittee decided to regard this assessment merely as an indication of the highest $r$ isk to be expected at low exposure levels, perhaps leading to an overestimation of the risk by a factor 10 .

\section{CONCLUSIONS}

In respect of the carcinogenic risk assessment of benzene, several conclusions were drawn. In spite of intensive research, it has not been shown that benzene is capable of inducing gene mutations. Benzene is a genotoxic substance, because great number of experiments have shown that benzene may cause different types of structural chromosome aberrations in yeasts, fungi, plants, insects and mammalian cells, including human lymphocytes. In in vivo experiments too, increased numbers of chromosome aberrations were found as a result of benzene exposure. Epidemiological studies of exposed workers have provided indications that benzene may cause an increase in the number of chromosome aberrations in humans as well (in peripheral 1 ymphocytes . Results of in vivo experiments with laboratory animals to investigate the potential of benzene to interact with chromosomal DNA are not stralght forward as to DNA-binding. As far as covalent binding occurs " it will be small in quantitative terms. The results of a number of animal experiments show that chronic administration of benzene may cause different types of tumours. Epidemiological research anong workers has irrefutably shown that exposure to comparatively high benzene concentrations $\left(>100 \mathrm{mg} / \mathrm{m}^{3}\right)$ results in an increased risk of acute non-lymphatic leukaemia. Accordingly, benzene should be viewed as a human carcinogen at high exposure levels.

The possibility cannot be excluded that the incidence of leukaemia resulting from exposure to benzene is due to an irreversible interaction with DNA, despite the fact that in the test systems applied to date, benzene has not been found capable of inducing gene mutations. The committee is of the opinion that benzene carcinogenesis should in principle be viewed as a stochastic process. A stochastic mechanism of action would imply that it is impossible to indicate a level of exposure at which there is absolutely no additional leukaemia risk. The committee therefore approves of the application of the linear "non-threshola"-model for risk extrapolation. Howewer, the committee is of the opinion that extrapolation of the available epidemiological data according to this conservative model leads 
to a considerable over-estimation of the actual risk. The considerations of the committee regard:

- In spite of considerable research effort there is still no proof of bentene" is capacity to directly interact ith chromosomal DNA. It is precisely this specific mutagenic activity that is viewed as strong evidence for a stochastic mechanism of action. The linear non-threshold model is based on this concept.

- The results of epidemiological research involving groups of workers exposed to comparitively low concentrations of benzene do not indicate an increased leukaemia risk;

- The toxic effects of benzene on haematology and haemopoietic tissues probably contribute to the development of leukaemia to the manifestation of alreadypresent oncogenic factors). Results of both animal experiments and epidemiological studies of occupational exposed workers indicate a connection between the incidence of blood anomalies such as cytopaenia and a plastic anaemia on the one hand, and the appaerance of leuaemia at a later stage on the other ${ }^{3}$. At exposure levels which preclude any cytotoxic effects it is to be expected that the chance of leukaemia developing will have decreased more than proportional1y. In the exposure range of the general population, far below haemotoxic levels, DWS-interactions can not be excluded. However, the toxic component in the proces of carcinogenesis is not present the hamatopoietic tissue is not in a "susceptible" statel.

The committee concluded that a worst case approach was taken by the risk assessment proposed in the Integrated Criteria Document, which was mainly based on the risk assessment conaucted by white ${ }^{\mathbb{1}}$. In view of the scientific information available, the comittee feels it is justifiable to arbitrarily increase the result of the linear extrapolation chosen in the criteria document by two orders of malnitude ${ }^{3}$. Thus the committee is of the opinion that at chronic exposure to mean ambient air concentrations of benzene below $12 \mu \mathrm{g} / \mathrm{m}^{3}$, the risk defined as one additional case of leukaemia in one million life-time exposed persons probably il not be exceeded.

\section{REFERENCES}

1. White MC, MS Cohen, Porter. Benzene risk assessment. Us Consuner Product Safety Comission, US Government, 1981. 
2. Environmental protection Agency. Federal rules and regulations. Mational enission standards for hazardous air pollutants. Regulation of benzene 1984 Vol. 9, no. 10 .

3. Rijksnstiut voor Volksgezondhedd en Milieuhygiene (National Institute of public Hedth and Environental Hygiene). ontwerp Basis-Dokument Benzeen, kapport no. B40760002, Bilthoven, 1986.

4. Fibhbin L. An overview of enviromental and toxicological aspects of aromatie hydrocarbons. I Benzere. Sc. Tot. Environ. 1984; $40: 189-218$.

5. Wallace LA, ED Pe11izari, TD Hartwe11, CM Sparacino, LS Sheldon, Felon. Personal exposures , indoor - outdoor relationships, and breath levels of coxic air polytarts measured for 355 persons in New Jersey. Atmos. Environ. 1985: 19: $1651-1667$.

6. Wester RC, HI Mibach, LD Gruenke, JC Graig. Benzene levels in ambient air and breath of stnokers and mon-smokers in urban and pristine enviromments. J. Toxicol. Envilion. Health 1986; 18: 567-573.

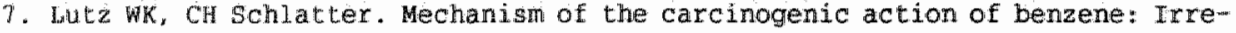
versible binding to rat liver DNA. Chem. Biol. Interact. 1977; 18: 241-245.

9. Gill DP', AF Ahmed. Covalent binding of carbon 14-labelled benzene to cellulat organelles and marrow nucleic acids. Biochem. Pharmacol. 1981; 30: 11271132 .

9. Arfellini G, S Grilli, A Collacci, M Mazzullo, G Prodi, In vivo and in vitro binding of benzene to nucleic acids and proteins of various rat and mouse organs. Cancer Letters 1985; 28: 159-168.

1.0. Rushmore TH, Snyder, GF Kalt. Covalent binding of benzene and its metabolites to DMA in rabbit bone marrow mitochondria in vitro. Chem. Biol. Interact. $1984: 49: 133-154$.

11. Kalf GF, R Snyder, TH Rushmore. Inhibition of DNA synthesis by benzene metabolites and their covalent binding to DNA in Rabbit Bone marrow mitochondria in vitro. Am. I. Ind. Wed. 1985; 7: 485-492.

12. Drobst Gg, RE HCMahon, Lf Hol1, CZ Thompson, JK Epp, SB Neal, Chemicallyinduced DNA synthesis in primary rat hepatocyte cultures: A comparison with bacterial mutagenicity using 218 compounds. Environ. Mutagen. 1981; 3: 1132.

13. Williams GM, C Tong, CV Brat. Tests with the rat hepatocyte primary culture/DHA repair test. In: Ashby $J$, serres de Fu, Draper M, Inshidme M, Wargolin BH, Mater BE, Shelby MD (eds). Evaluation of short-Term Tests for Carcinogens" Report of the International Programe on Chemical safety Collaborative Study on in vitro Assays. Elsevier Ansterdam 1985: $341-345$. 
14. Wartin $\mathrm{CN}$, J Campbell J. Tests for the unduction of unscheduled DNA synthesis in Hela cells. In. Ashby J, Serres de Fu, Draper , Inshidate H, Margolin BH; Matter BE. Sheiby MD (eds). Evaluation of short-Term rests tor carcinogens: Report of the International programme on Chemical safety collaborative study on in vitro Assays. Elsevier Amsterdam 1985: 375-379.

15. Barret RH. Assays for unscheduled ONA synthesis in Hela 53 cells. In: Ashby J. Serres de FJ, Draper $M$, Inshidate $M_{r}$ Margolin BH, Matter BE; Shelby MD (eds). Evaluation of Short-Term Tests for Carcinogens: Report of the Interna tional Programe on Chemical Safety Collaboratiwe study on in vitro Assays.. Elsevier Amsterdian 1985: 347-352.

16. Ashby J, FJ de Serres, M Draper, M Ishidate Jr, BH Margolin, BE Matter, WD Shelby. Evaluation of Short-Term Tests for Carcinogens: Report on the International Program on Chemical Safety Collaborative study on in vitro Assays. Elsevier Amsterdam, 1985.

17. Raalte van HCS, P Grasso. Hematological, myelotoxic, clastogenic, carcinogenic and leukemogenic effects of benzene. Regulat. Toxicol. pharmacol. 1982; 2: $153-176$.

18. Irons RD, DA Neptun. Effects of principal hydroxy - metabolites of benzente on microtubule polymerizatian. Arch. Toxicol. 1980; 42: 297-305.

19. Irons $\mathrm{RD}_{y} \mathrm{DA}$ Neptun, $\mathrm{RW}$ Pfeifer. Inhibition of Iymphocyte transformation and microtubule assembiy by quinone metabolites or benzene: Evidence for a comon mechanism. J. Reticuloendothel. Soc. 1982: 359-372.

20. Pfeifer RW, RD Irons. Inhibition of lectin-stimulated Iumphocyte agglutination and mitogenesis by hydroquinone: Reactivity with intra cellular sulfhydryl groups. Exp. Mo1. Pathol. 1981: 35: 189-198.

21. Brexson $\mathrm{GL}$, JL Wilmer, WH steinhagen, $\mathrm{AD}$ Kligerman. Induction of cytogenic damage in rodents after short-term inhalation of benzene. Environ. Mutagen. $1986 ; 8: 29-40$.

22. Tice $\mathbb{R R}$, MJ Sawey, RT Drew, EP Cronkite. Benzene - induced micronuclei in the peripheral blood of mice; A retrospective analysis. Enwiron. Mulagen. 1984; 6: 421 .

23. NTP Technical Report (289) on the toxicalogy and carcinogenesis studies of benzene in F244/N rats and B6C3FI mice (gawage studies). MIH Publication no. 84-2545. Department of Health and Human Servicesi 1985 .

24. Dean BJ. Recent findings on the genetic toxicology of benzene, toluene, xylenes and phenols. Mutat, Res. 1985; 154: 153-181.

25. Cronkite EP, RT Drew, T Inoue. JE Bullis.. Benzene hematotoxicity and Ieukemogenesis. Am. J. Ind. Med. 1985; 7: 447-456. 
26. Wmacher DE, I zelljadt. whe morphologica1 transformation of syrian hamster embryo cell by chemicals reported non-mutagenic to salmonella typhimurium. Carcinogeneds 1983; 4; 291-295.

27. McGregor D, I Ashby. Summary report on the performance of the cell transformation assys. In: Ashby * Serres de FJ, Draper M, Inshidate M, Margolin BH, Matter $\mathbb{B}_{\mathrm{L}}$, She by $\mathrm{WD}$ leds.). Evaluation of short-Tern Tests for Carcinogens: Report of the Internatonal Programe on chemical safety collaborative study on in vitro Hs says. Elsevier Amsterdam 1985; 103-115.

28. Aksoy $M, K$ Dincol, $S$ Exden, $G$ Dincol. Acute leukemia due to chronic exposure to benzene. Hrm. J. Med. 1972; $52: 160-166$.

29. Infante PF, JK Wagoner, RA Rinski, $\mathrm{R}$ Young. Leukemia in benzene workers. Lancet $1977: 76-78$.

30. Ott MG, JC Townend, WA Wiseck, RA Langner. Mortality among individuals occupatiorally exposed to benzene. Arch. Environ. Health 1978; 33:3-10.

31. Thorpe JJ. Epidemological survey of leukemia in persons potentially exposed to benzene: J. Occup. Med. 1974; $16: 375-382$.

12. Rinsky RA, AD Smith, R Hornung, T'G Filloon, RJ Young, AH Okun, PJ Ladrigan. Benzene and leukemia. M. Engl. J. Med. 1987; 316: 1044-1050.

33. Paganini-Hi11 A, E GJazer, BE Henderson. Cause-specific mortality among newspaper web press men. J. Occup. Med. 1980; 22: 542-544.

34. Monson RR, JL Fing. Cancer mortality and morbidity among rubber workers. J. Nat. Cancer Inst. 1978; 61: 1947-1953.

35. Yin SN, GL Li, FD Tain, ZI Fu, C Jin, YJ Chen, SJ Luo, PZ Ye, JZ zhang, GC Wang, XC zhang, HN Wu, QC zhong. Leukemia in benzene workers: a retrospective cohort study. Brit. J. Ind. Med, 1987; 44: 124-128.

36. Parkes HG, CA Weys, JAH waterhouse, A peters. Cancer mortality in the British rubber industry. Brit. I. Ind. Med. 1982; 39: 209-220.

37. Rushton L, Alderson. The influence of occupation on health. Some results from a scudy in the UK ofl industry. Carcinogenesis 1980; 1: 739-743.

38. Aksoy M. Benzene and leukemia, Lancet 1978: 441 . 
Gerard M.H. Swaen ${ }^{1}$

Jan M.M. Meijers ${ }^{1}$

1 Dpt. of occupational Medicine, University of Limburg. The Netherlands

Accepted for publication in British Journal of Industrial Medicine. 


\section{ABSTRACT}

Experimental toxicological studies have offered clear evidence that bentene induces neoplasms, and it is generally accepted that exposure to benzene is a risk factor for leukemia and in particular for acute non-lymphatic leukemi " However quantitative aspects of benzene risk assessment are still a mater of controversy. In several risk assessments an estimated 50 leukemia deaths per 1,000 deaths would arise from benzene exposures of $10 \mathrm{ppm}$ during a working life of 30 years. The assessment presented in this paper leads to lower estimates, which are more in agreement with the weak toxicological data. Eurthermore an approach is presented to incorporate the results of low exposure epidemiologic studies into the process of quantitative risk assessment.

\section{ABBREVIATIONS}

ppm, parts per million

TLV, threshold limit value

SMR, standardized mortality ratio

\section{INTRODUCTION}

In the past decades a substantial body of knowledge has accumulated regarding long term health effects of occupational exposure to benzene. Beside experimental data, this body consists of epidemiologic data from mainly retrospective cohort studies of workers occupationally exposed to benzene. Except for the ability of benzene to cause non malignant blood anomalies, the main chronic health effect of concern is the increased mortadity due to leukemia and in parti-m cular acute non-Iymphatic leukemia, of which several investigators have stated that this is the only increased risk after exposure to benzene. However, other investigators have pointed out that benzene induces a variety of malignant neoplasms, including Iymphatic leukemia and 1 ymphomas ${ }^{1,2,3}$. The relationship between exposure to high concentrations of benzene and the risk of leukemia is well docu- 
mented and generally accepted. Case reports and epldemiologic confirmations have 1ed to regutatory legislation throughout the world, as well in the field of accupational exposures. as exposures experienced by the general population ${ }^{40}$. Several risk assesments hawe been conducted for accupational exposures $11-15$. In a recent revied a $r$ ask asesment was presented based on the results of a retrospect ive cohort study of 1,006 exposed workers, applying a linear dose-response relationsipis

rollowng a request from the minitter of Welfare, Public Health and culture, a cominttee of the Halth Council of The Netherlands has drawn up a somewhat different rigk assessment for the risk of leukemia after exposure to benzene in amblent ar. It is the purpose of this article to apply this risk assessment to occupational exposures to benzene.

Seweral weaknesses of epidemiologic data can be identified that may form a source of controversy. The first weakness is the lack of accurate and reliable data regarding the exposure levels that existed in the past and have been experienced by the studied cohorts. "This is not a particular problem in the course of a qualitative risk assessment, in other words to assess if exposure to high concentrationis of a certain chemical is a risk factor for a particular neoplasm. However in the course of a quantitative risk assessment the estimation of past exposure will hawe substantjal impact on the outcome of the assessment. A second weakness of epidemiologic data is the lack of information regarding the mechanisms leading to the increased risks as observed in epidemiologic studies. Insight in the mechanism that is at work, is of great importance in the determination of the extrapolation model to be applied to assess the risks related to low exposure levels. The choice of extrapolation model may also have a great impact on the outcome of the risk assessment. A major issue is whether or not the chemical should be considered to be genotoxic or not. In case of a non-genotoxic agent it is custom to take a no-effect level approach and apply a satety factor to be on the afe 3 ide. In case of a genotoxic agent a non-threshold approach is generally applied, because it can be argued that even a small dose can evoke a carcinogenic effect. The non-threshold approach does not imply that the extrapolation model is linear or logistic. After a brief overview of experimental toxicologic data of the carcinogenic potency of benzene. several remarks will be made regarding the available epidemiologic data. Then the risk assessment proposed by the Health Council of the Netherlands will be described. 
Radioactively labeled benzene has been reported to be incorporated inco nucleic acids in liver, spleen, bone marrow and kidney cell of mice and rats ${ }^{16-18}$. Several recent publications have made covalent binding of benzene metabolites to DNA even more plausible ${ }^{19,20}$. However, these investigations were conducted by neans of isolated bone marrow mitochondria and their relevance for in vivo genotoxicjty is at least questionable. Inwestigations of effects of benzene on DNA-repair and the occurrence of unscheduled DNA-synthesis in mamalian cell cultures 21,22 and in bacteria ${ }^{23}$ have sofar not yielded any evidence of DNA interaction. In spite of extensive efforts there are no indications that benzene is capable of inducing gene mutations in bacteria, yeasts drosophila and mantialian cells ${ }^{24}$, if tests not capable of discriminating between gene mutations and reconbinations are excluded. benzene has been shown to be capable of inducing chromosome aberations in yeast. fungi, insects and somatic mamalian cells, including human lymphocytes. chromo some breakage phenomena such as translocations have been found both in vitro and in vivo in marmalian cells. These chromosome aberations were observed after benzene concentrations even lower than $10 \mathrm{ppm}$. Several in vivo experiments inaicate that the sensitivity of laboratory animals to clastogenic effects decreases with containing exposure 25,26 . Benzene has been tested for neoplastic transformation in a variety of test systems. However only in Syrian hamster cells an increase in the incidence of transformed cell. clones was observed 27,26 . Benzene has also been demonstrated to be capable of increasing the occurrence of tumors in zym bal's gland, a comparatively rare organ for tumor formation in laboratory animals 29 . On the basis of the multiple site carcinogenicity in animals, benzene can be considered as a potent carcinogen in animals and the carcinogenic process should in principle be viewed as a stochastic process.

\section{EPIDEMIOLOGIC DATA}

After case reports were published indicating a possible relationship between benzene exposure and the occurence of leukemia, many pidemiologic studies in this field were initiated. An extensive review of these studies has recent ly been published ${ }^{15}$. The findings of these studies leave no doubt that workers exposed in the past to high concentrations of benzene have experienced an increased morta- 
Iity fron leukenia. Both case-control studies and retrospective cohort studies have contirned this relationship. Howewer, several studies in low exposure groups have reported contradictory results. For instance in a retrospective cohort study of about 13,500 workers in the rubber industry an excess mortality risk for 1ymphatic leukemia observed ${ }^{9}$ and not for nonm 1 mohatic leukemia as has been reported by other epidemiologists. In several ather large studies of workers exposed to low concentrations of benzene no indications were found that these cohorts had experienced increased mortality rates for leukemia. In a study of 38,000 workexs employed in the petrochemical industry 18 cases of leukemia were observed compared to an expected number of $23^{30}$. In a study of similar size 134,781 warkers) that involved workers in the oil industry 30 deaths from leukema were observed, compared to an expected number of $32^{31}$. However in this study a doseresponse relationship appeared to exist, which was demonstrated by means of a nested case-control study design ${ }^{32}$. Again this case-control study confirmed the existence of a leukeria risk after exposure to high concentrations of benzene. A third study of benzene exposed workers that should also be regarded as negative is the study conducted by Parkes, in the British rubber industry ${ }^{33}$. In this study of 33,815 workers 31 leukemia cases were abserved as compared to an expected number of 28.

As has been pointed out by Hernberg, the interpretation of negative results of epidemiologic studies is a complicated matter ${ }^{34}$. In case of a negative outcome, ic is not always clear whether the negative finding is an effect of methodologic deficiencies or if there actually is no increased $x$ isk present in the cohort and exposure level under investigation.

The greatest weaknesses of the three large studies of low expsoures are the lack of quantitative exposure data and the possibility that a proportion of the "exposed cohort" has not at all been exposed to benzene. Despite these weaknesses the committee of the Health Council of The Netherlands decided not to disregard these flindings in establishing a rigk assessment. Thus the comittee was left with the task of incorporating positive results of high exposure studies and negative results of. low exposure studies in a risk assessment, low exposures being defined as lower than a time weighted average exposure of 10 ppm which is the current Thy walue in many countries. This contradictory conception has also been supported by Ecerac ${ }^{35}$. As a consequence it was decided not to estimate an overal relative isk for leukemia after exposure to benzene, as has been done in the evaluation of Vinyl chloride ${ }^{36}$. Two separate risk assessments were made, both based on the findings of epidemiologic studies. The first departed from the fincings in high exposure studies, the second from the findings in low exposure studies. Although the risk assessment conducted by the committee was intended for risks 
experienced by the gemeral population, it can al so be applied to the occupational enviromment.

\section{Risk assessment based on studies of highly exposed workers}

Prior to embarking upon a risk assessment several assumptions must be made. The first deals with the magnitude of risk after a particular exposure dose. The second is concerned about the extrapolation model. The first assumption can be derived from several cohort studies. A reasonable estimate of this risk, based on Kinsky"s risk assessment, is that workers on the average exposed to 40 ppn over a period of 10 years have experienced five-fold increase ith the risk of dying from acute non-1ymphatic leukemia $(S M R=500)^{13}$. Assuming a stochastic working mechanism. If a doubling of the dose also implies a doubling of the risk, a linear extrapolation model is suitable. Such a model can be formulated as:

$$
\text { SMR }=100+b \times d
$$

where SMR is the standardized mortality ratio (observed/expected $x$ 1001, $b$ is the tangent of the angle between the straight line and the horizontal axis (dose) and dis the benzene dose in ppm-years. By means of this model it can be calculated how many additional leukemia deaths per 1,000 deaths may arise from benzene dose of 300 ppm-years, as done by Austin et a.1 15 :

$$
500=100+b \times 400 \rightarrow b=1
$$

if $\mathrm{d}=300$ ppm-years then SMR $=100+1 \times 300=400$

Thus workers having received a total benzene dose of 300 ppm-years may experience a SMR of 400 .

In a western country such as The Netherlands, the age adjusted mortality rate for acute non-1ymphatic leukemia in males is 1.6 per $100,000^{37}$ and the total. morta1ity rate is 923.2 per 100,000 . This implies that approximately 1.7 deaths per 1.000 deaths is due to acute non-1ymphatic leukemia. In a population in which an SMR of 400 exists, $4 \times 1.7=6.7$ deaths due to acute non-lymphatic levkemia may occur per 1,000 deaths, which is an excess of approximately 5 deaths. This estimate is quite different from that proposed by Austin " "wich is in the range of about 50 excess deaths per 1,000 deaths. 


\section{Risy assment based on the results of low exposure studies}

There are three large epidemiologic studies of workers mainly exposed to low concentrations of benzene $30,31,33$. Thorpe conducted an epidemiologic study of 38,000 workexs of petroleum refineries ${ }^{30}$. Al though this study has several methodological weaknesges, the study could have detected a risk if there was one. Fushton and Adderson ${ }^{31}$ studied the mortality patterns of 35,000 male employees with a minimum of 1 year continuous service in the U.K. Oil Industry. There was no excess of leukemia. A third large study of workers potentially exposed to benzene focussed on the rubber industry. Parkes ${ }^{33}$ followed-up 34,000 British rubber workers for whom no increased risks could be detected. In these three studies combined a total number of $18+30+31=19$ leukemia deaths were observed. A 95\% two-sided conficence interval can be calculated around this combined finding, which is:

$$
\ln (\text { SMR }) \pm 1.96 \sqrt{1 / 0 \mathrm{DS}}]=(4.605 \pm 0.1125)=89-112
$$

This upper limit can serwe as a point of departure for the risk assessment. Again no accurate data on past benzene exposures is available. Since 10 ppr has been the threshold limit value in the early seventies, it may be reasonable to employ $5 \mathrm{ppm}$ during a period of ten years as estimate of the exposure. Subseguentiy it is possible to calculate $b$ in the linear model,

$$
\begin{aligned}
\text { SMR } & =100+b \times a \\
112 & =100+b \times 50 \\
b & =12 / 50=0.24
\end{aligned}
$$

which can be used to calculate the SMR given a total dose of 300 ppm-years.

$$
\begin{aligned}
& S M R=100+0.24 \times 300 \\
& S M R=172
\end{aligned}
$$

Since the confidence limits were based an total leukemia mortality, it seems appropriate to make an extrapolation for total leukemia mortality even though it is likely that the risk is restricted to acute non-lymphatic leukemia. The age adjusted death rate for total leukemia among males in the Netherlands is 7.6 per 100,000. The total mortality rate is 923.2 per 100,000 , which implies that 8.2 deaths per $\mathbb{1}$, 000 deaths will be due to leukemia, if no exposure to benzene occurs. Thus in a group of workers experiencing a dose of 300 ppm-years of benzene. associated with an estimated SMR of 172 , consequent1y $8.2 \times 1.72=15$ deaths of 
leukemia may occur, of which 8.2 are attributable to the "natural" backgrownd incidence of leukemia.

In analogy a risk assessment can be made Iimiting the potental risk to acute nom-Iymphatic leukemia. This perspective probably is more realistic given the observations cited earlier in this article.

In The Netherlands the annual age adjusted mortality rate form acute mon-1ymphatic leukemia is 1.6 per 100,000 males. For total leukemia this rate is 7.6 per 100,000 males, which implies that approximately 21 percent of leukemia deaths occurring in males is of the acute non-lymphatic type. Thus generalizing this figure to the three low exposure studies, an estimated 17 (21 percent) of the 79 leukemia deaths observed in these studies may have been of the acute non-iymphatic type giving a two-sided 956 confidence interwal of $62-161$ for the sMr. This upper limit may again serve as the SMR resulting from a benzene dose of 50 ppmyears, Next $b$ can be calculated:

$$
\begin{aligned}
\text { SMR } & =100+b \times d \\
161 & =100+b \times 50 \\
b & =61 / 50=1.22
\end{aligned}
$$

If a dose of 300 ppm-years is experienced, an SMR for acute non-lymphatic levkemia can be estimated by means of the linear madel as follows:

$$
S M R=100+1.22 \times 300=466
$$

This implies that instead of the 1.7 acute non-lymphatic leukemia deaths an estimated 8 deaths may occur per 1,000 deaths, of which 1.7 are attributable to the "natural" background incidence of acute non-lymphatic leukemia.

\section{DISCUSSTON}

There is no doubt that relatively long exposure to high concentrations of benzene increases the risk of dying from acute non-lymphatio leukemia. This observation has frequently been confirmed in epidemiologic studies. However, in studies of workers exposed to low concentrations this relationship has been absent or was confined to those workers who had been exposed to high concentrations in the past. It did not seem justified to disregard these negative fundings in $r$ isk 
assegsments as being merely an effect of methodologic shortcomings in these studies. Several risk asessments have been conducted, giving isks in the range of 50 axcess leukemia deaths per 1,000 deaths among workers exposed to 300 ppomyears of benzene. The risk assesment presented in this article clearly ieads to lower results than for instance the one prepared by Austin et al ${ }^{15}$. Both assessmerts are based on several assumptions which are very difficult if not impossible to verifY. Thus it remins of great importance to conduct updates of cohorts a.1ready identified as hawing been exposed to benzene. Although it is to the policy makers to decide whether or not to alter the current occupational standard, perhaps a guideline can be given to what level of risk will be regarded as acceptable in an occupational setting. This is more a matter of ethical nature than a scientific one. Nevertheless it should be considered that benzene is not the only chemical to which workers can be exposed, and that the inter individual susceptibility for the hematopoietic effects of benzene can differ widely. Perhaps one additional death per 1,000 deaths after a working life of exposure can serve as a guideline.

\section{REFERENCES}

1. Maltoni C. B Conti, G Cotti. Benzene: A multi-potential carcinogen. Results of long-term bioassays performed at the Bologna Institute of Oncology. Am. J. Ind. Med. 1983; 4: 589-630.

2. Cronkite EP, aE Bullis, T Inove, RT Drew. Benzene inhalation produces leukemia in mice. Toxicol. Appl. Pharmacol. 1984; 75: 358-361.

3. Maltoni C, C Scarnato. First experimental demonstation of the carcinogenic effect. of benzene: long-term bioassays on spraque-Dawley rats by oral administration. Med. Lav. 1979; 70: 353-357.

4. Aksoy M, K Dincol, $S$ Erdem, G Dincol. Acute leukemia due to chronic exposure to benzene. Am. J. Med. 1972; 52:160-166.

5. Infante $\mathrm{PF}_{\text {, JK }}$ Wagoner, RA Rinski, $\mathbb{R}$ Young. Leukemia in benzene workers. Lancet 1977: $76-78$.

6. Dtt MG, JC Townsend, WA Fisbeck, RA Langner. Mortality among individuals occupationally exposed to benzene. Arch. Environ. Health 1978; 33: 3-10.

7. Ringky RA, AB Smith, R Hornung, TG Filloon, RJ Young, AH Okun, PJ Ladrigan. Benzene and leukemia. N. Engl. J. Med. 1987; 316: 1044-1050. 
8. Paganini-Hill A, E Glazer, BE Henderson. Cause-specific mortality among newspaper web press men. J. Occup. Med. $1980 ; 22: 542-544$.

9. Monson RR, JL Fing. Cancer mortality and morbidity among rubber workers. J. Nat. Cancer Inst. 1978; 61: 1947-1953.

10. YIn SN, GL Li, FD Tain, ZI Fu, $C$ Jin, YJ Chen, SJ Luo, pz Ye, JZ Zhang, GC Wang, XC Zhang, HN Wu, QC Zhong. Leukenia in benzene workers: a retrospective cohort study. Brit. J. Ind. Med. 1987; 44:124-128.

11. White AC, PF Infante, KC Chu. A quantitative estimate of leukemia mortality associated with occupational exposure to benzene. Risk Analysis 1982; 2 : $195-204$.

12. Albert RE. Carcinogen" assessment group's final report on population risk to ambient benzene exposures. Research Triangle Park NC (EPA 450/5-80-004.), 1979 .

13. Rinsky RA, AB Smith, R Hornung et al. Benzene and leukemia: an epidemiologic risk assessment. N. Engl. J. Med. 1987; 316: 1044-1050.

14. Crump KS, BC Allen. Quantitative estimates of risk of leukemia from occupational exposure to benzene. OSHA, 1984.

15. Austin H, E Dellze11, P Cole. Benzene and leukemia: A review of the literaim ture and a risk assessment. Am. J. Epidemiol. 1988; 127: 419-439.

16. Lutz $W, \mathrm{CH}$ Schlatter. Mechanism of the carcinogenic action of benzene: Irre* versible binding to rat Iiver DWA. Chem. Biol. Interact. 1977; 18:241-245.

17. Gill DP, AE Ahmed. Covalent binding of carbon 14-labelled benzene to cellular organelles and marrow nucleic acids. Biochem. Pharmacol. 1981; 30: 1127-1132.

18. Arfellini G, S Grilli, A Colacci, M Mazzullo, G Prodi. In vivo and in vitro binding of benzene to nucleic acids and prateins of various rat and mouse organs. Cancer Letters $1985 ; 28: 159-168$.

19. Rushmore TH, $\mathbb{R}$ Snyder, GF Kalf. Covalent binding of benzene and its metabolites to DNA in rabbit bone marrow nitachondria in vitro. Chem. Biol. Interact. 1984; 49: 133-154.

20. Kalf GE, R Snyder, TH Rushmore. Inhibition of DNA synthesis by benzene meta" bolites and their covalent binding to DNA in kabbit Bone marrow mitochondria in vitro. Am. J. Ind. Med. 1985; 7: 485-492.

21. Probst GS, RE MCMahon, LE Ho11, CZ whompson, JK Epp, SB Meal. Chemlcallyinduced DNA synthesis in primary rat hepatocyte cultures: A comparison with bacterial mutagenicity using 228 compounds. Environ. Mutagen. 1981. 3: 11-32.

22. Barret RH. Assays for unscheduled DwA synthesis in Hela 53 cells. In: Ashby J, Serres FJ de, Draper M, Inshidate M, Margolin BA, Matter BE, Shelby MD (eds). Evaluation of Short-Term Tests for Carcinogens: Report of the Irternational programe on chemical Safety Collaborative Study on in vitro Assays. Elsevier Amsterdam 1985: $347-352$. 
23. Rijhgirstitut voor Volksgezondheid en Hilieuhyiëne (National Institute of Public Health and Bnvironmental Hygiene). Ontwerp Basis-Dokument Benzeen, 蛙apport no. 840760002, Bilthowen, 1986.

24. Mhby J, FJ de serres, M Draper, M Ishidate Jr, BH Margolin, BE Matter, MD Shelby (eds). Exaluation of Short-Term Tests for Carcinogens: Report on the International program on chemical Safety collaborative study on in vitro Assays. Elsevier Amsterdam, 1985.

24. Tice RR, MJ Sawey, RT Drew, EP Cronkite. Benzene - induced micronuclei in the peripheral blood of mice: A retrospective analysis i Environ. Mutagen. 1984; 6: 421 .

26. Dean $B J$. Recent findings on the genetic toxicology of benzene, toluene, xyllenes and phenols. Mutat. Res. 1985; 154: 153-181.

27. Macher DE, J Zelljadt. The morphological transformation of syrian hamster embryo cells by chemicals reported non-mutagenic to salmonella typhimurium. Carcinogenesis 1983; 4: 291-295.

28. Mecregor D, I Ashby. Sumary report on the perfarmance of the cell transformation assays. In: Ashby J, Serres de FJ, Draper M, Inshidate M, Margolin BH, Matter BE, Shelby MD (eds). Evaluation of Short-Term Tests for Carcinogens: Report of the International programe on Chemical safety Collaborative Study on in witro Assays. Elsevier Amsterdam 1985: 103-115.

29. Maltoni C, B Conti, G cotti et al. Experimental studies on benzene carcinogenicity at the Bologna Institute of oncology: Current results and ongoing research. Am. J. Ind. Med. 1985; 7: 41-446.

30. Thorpe a. Bpidemiological survey of leukemia in persons potentially exposed to benzene. J. Occup. Med. 1974; 16: 375-382.

31. Rushton $\%$, M Alderson. The influence of occupation on health. Some results from a study in the UK oil industry. Carcinogenesis 1980; 1: 739-743.

32. Rushton L, MR Alderson. A case-control study to investigate the association between exposure to benzene and deaths from leukemi in oil refinery workers. Br. J. Cancer 1981; 43: 77-84.

33. Parkes HG, CA Veys, JAH Waterhouse, A Peters, Cancer mortality in the British rubber industry. Bit. It. Ind. Med. 1982; 39: 209-220.

34. Hernberg S. Negative results in cohort studies - How to recognize fallacies. scand. T. Work Environ. Health 1981; 7: 121-126.

35. ECEOC (European Chemical Industry Ecology and Toxicology Centre). Technical report No. 16. A review of recent 1 iterature on the toxicology of benzene. Brussels, Belgium, 1984 .

36. Swaen GMH, AKM de Hollander, R Kroes et al. A scientific basis for the risk assessment of Vinyl Chloride. Regulatory Toxicology and Pharmacology 1987; $7: 120-127$. 
37. Central Bureau of Statistics. Atlas of cancer mortality in the wetherlands. The Hague staatsuitgeverij, 1980 . 


\section{FINAL DISCUSSION}

The field of occupational Heal th is characterized by the great number of disciplines that participate in its advancement. Occupational physicians have a key position in the structure, because of their medical background and their practical knowledge of the actual working condition. The occupational physician may seek support of other disciplines in the process of solving a particular problem that he/she may encounter. An industrial hygienist can be consulted in matters that concern the situation on the work floor and if improwements of the working conditions are to be made. An epidemiologist may be of assistance in case of a health risk possibly related to a specific exposure. It is difficult to provide guidelines regarding the usefulness of consulting an epidemiologist. If a particular suspicion can be investigated in an epidemiological manner will greatly depend on the availability of records. Another factor that will be relevant for the succesfulness of collaborative efforts between an occupational physician and an epidemiologist is a sense of mutual understanding and respect for each others specialized knowledge. The epidemiologist may ask certain questions that may not seem very relevant to the matter, such as: How far do the personel files go back in time? Have filles of former employees been destroyed recently? Does the compary have an own pension fund. It is not always easy to explain why these maters will determine the type of epidemiological study that can be carried out. On the other hand the epidemiologist must realize that any epidemiologic study takes place in a certain context. This context requires that the occupational physician is informed and supports the study methods that will be applied, so that he/she can inform management and employees about the project. In The Netherlands the situation provides ample opportunity for epidemiologists and occupational physicians to conduct collaborative epidemiologic studies, which is illustrated by the papers presented in the first part of this thesis.

The study of coke plant workers indicates that the coke oven workers have been at higher risk for respiratory disease mortality than population of non-exposed workers. This study also demonstrates that retrospective cohort studies in the Netherlands are feasible. Particularly the follow-up phase in the Netherlands jis relatively easy to carry out, because of the availability of the population registries. However, one aspect that may need some modifiction in order to 8 implify the conduct of retrospective cohort mortality studies is the ascertainnent of the causes of death. In the coke plant study it took nearly four years of negociating and patience to abtain the causes of death from the central Bureau of statistics. Recently a system of cancer registration has been created in the 
Netherlands. Howewer, this system can not yet be helpfull in the conduct of retrospectve cohort atudies, because these studies require cancer incidence data over periods in the past.

Furthermore, knowledge regarding long tern cancer risks in occupational settings have a brodder relevance than merely the occupational environment. The results of occupational cancer mortality studies can be extrapolated to exposures occurrirg in the general environment and thus contribute to the scientific basis for ervironmentid carcinogen tisk assessment.

Although this approach requires several assumptions, such as the level of exposure concentrations that occurred in the past and the type of dose-response curve to be applied in the extrapoletion. it has the great advantage that it is based on risks actually observed in humans. In those evaluations of chemicals, for which ample human data are available, these are given priority over experimental data. The number of chemicals for which human data exist is still limited compared to the large number that may be encountered in the workplace or the general. ervirontent. Exposures to one particular chemical is hardly ever encountered in the occupational environment, leaving the epidemiologist in a situation in which only the health effects of exposure to the total mixture can be evaluated. Another limitation of epidemiology is, that chemicals to be introduced into the workplace or the general environment can not yet be studied regarding their long term health effects:

Despite from these limitations epidemiologic research can make a substantial concribution to the knowledge about health risks related to particular exposures and in the near future it can be expected that epidemiological studies in occupational health ili be comon practice. 
SUMNARY

Workers can be occupationally exposed to chemicals that may form a heath risk. same of these chemicals may have the potency to increase the risk of cancer in these exposed workers. Epidemiology is particularly suited to evaluate these risks. The central theme of this thesis is the identification and evaluation of those working conditions that may impose a cancer risk upon the workforce.

Since epidemiological studies in this field are scarce in The Netherlands, the first paragraph of section I provides an impression of the feasibility of retrospective cohort studies. This paragraph is followed by the reports of several. occupational cancer mortality studies carried out in The Netherlands. In the first the results are reported of a retrospective cohort study of 6.872 workers of whom 1,132 had worked on the top or at the side of coke ovens. In the exposed cohort an excess mortality from lung cancer and non-malignant respiratory diseases was observed. These findings are in agreement with the results of studies carried out in Great Britain. The high cancer risks in coke oven workers reported from the united states could not be confirmed.

In the third paragraph of Section I the results of a similar study of 4.527 coke plant by-product facility are presented. Together with the former study. they formed the "coke plant project". There appeared to be a higher mortality than expected from lung cancer among the personel of the tar destllery than expected from lung cancer among the personel of the tar destillery. although it did not reach statistical significance. Among the workers of the benzene plant, were regular exposure to benzene occurred, no excess leukemia mortality was obserwed. In the coke shipping department indications were found for increased risks for gastric cancer and non-malignant repiratory diseases.

In the last paragraph of section I the results are reported of a case-control study to investigate the risk of gastric cancer in coal miners. For this purpose 683 male cases of gastric cancer were selected from the regional pathology departments, together with 683 age matched controls, free of that disease. Fron ald 1,366 subjects it was determined if they had ever been employed as a coal miner in a Dutch coal mine. Mo indication was found for the existence of a risk of gastric cancer after prolonged exposure to coal mine dust.

Section II of the thesis is concerned with several methodological issues of retrospective cohort studies. The results of epidemiologic studies depend upon two aspects: the first being the actwal existence or absence of a cancer risk; the second being the walidity of the study desigm. Suppose an epidemiologist 
investigates a truly existing risk, but by means of an invalid study design it may happen that no rish is observed. Unfortunately it is impossible to study these wo aspect separately without possessing absolute knowledge about reality or without possessing a totally valid study design. None of these are available yet. Yet an alternatiwe in the form of a survey was carried out of 179 published papers regarding occupational retrospective cohort studies. The industrial branch with relatively most negative studies was the chemical industry. Regarding the study design, most study with a positive outcone required a certain minimal exposure period for workers to be eligible, had a low percentage of lost to followup and had a non-exposed workforce as reference group. Furthermore relatively many studies carried out in the Scandinavian countries were positive.

similar approach was taken to investigate the effect of study design parameters on the occurrence of the "Healthy worker Effect" (HWE). In many retrospective cohort studies the total observed mortality is called the Healthy worker Effect. The HWE is party related to selection processes prior to employment. However, it is also possible that design characteristics are related to the HWE. In order to investigate this possible relationship, a surwey was conducted of 270 published retrospective cohort studies. It was observed that in larger studies the HWE occurred more frequently than in smaller studies. There was no relationship with average duration of follow-up.

The eventual aim of conducting retrospective cohort studies is to obtain knowledge regarding the long health term effects of exposure to specific chemicals.

In Section III.1 the use of epliemiology in risk assessment is discussed, after wich several risk assessments of environmental and occupational exposures are presented. The risk assessment of environmental exposure to vinyl chloride monomere based entirely on human data seems to yield higher exposure limits at a given risk than risk assessments based on experimental data. In the case of bengene an additional problem is encountered. There is consensus regarding the carcinogenic risk imposed by relatively high concentrations of benzene. However, this may not be so for low concentrations. 
Het kan woorkomen dat werknemers tijdens de vitoefening van hun beroep in kontakt komen met stoffen die op de lange termijn de gezomaheid nadelig kunnen belinvloeden. Enkele van deze stoffen bezzten de potentie on het risiko van het krijgen wan kanker te vergroten. De epidemiologie is bij uitstek geschikt woor het beantwoorden van deze vraag. Het centrale thema var dit proefschift 1 s de opsporing en evaluatie van arbeidsomstandigheden die het risiko op kanker werhogen.

Aangezien in Nederland slecht incidenteel epidemiolagisch onderzoek is verricht op dit gebied, is de eerste paragraaf van Deel I gewijd aan de Nederlandse situatie voor wat betreft het uitvoeren wan epidemiologisch onderzoek in de arbeidssituatie. Hierop volgen de verslagen over enkele epidemiologische studies. In de eerste van deze is de sterfte onderzocht van 6.872 werknemers, waarvan er 1.132 werkzam zijn geweest op of in de nabijheid van cokesovens. Deze werknemers bleken een verhoogd risiko te hebben op sterfte tengevolge van longkanker en niet kwaadaardige aandoeningen van de luchtwegen. Deze bevindingen komen overeen met de onderzoeksresultaten uit Groot-Brittannië. De hoge sterfterisiko's die onder werknemers van cokesovens in de verenigde staten geobserveerd zijn, aijn in Wederland niet waargemomen. In paragraaf 3 van Deel $I$ is het verslag van een onderzoek naar een subgroep van het projekt, namelijk van de sterfte onder werknemers die op andere afdelingen dan de ovens van de cokesfabrieken gewerkt hebben. Hierbij was vooral de aandacht gevestigd op het personeel wan de chemische sektor. In de teerdestillatie bleek sprake te zijn van een lichte verhoging van de longkankersterfte. In de benzolafdeling, war aanzienlijke benzeenkoncentraties in de lucht voorkwamen, was geen sprake van een verhoogde sterfte an leukemie. De werknemers van de cokeswerlading hebben mogelijk een verhoogde kans on aan ziekten wan de luchtwegen of magkanker te sterven. Naast dit retrospektieve kohortonderzoek wordt in Deel I verslag gedaan van een patiënt/kontrole onderzoek. De vraagstelling van het patiënt/kontrole onderzoek was of mijnwerkers van de voormalige Nederlandse steenkolenmijnen een verhoogd $x$ iko hebben gelopen op het krijgen van magkankex als gevolg van het ingesilkte mijnstot. van 683 mannelijke maagkankerpatiënten en een op leeftijd gematchte kontrolegroep is nagegaan we er ooit als ondergronds mijnwerker werkzaam was geweest. Het onderzoek lewerde geen aanwjzing op woor het bestan wan een magkankerrisiko onder mijnwerkers.

Deel II van het proefschrift betreft enkele methodologische aspekten war retrospektief kohortonderzoek. De bevindingen van epidemiologigch onderzoek hangen af. 
van twee aspekten. wen eerste naturlijk wam wat ex zich in de verkelijkheid afspeelt. Een tweede bepalende faktor is de methode die door de epidemioloog geyolgd wordt. stel dat de epidemioloog een daadwerkelijk bestaand ris iko bestudeerd, mar net met de korrekte" methoden, dan kan het zijn dat het risiko toch niet gewonden wotkt. Het is echter niet moglijk deze twee aspekten los wan elkar te bestudeten, zonder te beschikken over het "juiste" inzicht ower de werkelijkheid of over de meest korrekte" onderzoeksmethode. Geen van beide zijn voorhanden. On toch eventuele verbanden te bestuderen tussen de methode van onderzoek en het uiteindelijke resultat is een survey uitgevoerd, gebaseerd op 179 gepubliceerde artikelen wan retrospektieve kohortonderzoeken en hun resultaten. In de chemische industrie kwamen relatief de meeste onderzoeken voor waarin geen verhoogd kankerrisiko werd aangetoond. voor wat betreft de onderzoeksopzet bleek dat bij studies met en bepalde minimum latentietijd, met een laag percenlage lost to fallow-up en met een niet-blootgestelde referentiegroep, de grootste kans hadden om een kankerrisiko te rapporteren. voorts bleken relatief veel studies ult scandinavie positief te zijn.

Eenzelfde aanpak is gevolgd bij het bestuderen van faktoren die gerelateerd zijn met het aptredien wan het "Healthy worker Effect" (HWE). In veel retrospektieve kohortonderzaeken blijkt de totale sterfte lager te zijn dan de sterfte in de algemene bevolking. Dit verschijnsel noemt men het Healthy worker Effect. Gedeeltelijk is het HE terug te voeren op sejektiemechanismen bij de sollicitatie en indienstreding. Maar het is mogelijk dat ook de onderzoeksopzet een rol speelt bij het optreden van het HWE. Zo bleek, dat in grotere studies vaker een HWE optrad, maar dat het HWE niet samenhing met de gemiddelde duur van de follow-up. Het uiteinalelijke doel van retrospektief kohortonderzoek is het verkrijgen van inzicht omtrent de lange termijn effekten van blootsteling aan een bepalde stof voor de mens.

Deel III beschrijt: de rod van de epidemiologie in het proces van risikoschatting. De voordelen, mar ook de beperkingen van epidemiologisch ondetzoek komen dan de orde, waarna in de volgende drie paragrafen enkele risikoschattingen wolgen, zowel op het gebied wan het milieu als de arbeidssituatie. De risikoschatting van blootsteling aan vinylchloride monomeer op basis van humane gegevens lejat tot een hogere grenswaarde bij een gegeven risiko dan een schatting op basis van experimentele proefdiergegevens. Bij de risikoschatting wan benzeen komt men nog een extra probleem tegen. Er bestaat namelijk geen overeenstemming ower de vraag of ook lage blootstellingen an benzeen een carcinogeen effekt kunnen hebben op de mens. 
Spidemiologie is de wetenschap die de spreiding van ziekte onder de bevolking onderzokt en de faktoren die daarop van invloed zijn (Lilienfeld, 1980).

Het is een wetenschap die in Nederland steeds meer de aandacht krijgt die ze verdient. Eind jaren zeventig werden in de Tweede Kamer vragen gesteld over het belang van epidemiologie en over het opleiden van epidemiologen. ondermeer op grond hiervan heeft het Koningin wilhelmina fonds vanaf 1980 enige van har fellowships beschikbaar gesteld voor het opleiden van epidemiologen. Na een jaar aan de Johns Hopkins Univers iteit in de Verenigde Staten gestudeerd te hebben in het kader van de KWF Fellowship, werd mij door mijn mentor Prof. Dr. Sturmans gevraagd of ik me wilde specialiseren im onderzoek nar ziekte in samenhang met het uitoefenen van bepaalde beroepen c.q. "beroep en kanker". Besloten werd om een periode van één jaar te reserveren voor het me op de hoogte stellen van de Nederlandse situatie en woor de vaorbereiding van een onderzoek op dit gebied. Mede door zijn stimulatie kon aan het eind van dat jaar een onderzoeksprotokol bij het koningin wilhelmina Fonds worden ingediend. op 20-10-1982 besloot het kwF dit onderzoek financieel te ondersteunen.

Bij de totstandkoming van het protokol en de uitvoering is de houding van het betrokken bedrijf van doorslaggevende aard geweest. Tijdens een orienterende stage in het bedrijf waren Dr. Winter (direkteur van de Bedrijfsgezondheidsdienst) en Ir. Scheffers (milieuhygiënist van de Centrale veiligheids- en Milieudienst) steeds weer bereid afspraken te arrangeren en mij de nodige stimulans te geven. Terugkijkend op de periode van dataverzameling van februari 1983 tot februari 1989 lijkt het alsof het onmogelijke toch is uitgevoerd. Immers er waren talrijke momenten en beslissingen waarop het onderzoek stuk had kunnen loper. Maar dit is niet gebeura.

Allereerst wil ik Prof. F". Sturmans en Prof. Tj. de Boorder bedanken voor hun grote inzet tijdens de uitwoer van het projekt en hun grote bijarage in de tot standkoming van dit proefschrift. Ook de wardevolle suggesties van de leden wan de Beoordelingscomissie mogen niet onvermeld blijven.

Wervolgens gaat mijn dank uit naar Esther Kahle. Ik kan me die eerste dag in de kelder van het Centraal Archief nog goed herinneren. Een archief bestaande uit 150.000 dossiers die allemal ingezien zouden moten worden. Je zal wel gedacht hebben: "maar ben ik nu weer aan begonnen?" Dat dacht ik namelijk zelf ook. Gelukkig kregen we al snel hulp wan Frans Bettink en Bep Erven, die ook hun portie van het werk zonder morren voor hun rekening hebben gemomen. Die maanden in het archief zullen voor mij altija een speciale betekenis blijwen behouden. 
Zonder de hulp van de heren slijpe en Selissen waren we in het central Archief zeker het spoor bijster gerakt. Ook aan Jos Slangen en later Marliese van wissen is het te danken dat alles tot een goed einde gebracht is. Zij stonden elke keer weer klakr om vol enthousiasme de schouders er flink onder te zetcen. Miet onvermeld mogen blijven de energie die Harrie wetzelaer van het Rekencentrum in de atumatisering gestoken heeft, Karel Groels van Financiele zaken die altijd weer bereid mij bij te staan op het gebied wan financielle zaken en Hub Ruyters en Marjo zwanenburg van personele zaken voor bun ook in moeilijkere tijden altijd vriendelijke en toegewijo assistentie.

ook gaat mijn dank ult naar al die honderden gemeente-ambtenaren die hun medewerking verleenden aan thet onderzoek en zo een onmisbare schakel hebben gewornd. Datzelfde geldt voor de heer Delforterie en zijn medewerkers van het Centraal Bureau voor Genealogie.

Daarnast mag ook de rol van het Centraal Bureau voor de statistiek niet zonder enige dandacht blijven. De besprekingen waren zeker niet de gemakkelijkste die ik me kan herimneren, maar een woord van dank is ook hier zeker op zijn plaats. Wet name de heer Bonte en in een later stadium John de Jong hebben er zorg voor gedragen dat alles op zijn pootjes terecht kwam.

ook will ik graag Lex volovics bedanken voor zijn hulp bij de statistische analyse. Dat gelat niet alleen voor de analyses die in dit proefschrift opgenomen zijn. mar ook voor die vele andere.

Tens lotte gaat mijn ank uit naar de twee vakgroepen, Epidemiologie en AMr (voorheen Arbeidsgeneeskunde), die beide een goede thuisbasis vormden voor het epidemilologisch veldwerk.

Dit onderzoek was niet mogelijk geweest zonder de medewerking van die honderden personen van zeer verschillend pluimage.

voor mij is wetenschappelijk onderzoek zeker niet geestdodend of demotiverend geweest, ondanks alle problemen war ik telkens weer mee gekonfronteerd werd. leder nieuw projekt brengt weer zoveel nieuwe situaties en kontakten met zich mee dat elk nileuw projekt weer een uitdaging wordt, hopond op een kans een goede/ rechtvatardige inschat ing te kunnen maken van de eventuele gevaren die mensen lopen tijdens de uitoefening van hun beroep. 


\section{CUREICULUM VITAE}

1966 - 1972 : HBS-B te Amsterdam en Beek, Ubbergen.

$1973-1979$ : Doktoraal examen Medische Sociologie, Rijksuniversiteit Groningen.

$1980-1982$ : Fellowship Koningin wilhelmina Fonds ter verdere opleiding in de epidemiologie.

1981

: Master of Public Health, Johns Hopkins School of Hygiene and Public Health te Baltimore, Verenigde staten.

1983 - 1984 : Wetenschappelijke medewerker op projektbasis, Capaciteitsgroep Epidemiologie, Rijksuniversiteit Limburg.

1984 - : Universitair Docent Vakgroep Arbeidsgeneeskunde, Milieugezondheidkunde en Toxicologie, Rijksuniversiteit Limburg. 